\title{
THE
}

\section{REPOSITORY OF SHADOWS}

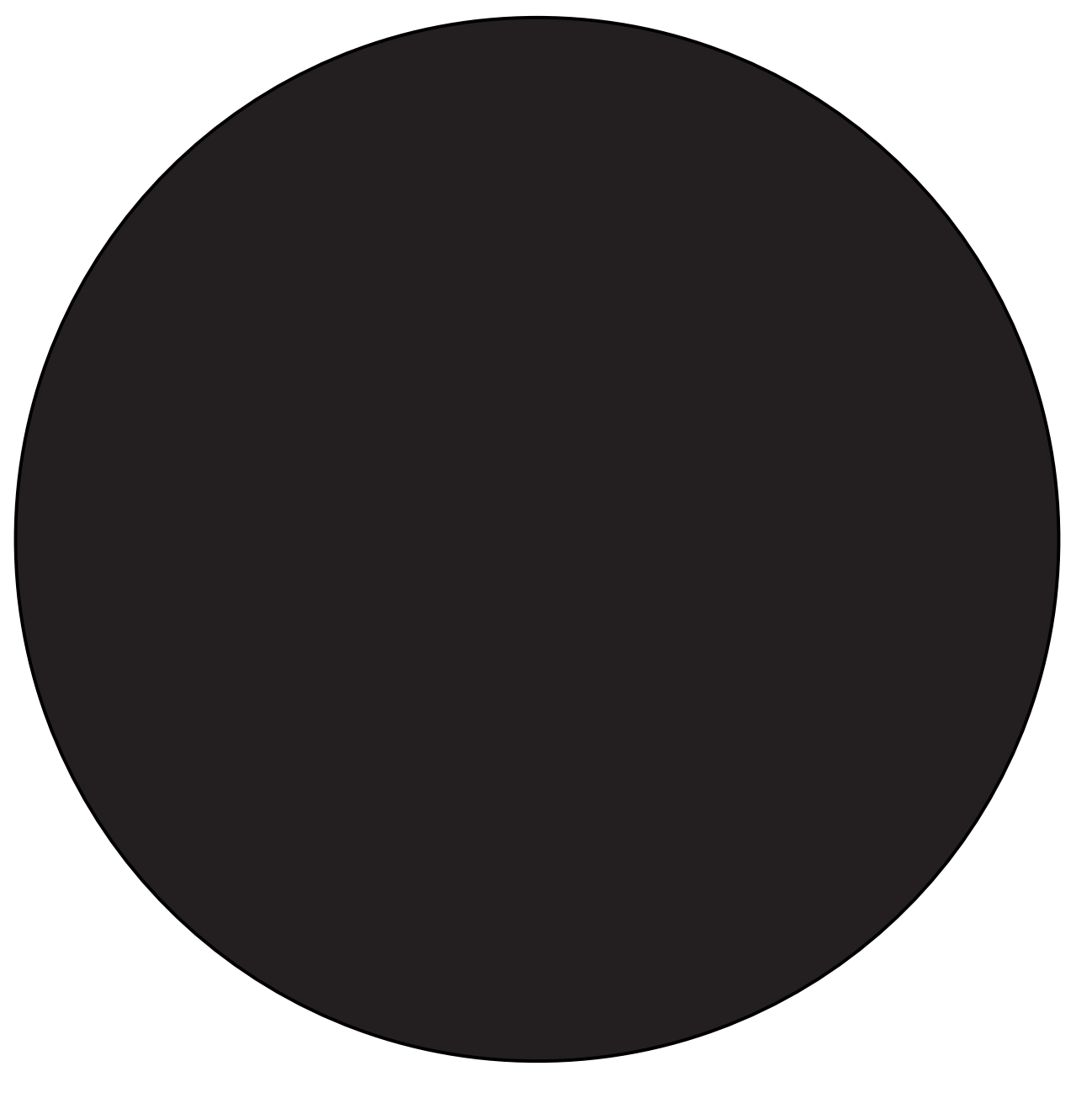

A thesis by Nick Wilkey. 
<smiles>C1CCCCCCCCCCCCCCC1</smiles> 

REPOSITORY OF SHADOWS

\author{
An Inquiry into Arcihtectural Drawing and \\ the Realm of the Shadow.
}

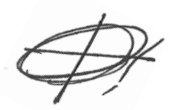

Nicholas Anthony Wilkey

a 120-point thesis submitted to the Victoria University of Wellington in partial fulfillment of the requirements for the degree of Master of Architecture (Professional)

Victoria University of Wellington School of Architecture 
In Haruki Murakami's Hard-Boiled Wonderland and the End of the World, reality and imagination are infused in an interplay of narratives. The story is about discovering the identity of Self, using a walled city as a metaphor for the subconscious. The novel weaves the stories of two characters, the external selfand the internal self, each chapter flicking between the reat ansetenterean, from conscious to unconscious. Murakami provides the reader with a contemplation on the nature of existence, being versus non-being. Dr William S Haney, Professor of Literary Theory and specialist on culture and consciousness, argues that the shadow in Murakami's allegory is a representation of the mind. As the narrative unfolds, the shadow-stripped from its owner-slowly dies, causing loss of memory, emotion and desire. The relinquishing of one's shadow in the allegory suggests a loss of the metaphysical aspect of Self. The Shadow is not merely seen as an immaterial entity; rather it is the sign of full corporeality. The Shadow grants meaning to existence, illuminating the reality that we cannot perceive the light without the darkness.

This thesis is born out of a concern for the dearth of meaning in architecture in an age of uncertainty. In the modern contemporary sphere, we have become obsessed with the image, with rationalistic tendencies; with evermore light and luminosity, architecture has primarily been caught up in trying to order and rationalise the world. In this condition of objectification and reduction, architecture risks falling into a trap of homogeneity, thereby limiting itself to an empty datum of quantification. Thus, the unhygienic, the disorder and the chaos, the darkness that grants life its pungency, have been 'relegated to the shadows'. Roberto Casati, senior researcher and Professor of Philosophy at the Centre National de la Recherche Scientique and an authority on shadow perception, argues that shadows avoid direct reading: "[ $t]$ he interaction of the two unequal brothers has been described in different ways, from the notion that shadows are 'holes in the light' through to the opposite idea that they are 'the remaining representatives on earth of the cosmic darkness, otherwise torn apart by light"'. Viewed in this sense, Shadows can be seen as both corporeal operation-bound to the physical cycles of earth, moon and sun-and metaphysical entity, alluding to the primordial darkness before the birth of light and matter. 
The allegory of the Shadow in Hard-Boiled Wonderland can be seen as a rumination on the loss of the metaphysical aspect of Self in a contemporary cybernetic age. In Murakami's novel, the shadow cannot enter the walled Town; it must be left behind in the Shadow Grounds, the threshold between inner and outer realms. The Gateway, as described in Murakami's novel, becomes the provocateur for this thesis. Interpreting Murakami's architectural and allegorical program of the Gateway and Shadow Grounds in relation to Penelope Haralambidou's seminal article "The Allegorical Project: Architecture as Figurative Theory", this design-led research investigation interrogates the use of the Allegorical Architectural Project as a critical method. Allegory provides a structure of thought whereby meaning is not grasped immediately, but rather through progressive discovery and continual interpretation of its ambiguous traits. Ambiguity in architecture has the ability to appear everchanging, resist resolution and remain open to interpretation.

The methodology of the investigation explores the spatial realm of the shadow through the critical and creative process of drawing. The principal aim of this thesis is to journey into the darkness, to embrace the shadow of the unknown, searching for a space inbetween-between light and shadow, architecture and art, reality and fiction, the constructed and the imagined. Using Haruki Murakami's Hard Boiled Wonderland and The End of the World as a generator and provocateur, the research employs the notion of the shadow as both mythological entity and corporeal signifying process. Rather than seeking concrete conclusions, it posits a speculative allegorical architectural project that invites critical engagement and interpretation. It argues that architecture occupies the liminal position between darkness and light, the true place of human existence, and as such, the design of Shadow is essential to the meaningful design of architecture.

The thesis investigation asks: how can the speculative architectural drawing be used as a means of interrogating the realm, and enhancing our awareness of, the shadow in architecture? 
Unclose your mind,

you are not a prisoner.

You are a bird in flight,

searching the skies for dreams.

-Haruki Murakami, Hard Boiled Wonderland and The End of the World. 
During my fourth year at architecture school, my supervisor gifted me a novel. The title, Hard-Boiled Wonderland and the End of the World, instantly had me fascinated. What was written in the following pages, took me on a journey of discovery. Through the cavernous underworld of subterranean Tokyo, into a walled city where people live without their shadow, the novel, part hard-boiled detective story, part surrealist fantasy, weaves the story of two characters-the real and the dream, the inner and outer, conscious and unconscious. Haruki Murakami, the Japanese author of the novel, deals with issues about identity and consciousness, elevating the mundane to a sort of metaphysical level. At his core, like many artists, Murakami seeks to find clarity within the murkiness and transience of human existence. It is through this story that my mind was opened up to the possibilities of storytelling as a way of stirring the soul and tugging at the depths of the imagination. It allowed me to introspect on my own inner workings and discover clarity within the chaos of the everyday.

The past twelve months have enabled me to delve deeper into the aspects of architecture that truly resonate with me. A fascination with drawing and story-telling underlies the core interest of this investigation. It has enabled me to delve deeper into my own personal identity, both as an architect and artist, and as an individual. It is through this journey that I hope to enable other people to embrace their own shadow-thus triggering a deepening of individual transformation and social aspiration. 



\section{ACKNOWLEDGEMENTS}

I would like to first of all thank my supervisor Daniel Brown, for his relentless enthusiasm, and for engaging me in the hunt for shadows. His ability to find clarity within the layers of obscurity has been paramount. His continuous support has been unwavering throughout my post-graduate degree, for this I cannot thank him enough.

To my friends and classmates, I could not have done it without you, thank you for returning me to reality.

To Crystal, for allowing me to dream, but who kept my feet on the ground.

And finally, to my parents and family who have shown their unconditional love and support throughout the past five years of study. Words cannot truly express my gratitude.

Thank you. 


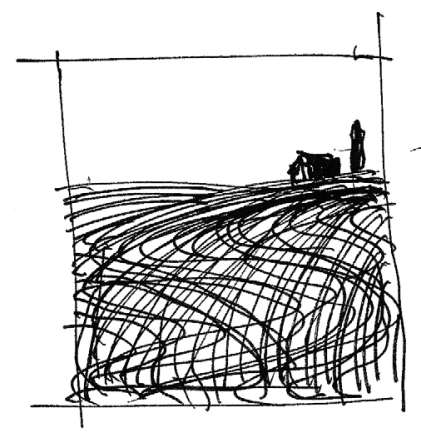

Figure 1. Landing. Sketch by Author 
1 Coma: Beginnings

I. Empty of Shadows

II. Making a Shadow

III. The Fall: A Proposition

IV. In the Realm of...

V. A Working Method

VI. Research Objectives

VII. Thesis Structure

VIII. Embarking/ Disembarking

늠

16

Metaphormosis: Allegorical Architecture as Critical Method

1.1 A Tale of Two Worlds

1.2 Constructing a Narrative

1.3 Allegorical Architecure as Critical Method

1.3.1 Double Meaning

1.3.2 Figurative Geometry

1.3.3 Visual + Verbal

1.3.4 Battle \& Progress

1.3.5 Unfinished

Metamorpheus: Architecture of Shadows

2.1 Shadow as Refuge

Perceptual_chiaro / oscuro

2.2 Shadow as Threshold

Temporal_Space / Time

2.3 Shadow as Trace

Ontological_shadow / substance

2.4 Shadow as Projection

Logical_Difference / Repitition

2.5 Shadow as Sublime

Affective_threat / protection

$\frac{m}{\frac{1}{\pi}}$

Metamorphosis: Architecture as Drawing

3.1 Drawings as Loci for Thought

3.2 Traces and Architecture

3.3 Cosmopoiesis of Architectural Drawings

IV. Bibliography

V. Sources of Figures

Volume 2

Coda: Through the Unknown Gate

I. Prologue

II. The Repository of Shadows

III. Epilogue

IV. Conclusion 


\section{COMA}

coma*

/'kəumə/

noun: coma; plural noun: comas

a prolonged state of deep unconsciousness

from Greek kōma 'deep sleep’ 
Light is meaningful only in relation to darkness,

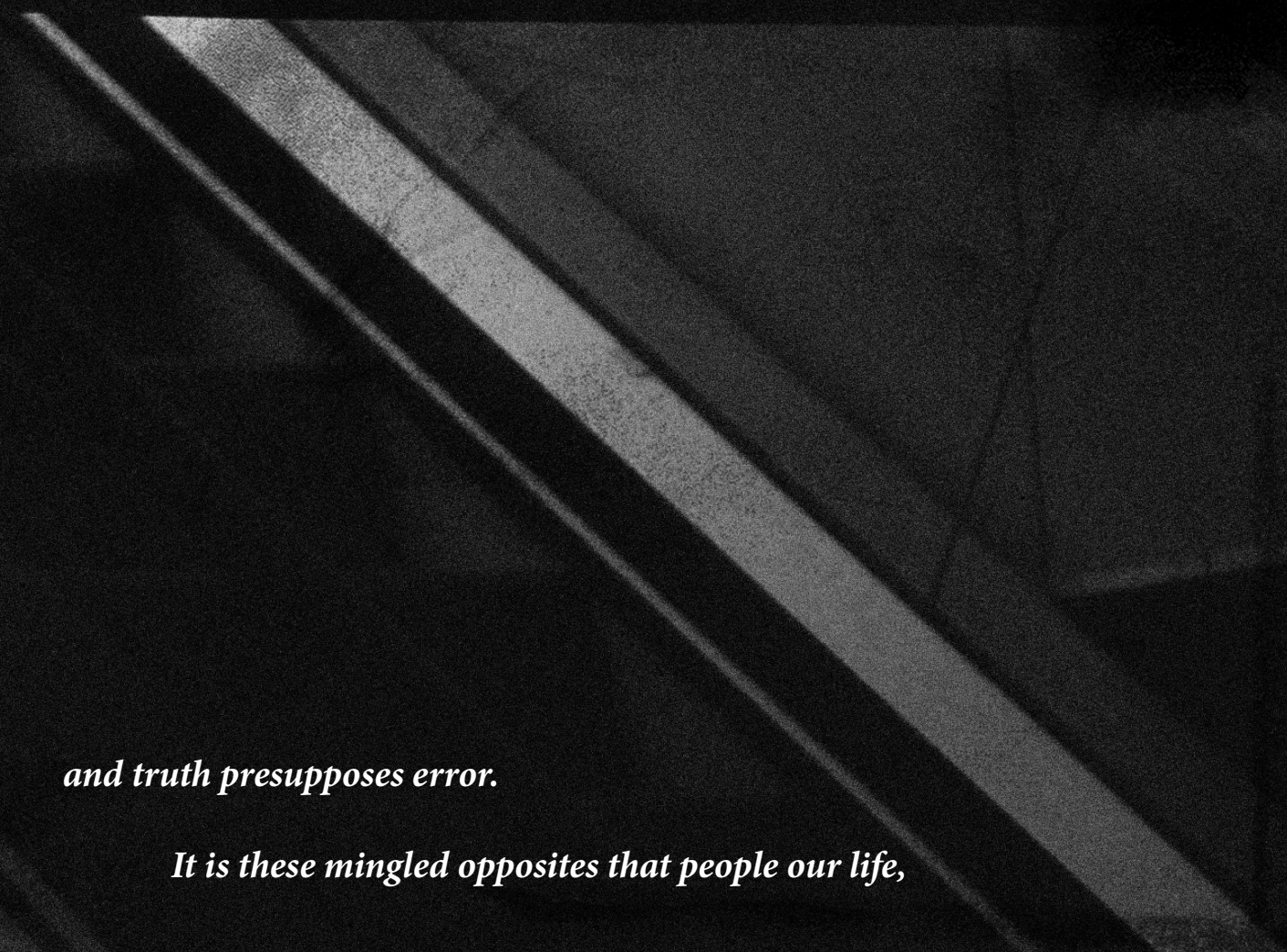

which make it pungent, intoxicating.

We only exist in terms of this conflict, in the zone where black and white meet." 
At the mercy of hyperrealism, and swathes of fraudulent materials, an endless sterility of illuminated surfaces now pervades our built environments. We have defined our world by its material limitations and therefore have become blind to the metaphysical, the realms beyond the senses that pervade material reality. In the modernglobalisedworld, obsessed with theimage, with rationalistic tendencies, with evermore light and luminosity, architecture has primarily been caught up in trying to order and rationalise the world. In this condition of objectification and reduction, architecture risks falling into a trap of homogeneity, thereby limiting itself to an empty datum of quantification. Our physical realm is now empty of 'shadows'. Opposed to the rationalist ideals of architectural modernism, and concerned with the dearth of meaning and identity in architecture in a contemporary world, this thesis calls for the re-integration of shadow within the design of architecture.

This design research-led investigation seeks possible speculative architectural outcomes that go beyond conventional methods of architectural design and traditional modes of representation. It searches for a speculative solution that reveals and celebrates the realm of the shadow in architecture. 

intertwined. Odd numbered chapters tell the story of the conscious world (Hard-Boiled Wonderland) and even numbered chapters tell the story of the unconscious world (End of the World). At the end of the book, the reader comes to understand that both stories are one. The first is the story of light, the second the story of darkness. Neither story can exist without the other.

Murakami presents two seemingly opposing narratives, two worlds, yet through the obscuring and parallel layering of these stories, we soon recognise in the murkiness and ambiguity that they in fact represent one story, one world. As the novel progresses, inner and outer merge, above blends into the below, conscious slips into the unconscious. The Shadow in the story is used as an allegory for the mind, the unconscious, the dream. Through this literary allegory Murakami offers an ambiguous provocateur for questioning the nature of reality and provoking a shift in awareness. It is through literary allegory, dualities that seem opposed but work toward their progressive resolution, and ambiguity that Murakami provokes experiential and existential thought.

This profound piece of literature invokes our contemplation about the true nature of reality; it challenges the disparity between subject and object, inner and outer. It provokes us into recognising that without the unconscious, the conscious cannot exist; without the shadow, the light cannot exist. Reality is a binary field-no longer dualistic, but rather a fluid spectrum, oscillating between negation and reconciliation. 


\section{THE FALL: \\ A PROPOSITION}

This design-led research investigation is conceived around Haruki Murakami's Hard-Boiled Wonderland and the End of the World, which represents a provocative and allegorical response to the loss of identity, meaning and the shadow in an increasingly technologised age. This thesis seeks to interrogate the realm of shadow through the adoption of allegory-mythological, philosophical and historical associations of the shadow in architecture, and the drawing. Murakami's novel acts as a provocateur and starting point to generate unique architectural responses and allow the design process to break with normative rational precepts.

Using Murakami's architectural and allegorical program of the Gateway and Shadow Grounds as provocateurs, it argues that the notion of the threshold is fundamental to the investigation of the shadow. As the shadow is not confined to a fixed language or form, it occupies the liminal position, limina, between absence and presence. Louis Kahn placed the shadow in a similar position of importance; in his book Between Silence and Light, he writes, lies a "threshold which is inspiration, the sanctuary of art, the Treasury of Shadow"(Lobell, 20). The aim is to occupy a space inbetween architecture and art, light and shadow, reality and imagination, thus re-interpreting the preconceived norms of architectural form, experience and space. Investigation of the shadow and the notion of architecture as threshold have rarely been explored in architecture. The investigation is grounded in the realm of speculative architectural drawing, aiming to identify links between the making of a drawing and the making of architecture. It questions how architecture can be embodied in the drawing, and how this notion can interrogate and subvert normative presumptions of threshold, artefact, occupant and context. It argues that architecture has the potential to find points of departure, set up new modes of inquiry and tug at the depths of the imagination.

It is the purpose of the investigation to enhance our awareness of the shadow. It is motivated by a desire to acknowledge that the world of darkness is the foundation of the world of light, that order is integrated with chaos, and that above and below occur as one. 
Out of the milieu, this research investigation asks:

How can the speculative architectural drawing be used as a means of interrogating the realm, and enhancing our awareness, of the shadow in architecture?

The 'in-between' is also then the realm of conscious and unconscious speculation and questioning - the 'zone' where things concrete and ideas are intermingled, taken apart and reassembled-where memory, values and intentions collide.

-Fred Koeter, "Notes on the In-Between", Harvard Architecture Review, Spring 1980. p68-69. 
This design-research investigation exists in OF... the realm of speculation. Rather than seeking fixed conclusions or polemical reductions, it posits a series of drawing investigations into the role of shadow in architecture. The investigatory scope of this research is an architecture based in drawing, as drawing Whiws for duplicity and multiplicity of Wherpetation, in this regard it is reflective of the qualities of the shadow.

Due to constraints in time, resource limitations and scope, the drawing acts both as a site of potential imaginaries and a working surface (Spiller, 26). The investigation applies speculative and allegorical approaches unveiling the realm of shadow in architecture. The project challenges normative presumptions of architectural artefact, context and occupant, placing emphasis on the drawn artefact. The drawing is seen as more than a tool of representation; it embodies architectural constructs, space and ideas. As such, traditional notions of programme, site context, construction costs and engineering requirements fall outside the scope of this investigation. The bounds of physical limitations become freed, allowing architecture and the drawing to be seen as material for exploration beyond traditional conventions.

It is intended that drawing no longer be seen as a means to an end, simply a communicational tool, but drawing as a vehicle of creativity (Vesely). The emphasis shifts from drawing as image, to drawing as work, or process, a creative act that is somehow analogous to the actual construing and constructing of architecture. (Frascari, 5). Through this understanding of the drawing as both as a vehicle for creativity and projective reality, one starts to interrogate architectural production and creation and thus start to invite other imaginative possibilities for architecture. Drawing in this mode, is re-presentational; that is it does not simply represent a world already in existence, but instead attempts to re-present the world in ways previously unseen, to make the banal appear fresh and the old appear new (Corner, 181). Architectural drawing, therefore, can be used as a critical method, distancing the architect from the construction site and redefining them as an analyst of spatial phenomena, better grasped and investigated through drawing and text. (Haralambidou. 225) 


\section{A WORKING \\ METHOD}

The methodology for this proposal stems from an understanding of the architectural project, not just as a concretised solution to a given problem, but rather as a vehicle for critical discourse that weavesvisual and textual descriptions in order to generate new understandings of architectural design. It is intended that the investigation not merely provide a solution to a current issue, but rather, speculate on the poetic capacity of architecture to invite interpretation and engagement-one that re-establishes the human values of architectural practice beyond narrow technical parameters and recognises that architecture has the potential to participate in the realm of action (Kunze, 85).

The framework for this investigation is based on a form of inquiry where understanding is gained through the process of design and creation. In this mode, research questions are framed, with literature and theory providing the platform from which to explore them through design.

The term 'design' derives from the Italian disegno, meaning drawing and suggesting both the drawing of a line and the drawing forth of an idea (Hill, 6). Knowing is then embodied in the act of inquiry, facilitating a symbiotic process of creation and reflection. Through the act of designing, one produces knowledge and thus develops a deeper understanding. Knowledge and experience, as Henk Borgdorff notes, are founded "in and through practices, actions and interactions" and "pre-reflexive artistic actions embody knowledge in a form that is not directly accessible for justification" (Borgdorff, 47) The research aims to develop methods for investigating the realm of the shadow in architecture. 
This design-led research investigation begins with the COMA and concludes with the CODA. The first codex, COMA, represents the underlying design research of the thesis's dual narrative; it interrogates the dream-like world of the architectural shadow through iterative design experiments that critically reflect and build upon the literature and case study review.

The second codex, CODA--a word meaning the final piece of a musical score, or the last chapter of a book or play that "concludes" a work--represents the resolution of the thesis's dual narrative, the developed design.

COMA first articulates the overall Aim and Objectives of the investigation; and has briefly outlined a Methodology and Scope. The thesis is divided into three key parts: METAPHORMOSIS (derived from 'metaphor'), METAMORPHEUS (derived from 'Orpheus') and METAMORPHOSIS (derived from 'morphosis').

It is the purpose of the investigation to identify the links between them and interrogate how to occupy the space opened up by each of these relationships.

In this investigation, allegory provides the critical framework, the shadow provides theinhabitant, allegorical provocateur and narrative subject, and drawing is the ground on which to explore and test. The structure of the thesis seeks to form a progressive evolution of thought from the use of allegory, through the shadow and into the transformation of the drawing-each insight building upon the other.

The theoretical grounding and case study review is integrated into three chapters, design experiments build upon this ground. Each of the three key parts of the thesis interrogates one of the three principal research objectives: 
METAPHORMOSIS

R01: to explore how allegory in the form of narrative can provide a critical framework for architecture.

METAMORPHEUS

RO2: to identify historical and mythological notions of the shadow in relation to architecture, exploring them through the language of the drawing.

\section{METAMORPHOSIS}

RO3:to interrogate the architectural drawing, exploring its potential for inviting an allegorical architetcural project. 


\section{COMA}

BEGINNINGS.
I. Empty of Shadows... articulates a problem statement

II. Making a Shadow... introduces Murakami's allegory of the shadow

III. The Fall: A Proposition.... proposes the use of Murakami's allegory of the shadow as an provocative catalyst for architecture

IV. In the Realm of... establishes a scope for the project

V. A Working Method... describes the process of inquiry

VI. Research Objectives... outlines the principle objectives of the research

VII. Thesis Structure... depicts the structure of the research document

VIII. Embarking/ Disembarking... is about embracing the unexpected in the hunt for shadows 
METAPHORMOSIS AS CRITICAL METHOD.

\section{R01 to explore how allegory in the form of narrative can provide a critical framework for architetcure.}

Part I interrogates the use of allegory and narrative in architecture. It further introduces Haruki Murakami's novel Hard Boiled Wonderland and the End of the World, using Jerome Bruner's "Narrative Construction of Reality" as a way of identifying key literary features in the novel. Cathy Ganoe interprets the use of Bruner's literary features within the context of interior design. These features will be used as a means of interrogating and informing decision making within the realm of speculative design.

Penelope Haralambidou's “The Fall: Allegorical Architectural Project as Critical Method" presents a critical investigation of allegory in architecture. The article discusses Haralambidou's own installation art, The Fall, and its use of allegorical narrative, which she uses to provide critical insight into the nature of architectural representation. She goes on to propose a theoretical background for the use of allegory in architecture and offers allegorical traits, suggesting how these might be used as tools in the evaluation of the allegorical architectural project. Allegorical traits include:

1.3.1 DOUBLE MEANING the duplicity or multiplicity of meaning that invites interpretation

1.3.2 FIGURATIVE GEOMETRY the use of figurative elements to denote structural relationships

1.3.3 VISUAL + VERBAL the reciprocity between visual and textual description

1.3.4 BATTLE \& PROGRESS the similarity to a conflict-opposition between two forces-or a journey

1.3.5 UNFINISHED the state of being unfinished.

This section of the thesis will also provide insight into the allegorical traits as identified by Haralambidou, placing each of them within the architectural realm through relevant literature and precedent studies. These studies will provide working strategies for implementing allegorical traits within design explorations, translating them in both poetic and spatial senses. Part 1 identifies how allegory can be employed as architectural design mechanisms that invite critical engagement. 
RO2 to identify historical and mythological notions of highlight the historical, philosophical and mythological notions of the shadow in relation to architecture. While a full traversal of the literature on the shadow in architecture is outside the scope of this investigation, Part II seeks out key concepts and ideas to translate through expressive design experiments.

As a response to the rationalist tendencies of architectural modernism, VIA 11: Architecture and Shadow, is a collection of essays that arose out of an ongoing examination of the "other" in architecture. A collection of writings on the shadow and architecture from the likes of Marco Frascari and Tadao Ando, this special edition journal became an influential platform for investigating the shadow. It offers many points of departure for the study of shadow in architecture, this investigation proposes to use these, as well as Arden Reed's classifications in "Signifying Shadows" as generators for design experiments into the shadow. These include:

\subsection{SHADOW AS THRESHOLD Temporal_space / time}

\subsection{SHADOW AS REFUGE Perceptual_chiaro / oscuro}

\subsection{SHADOW AS TRACE Ontological_shadow / substance}

\subsection{SHADOW AS PROJECTION Logical_difference / repetition}

\subsection{SHADOW AS SUBLIME Affective_threat/protection}

Reed argues that, due to its multiplicity of readings, meanings and interpretations, the shadow cannot be fixed nor defined. The drawing becomes the mode with which to investigate because the drawing allows for duplication, multiplication and shifting of meaning to occur. As Arden Reed argues, shadows avoid direct signification; they occupy a position of ambiguity between the aforementioned classifications, forever being altered, composed and recomposed by the perception of the viewer as well as by the passing of time and shifting of the seasons. The aim of Part II is to develop ideas about the shadow in relation to architecture and actively translate these through drawing. 
RO3 to interrogate the architectural drawing, exploring its potential for inviting speculative architectural outcomes.

Part III will look to examine the role of the drawing the in architecture. It will seek out methods and modes of drawing based on Marco Frascari's Eleven Exercises in the Art of Architectural Drawing, interrogating them as strategies for exploring the speculative architectural drawing.

\subsection{DRAWINGS AS LOCI FOR THOUGHT}

\subsection{TRACES AND ARCHITECTURE}

\subsection{COSMOPOIESIS: DRAWING AS WORLD-MAKING}

It also draws on Neil Spiller's "Drawing as Communicating Vessels" where he sites the potential of speculative architectural drawing, "the explorative, or 'magical' drawing is a site of both understanding and emergence, a repository of information and a 'working' surface on the one hand, and the location of multiple potential imaginaries on the other." (French) As Neil Spiller notes: "it is the making of the drawing that builds our understanding of our world" (Spiller, 268)

Based on these ideas, the goal of Part III to apply the learnings from the previous chapters and to morph these through the language of the drawing. Seeking to apply both allegorical traits and notions of the shadow, this chapter enlists the potentials of drawing in inviting an allegorical architectural project. 


\section{CODA}

THROUGH THE

UNKNOWN GATE.

This separate codex is conceived as an architectural narrative, paralleling a journey through Haruki Murakami's Gateway in his novel Hard Boiled Wonderland and the End of the World. It serves as the final outcome of the research investigation as well as a stand-alone journal that invites engagement and critical speculation around the role of the Shadow in architecture.

The drawings are re-contextualised to test the application of design research investigation outcomes of the allegorical narrative of the Gateway and the Shadow Grounds. It aims to integrate both visual and textual descriptions to insight and allegorical architectural project. It depicts the journey through the threshold of the realm of shadow:

Included in this volume are the critical reflections and final remarks. 


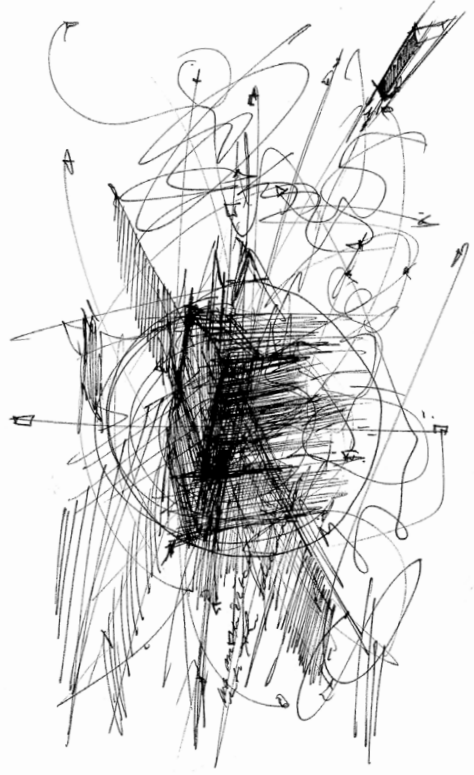

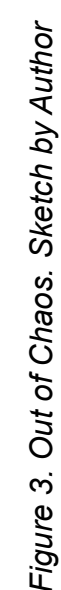


EMBARKING /

DISEMBARKING
In order to embark upon this investigative journey, one needs to identify the platform from which th thembark. It is the pitpose of this design research investigation to straddle the threshold between art and architecture, identifying the relationships between the creation of a work of art, and the creation of a work of architecture. As an intial exploration into the shadow, it seemed important to embrace the unexpected possibilities that arise out of intuitive and emotional responses. In the words of Andrew Ballantyne, who dissects the philosophical ideas put forward by Gilles Deleuze and Felix Guttari in their seminal work, $A$ Thousand Plateaus:

One opens up to chaos, makes oneself receptive to what one finds there, steps outside the structured world of habits and common sense, and sees what happens (Ballantyne, 25).

Chaos designates the interplay between stability and instability or, between actuality and virtuality. The actual (the sensible) entails states of affairs, bodies and individuals, and the virtual (the intangible) is represented by the incorporeal events that shape and morph these acutalities. Forever altered and recomposed by the intangible, the individual seeks new ground at all times. Chaos is also closely associated with notions of the shadow, being the antithesis of light and of order. Its etymology derives from infinite darkness or something akin to water, formless, expansive, emptiness, or void. It is the purpose of this investigation to embrace the ever-recurring creative moment, the genuine intuitive and spontaneous responses-the pull of the deep. Within the context of this thesis, poetic and intuitive responses are privileged as a way to form understandings not directly accessible to words. Out of a given set of conditions, it embraces the chaos of the unknown to alter and recompose normative understandings of the archietctural design process. 


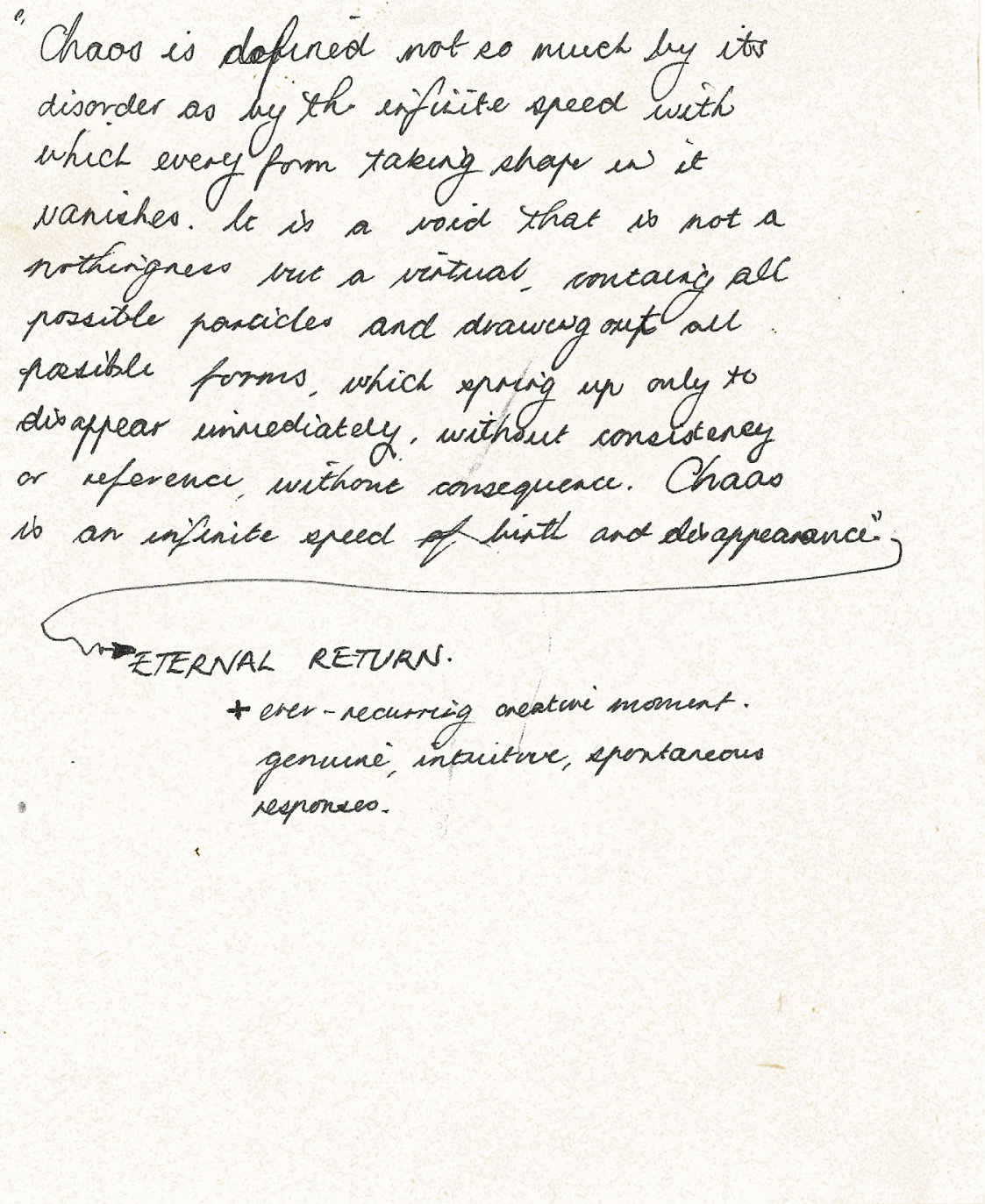

"Chaos is defined not so much by its disorder as by the infinite speed with which every form taking shape in it vanishes. It is a void that is not a nothingness but a virtual, containing all possible particles and drawing out all possible forms, which spring up only to disappear immediately, without consistency or reference, without consequence. Chaos is an infinite speed of birth and disappearance." 

To me, the richest truth exists not within any single source, but amidst the perpetually shifting realm between them, within the world of relationships. It is here that it is possible to discover the interconnectedness that lies between all things - a set of correlations connecting the disparate parts of our universe. It is foolish to deny that man has two (seemingly competing) sides. Humans are both biological creatures and emotional beings, capable of both mathematical reasoning and poetic expression. And yet this characteristic cannot be confined to the inherent probelms of philosophical dualism; we exist not as two separate beings, but as a single entity.

This is where I search, within the world of ambiguity and discovery - the between space. 


\title{
Part 1
}

\section{METAPHOR ${ }^{*}$ MOSIS}

\author{
Allegorical Architecture \\ as Critical Method
}

R01: to explore how allegory in the form of narrative can provide a critical framework for architecture. 


\section{6}

The ever present enigma of the human condition is only denied by the foolish. And it is this mystery architecture must address. Part of our human condition is the inevitable yearning to capture reality through metaphors. Such is true knowledge, ambiguous yet ulitmately more relevant than scientific truth. 


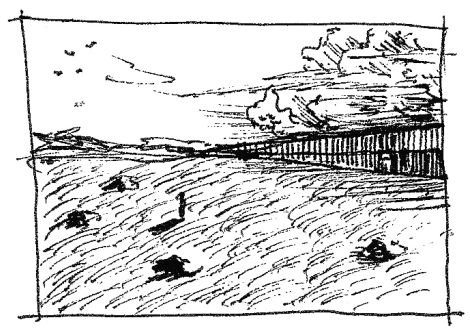

Figure 1.1. The Wall. Sketch by Author 

allegory in architecture. It will aim to highlight and explore the narrative in Haruki Murakami's Hard-Boiled Wonderland and the End of the World, as a way of expressing the interplay between light and dark, inner and outer. Narrative theory will be engaged to help provide a robust foundation for exploring the construction of a fictional narrative. Jerome Bruner, in his paper "The Narrative Construction of Reality", identifies key features of narrative construction in literary fiction. These features will be used as a means of unveiling i mportant narrative tools, as well as interrogating and informing decisionmaking within the design process. Bruner's key features reveal how narrative is ultimately constructed through interpretation, reintroducing to us the importance of our own unique personal narratives in the engagement of creating and viewing. Cathy Ganoe relates Bruner's theory to a design framework, identifying the links between interior design and narrative.

Murakami provides mechanisms and provocation for interrogating the interplay of light (conscious) and shadow (unconscious). By presenting us with two narratives in parallel and ultimately blurring and merging them, we start to understand ourselves and our world as no longer separated by light and shadow, but rather as a continuous confrontation between these two dualities. The principle aim of PART 1 is to explore the use of literary allegory and the mechanisms adopted by Murakami to ultimately enable speculative design responses.

It uses of Penelope Haralambidou's article “The Fall: Allegorical Architectural Project as Critical Method" as a working framework for critically engaging allegory in architecture. This section of the research will critically engage with the traits, as outlined by Haralambidou, through relevant literature and cast study reviews. Iterative sketch experiments explore these ideas, sequentially building upon one another, providing a working method for implementing an allegorical approach in the design process.

The applicaition of Haralambidou's framework to an architectural interpretation of Murakami's allegory is used to interrogate the shadow in architecture where layering, blurring and ambiguity provide conditions for exploring these ideas in the context of the drawing. 
1.1 A TALE OF In Murakami's novel, Hard-Boiled

Wonderland and the End of the

TWO WORLDS World, reality is no longer defined by a linear timeline, a singularity of consciousness is opposed and the urge to see things as coexistent and side by side the allegory. William S. Haney, a specialist on the topic of consciousness and its relation to culture discusses, in depth, the themes and issues being addressed in Murakami's novel. He brings to light the theme of the conscious vs unconscious, being vs non-being, within the narrative. Upon entering the walled town in the novel, the narrator is stripped of his shadow; Haney confesses that the walled town in a represntation of the mind and the shadow the unconscious. Haney brings to light the idea of a plurality of consciousness, expressed through alternating chapters and differing timelines. The idea of the conscious (light) and unconscious (shadow) realm is also expressed through architectural tropes, depicting the inner contradictions and development of the individual in space as well as in time. Thematically, Murakami explores the nature of self, the way in which who we are is entirely defined by the experiences and memories that comprise our consciousness.

In the Japanese language, the distinctions between watashi and boku play a major role in helping to unravel Murakami's themes.

The figure table on the opposite page provides a clearer understanding of the parallel narratives and their differences/ similarities.

image relates to identity. identity is relational.

$\operatorname{mind} /$ body

public/private

external/internal

subject/object

male/female

autonomous/personal

conscious/unconscious

being/non-being

light / shaow

Each pair of opposites complements the other. Without contrast, things would deteriorate into sameness. Without balance, things would deteriorate into extremes and self-annihilate. The key is balance (Suman). 


\section{HARD BOILED THE END OF THE WORLD \\ WONDERLAND}

WHO? Watashi- gender neutral, Boku-male, informal feminine, formal

WHAT? physical self imagined self

Past tense-first person Autumn to Winter

WHEN? September 28th - October

3rd

HOW? $\quad$ Past tense-first person

Present tense-first person

Subterranean Tokyo, allusions

WHERE? to Alice in Wonderland/ ancient mythologies of a journey into the underworld. It depicts a cavernous underworld filled with INKlings (mysterious and dangerous sewer dwelling creatures).
Dreamlike walled city, where one-horned beasts roam and the inhabitants live a life without their shadow.

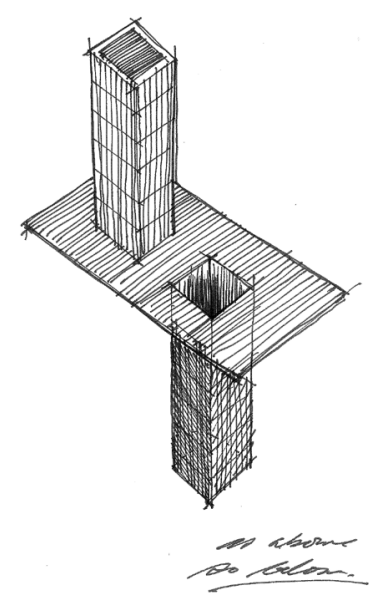


Using Jerome Bruner's article "A Narrative Construction of Reality" as a framework, the following section aims to NARRATIVE identify the literary tools at play within the novel. These mechanisms will be related to four selected features of literary fiction, as laid out by Bruner. Highlighting the construction of the novel through Bruner's features provides a method for reinterpreting literary narrative features into architectural narrative. Cathy Ganoe's article "Design as Narrative" provides useful clues to how these features of the story might be translated into architectural design mechanisms. The following features are identified as particularly relevant to the thesis investigation:

Canonicity and Breach / INNOVATION

Referentiality / TRANSFORMATION

Normativeness / MULTIPLICITY

Narrative Accrual / CONVERGENCE

\subsection{1/ Canonicity and Breach}

'Canons' are a general rule or principle-the convention of telling a story. However, Bruner argues that in order for novel and unique interpretations to exist, the cannon must be breached. It is the breach that provides fertile ground for innovation. According to Bruner:

For to be worth telling, a tale must be about how an implicit canonical script has been breached, violated, or deviated (11).

The breach suggests convention ought to be challenged, hence be interpreted anew. In the case of the novel, Murakami jilts conventional narrative structures and embraces an altogether more compelling plotline, seeking to translate the complexity and enigma of the human existential condition through juxtaposition, parallel realities, and through the blurring, and shifting of these realities. The gap opened up by the ambiguous and parallel narrative sequence allows the reader to insert their own creative input and subsequently traverse the space between worlds. The research argues that architecture also leads to people seeing the ordinary in a new light. Ganoe argues that innovation arises out of the use of form and space to alter normative thinking. The design investigation employs the allegory of Murakami's shadow to stir innovative and provoking speculative design responses. 
According to Bruner narrative is not only a form of referring to reality but of constituting it. Bruner argues that it involves collecting verisimilitudes (the appearances of truth), rather than verifiable facts(Bruner, 13). Narrative 'truth' is judged by its verisimilitude rather than its verifiability (Bruner 13) . It creates a world of its own. The narrative invites us to bear witness to that world. Alternate realities are capable of heightening our experience, and establishing a space of transformation that can act as "a place where inner and outer realities may merge"

Murakami's use of literary architectural tropes belong to a canon of metaphors that exist within the collective myth, these coalesce to create a certain meta-narrative. Seemingly endless corridors with infinite rooms alludes to Jorge Louis Borges's "Library of Babel", the idea of an omnipotent force that presides over a nameless town can be seen as a reference to Franz Kafka's The Castle. These allegories live on within the collective unconscious, their spaces realized through the imaginative act.

This thesis explores spatial concepts and architectural ideas through the construct of a dream-like realm paralleling the threshold of the Gateway and the Shadow Grounds in Murakami's novel. The site exists within the imagination yet its concepts draw from real-world truths and ideas.

[Dub] Music no longer has a final outcome; rather, it exists in a constant state of flux .... [Writers are still] using storytelling techniques invented in the nineteenth century ... We need to explore new ways of telling stories; new ways of allowing narrative to partake of the liquid experience.

- Jeff Noon, Cobralingus, Codex Editions (Brighton), 2001. 
Normativeness refers to the

establishment of norms within

the construct of a narrative that is constantly being restructured by the changing viewer (Bruner 16). One's individual reality is constantly shifting in the relationships and interactions with their inner and outer world. Ganoe interprets this as the multiplicity of the experience of space, in that no two people's experience is the same, even within the same spatial realm (9). According to Bruner:

These norms are located within the changing narrative of the individual in relationship with their physical, social and psychological world (9).

This is evident in the reversal and thematic interplay of utopia/ dystopia within the novel. The narrator in Hard Boiled Wonderland is seemingly content with his life, whilst the narrator in the End of the World finds himself in a dystopic walled town governed by a mysterious force where one is stripped of their shadow. As the novel progresses however, the perception of each setting is reversed. Utopia becomes dystopia as Watashi embarks on a journey through the caverns underneath Tokyo, straying further from the known. Dystopia becomes utopia as Boku discovers the limits of the town, falls infatuated with the Librarian and feels the contentment of the eternal timelessness in the town, relishing in everything that is. Yet neither of these worlds is either one or the other. At the conclusion of the novel, the Shadow, in an effort to leave the town, plunges into The Pool and thus perishes. Murakami does not refer to what happens next, yet interpretation of the novel suggest that without the Shadow, the physical outer self slips into a state of deep unconsciousness, a coma. We are left with no answers. The meaning does not give itself up. Bruner confesses:

Narrative, I believe, is designed to contain uncanniness rather than to resolve it... [T] he 'consoling plot' is not the comfort of a happy ending but the comprehension of plight that, by being made interpretable, becomes bearable" (16).

Byallowing for interpretation, it becomes critical and forces contemplation and introspection. Within the context of this thesis multiplicity both in mediums and in processes becomes a way of heightening ambiguity. Within a richly layered narrative and design sequence, no two readers will draw the same conclusions. The experience of the work is dependent of the individual's own relationship to their physical, social and psychological realms. 
Narrative accrual is the notion of the parts in relation to the whole-it is how the story is understood as a collection of elements converging to become a a whole (Bruner 19). This allows us to understand 'canonicity' and when a 'breach' has occurred.

In the novel there is a certain urge to see all things as being coexistent and to perceive and depict all things side by side and simultaneously, although across scales of space and time. The ambiguity and disjunction between narratives, forces the canon to be breached. It jolts our understanding of the narrative sequence and begins to question how the two realms interrelate. The whole is represented in the parts, the two converging toward the end.

John MacQueen, in Allegory, part of a series entitled The Critical Idiom, provides a historical overview of literary allegory, where he recognises its origins as philosophic and theological, closely associated with narrative in the form of myths. (Haralambidou, 226) Claude Levi-Strauss stresses that, "mythical thought always works from the awareness of oppositions towards their progressive mediation" (Levi-Strauss, 99). The symbolic mediation in myths offers inspiration for culture and culture members to heal, flourish, or accept their reality. With this notion, allegory in the form of narrative myth can be used as a critical starting point, shifting the normative methods of design, recognizing the potential for architecture to embrace alternative modes of generating meaning. Ganoe argues that designing is akin to storytelling, calling for the use of narrative as a design framework that allows for expansion of meaning, "The characteristics of the narrative that help to organize the complex world of people, entities, and events through the language of stories provides a flexible framework for understanding and expanding the meanings of design" (Ganoe, 1999, p.2) According to Sheila Danko:

Storytelling, like designing, is a creative process of selecting and organizing chaotic events that enable us to discern how diverse elements come together to form meaningful experiences (Danko, 12).

It enables justification for the construction of a world from fiction, allowing us to better understand and make sense of our own world in an imaginative and novel way. It is similar to Roman Jakobson's maxim: "The task of the artist is to make the ordinary strange". (Jakobson, 21) 
1.3 Allegorical Architectural Project as Critical Method.

Penelope Haralambidou

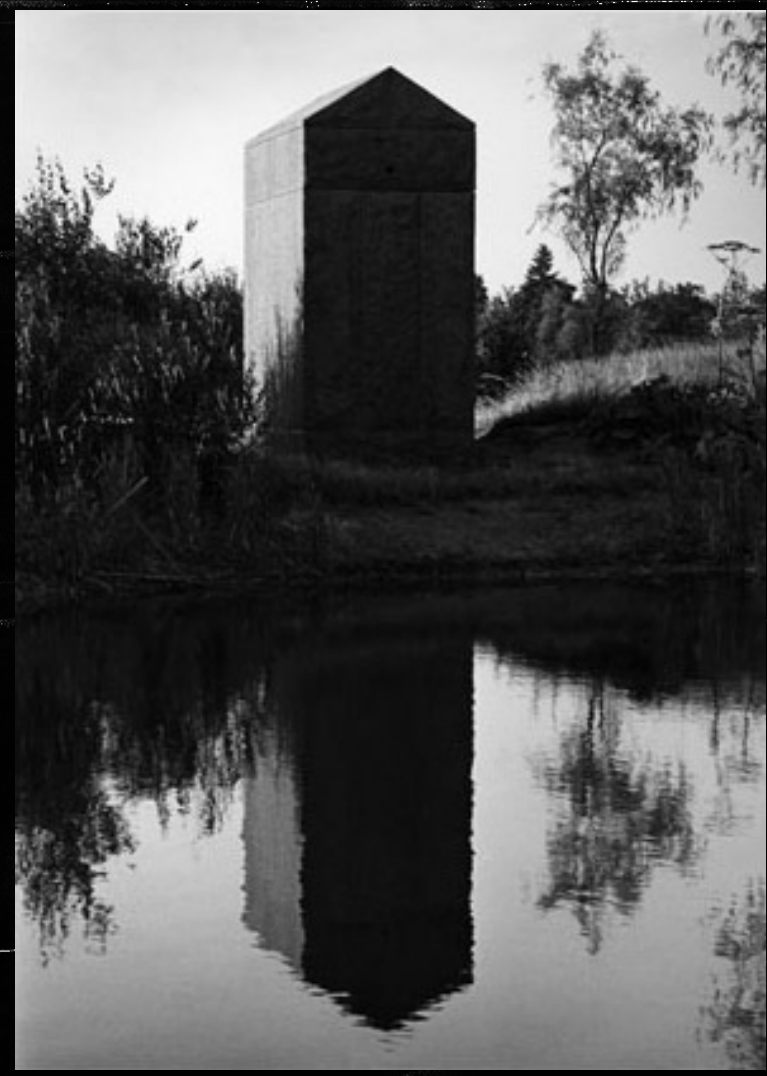

1)

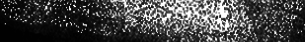

Figure 1.3. Stone House with Soul Hole. Hannsjorg Voth. 
The allegorical architectural project can be employed to unravel another piece of work, a site or drawing itself by questioning its underlying syntax: allegorical design reveals an analytical inclination and becomes a vehicle for criticism

(Haralambidou, 225)
Dr. Penelope Haralambidou, Associate Professor and Director of Communications at the Bartlett School of Architecture, writes that "narrative can be used as a tool for grasping and developing spatial ideas," thus "inviting interpretation and duplicity of meaning"(Haralambidou, 226) Allegory as a form of narrative does not readily convey meaning but rather uses enigma or ambiguity to invite open-ended interpretation. Haralambidou cites "the term allegorical, deriving from the Greek allos, other, and agoria, speaking, signifies a duplicity of interpretation." She calls for an alternative critical practice that employs architectural drawing, the language of describing buildings, to articulate something 'other' (234). She considers how allegory offers a critical departure in architectural design and theory.

This thesis calls for re-examination of conventional practices in architectural design. It reconsiders notions of context, occupant, and architectural artefact through speculative and allegorical means, seeking to challenge conventional presumptions of 'form' and 'shadow'. It offers a re-evaluation of the realm of shadow in architecture through the adoption of an allegorical framework. The following section reveals insight into the allegorical traits as outlined by Haralambidou; these are grounded through critical engagement and relevant precedent studies. The case studies, whilst each evidences one of the traits, all speak of allegory in a wider sense. They have also been selected based on the significant role that the shadow plays. Allegorical traits include:

DOUBLE MEANING

The open invitiation for interpretation;

FIGURATIVE GEOMETRY

the use of figurative elements to denote structural relationships;

VISUAL + VERBAL

the reciprocity between visual and verbal;

BATTLE AND PROGRESS

the similarity to a battle - an opposition between two forces - or a journey;

UNFINISHED

and the state of being unfinished. 

By saying one thing and meaning another, in all allegories there is a duplicity of meaning. But the link between what is articulated and its interpretation, as well as the intentions of the author, differ. Knowledge, or the creation of meaning, does not spring out of narrative structure but rather is co-created by the author/ artist and the receiver. Catherine Kohler Reismann, Research Professor at Department of Sociology at Boston College notes: "Meaning is fluid and contextual, not fixed and universal. All we have is talkand texts that represent reality partially, selectively, and imperfectly"(Reismann, 15) Meaning is born out of engagement between thought and mode, subject and object. Critical interpretation has the ability to unvcover meanings not consciously intended by the author. Marcel Duchamp approved all interpretations of his work and was reluctant to give any of his own, describing the artist as a:

Mediumistic being who, from the labyrinth beyond time and space, seeks his way out to a clearing [...]. All his decisions in the artistic execution of the work rest with pure intuition and cannot be translated into a self-analysis, spoken or written, or even thought out (Duchamp, 138).

For Duchamp, the work succeeds if it triggers many interpretations, because it is not the artist alone who performs the creative act: the viewers make their own contribution (Haralambidou, 230). Therefore, the work of art is an allegory in receiving, interpreting, but also in making. Allegorical architecture also exists within this realm. Drawing from a range of metaphors and analogies, the allegorical architectural project is a work of art in itself, triggering critical interpretation and alluding to something "other". Architecture 'is an interpretive, critical act', both the process of design and the experience engages the poetic imagination to trigger memories, associations, and emotions. The phenomenon of the poetic imagination allows us to explore the being of man considered as the being of a surface, of the surface that separates the region of the same from the region of the other (Bachelard, 222).

Johnathan Hill argues that in order for invitation for interpretation to occur a space of ambiguity must be opened: "A gap indicates that something is either unnoticed or missing. Signifying incompletion, a gap invites the viewer or user to attempt to complete the montage. A gap is an opening, possibility for a period of time, between seemingly more substantial conditions, known in montage as fragments"(Hill, 67) A gap opened up in front of the drawing allows the viewer to place their own reading and interpretation on the work. In this sense, a gap is opened up between concept and reality, whereby the things themselves are animated with a vital energy, a space of ambiguity and immanence. The propensity for interpretation exists in the void between what is given and what is omitted. Allegory provides the critical framework for this investigation, yet allegory is not viewed here in the sense that is says one thing and implies another. In fact, what the work has to say can only be found within itself- within the interaction between reader and text, grounded in language, and yet beyond it. For the sake of this investigation, artistic practices become a way to provide a space for interpretation. 
Two seminal New Zealand artists, Ralph Hotere and Shane Cotton, both deal with BLACK WINDOW the shadow, identity and meaning in W. thesis investigation, these artists provide compelling precedents for mounting speculative design experiments into the allegory of the shadow. Both artists deal with the shadow and darkness as a life force. In the paintings we see a conflict and resolution between light and dark. The methods and tactics employed in the paintings act as architectural design mechanisms to explore Murakamis allegory.

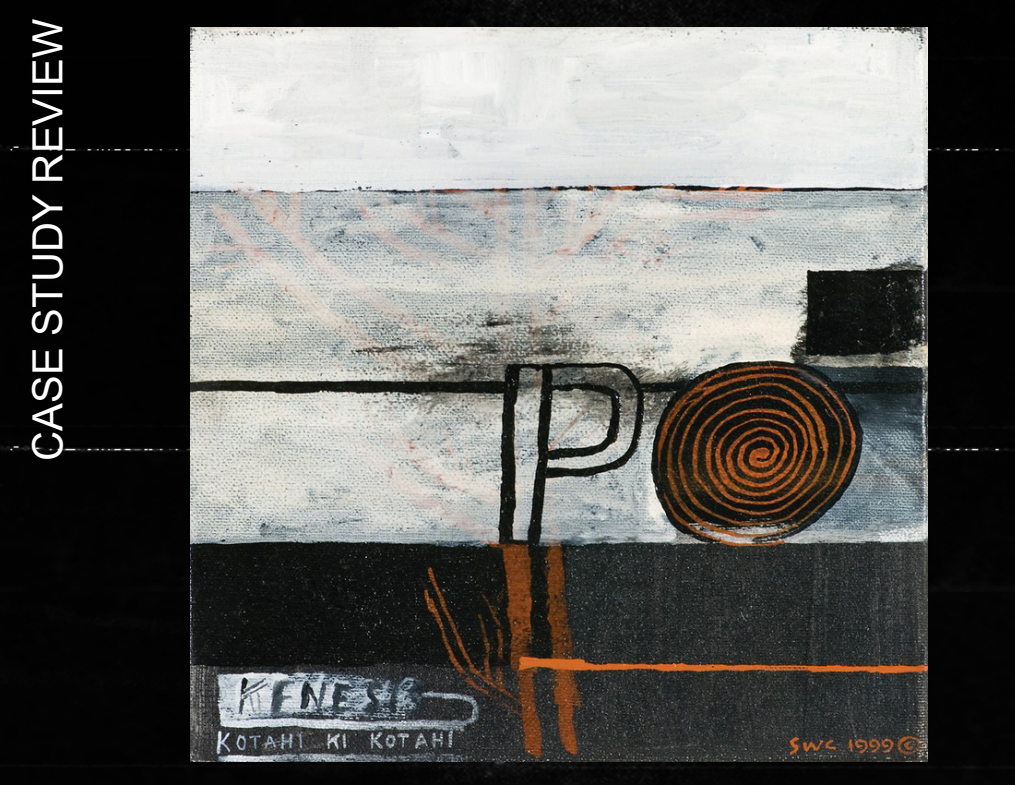

Figure 1.5. Kenesis: Kotahi-ki-Kotahi. Shane Cotton.

\section{SHANE COTTON}

The painting evolves from the darkness at the bottom to the lightness at the top. There is a russet coloured tree growing out of the darkness at the base. But instead of becoming more and more visible as it enters the light, it becomes more and more veiled by the light.

In te reo Maori, the title Kenesis: Kotahiki-Kotahi translates as Genesis: One-onOne. Po means evening. There is a tree growing beneath the layers of paint. 
Hotere's Black Window-Towards Aramoana, depicts a white cross upon a black background. Traces of language and meaning have all but been eliminated. However, on closer inspection, layers begin to appear, just outside the black square scuffs of acrylic paint suggesting an image beneath or beyond the panel of darkness. The painting obscures the image as opposed to revealing. Despite the darkness, there's often a sense of illumination behind Hotere's paintings. There exists a stark juxtaposition of nothingness and fullness simultaneously. The use of a salvaged window frame implies a larger context and brings the physical traces of its previous life into a new setting. The 'black window' reverses the usual function of a window as a light source and subverts it, the painting becomes a threshold with which to look into the darkness.

Imbued within the painting is a sense of the sacred within the ordinary, and a concern for the growing rift between the natural and human-made world. "In the end, I think the art may be simply alchemicaltransforming appetite into ecstasy, the base into precious, and suffering into something almost ritualised-common anguish with the grandeur of a mountain for its backdrop"(O'Brien). The work subverts all meaning; it can be seen as a window at night, a blackboard, the Southern Cross, or a letter T. The cross form, whilst carrying religious symbolism and connotations, also represents a compass or viewfinder, a signification of orientation. This case study is pertinent to the research investigation as it questions the notion of 'form' and 'shadow'. Notions of layering, obscuring, convergence all present themselves in the work. It shows that meaning is inherent in the relationship between the subject and object-ultimately dependent on the viewer to complete its meaning.
And then, sometimes, the registers of ground and figure shift, and its dark in the painting and light where you stand to look at it. Or, paradoxically, the light is dark (O’Brien, 13)

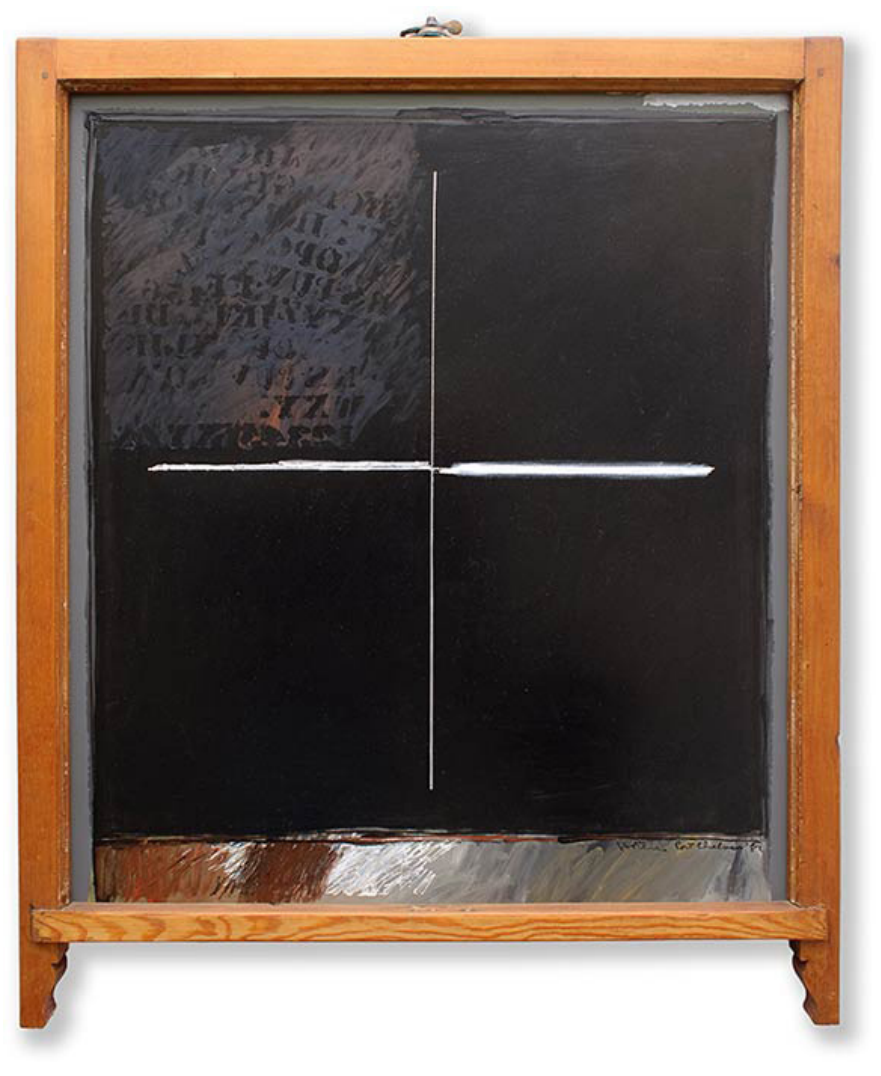

Figure 1.6. Black Window-Towards Aramoana 

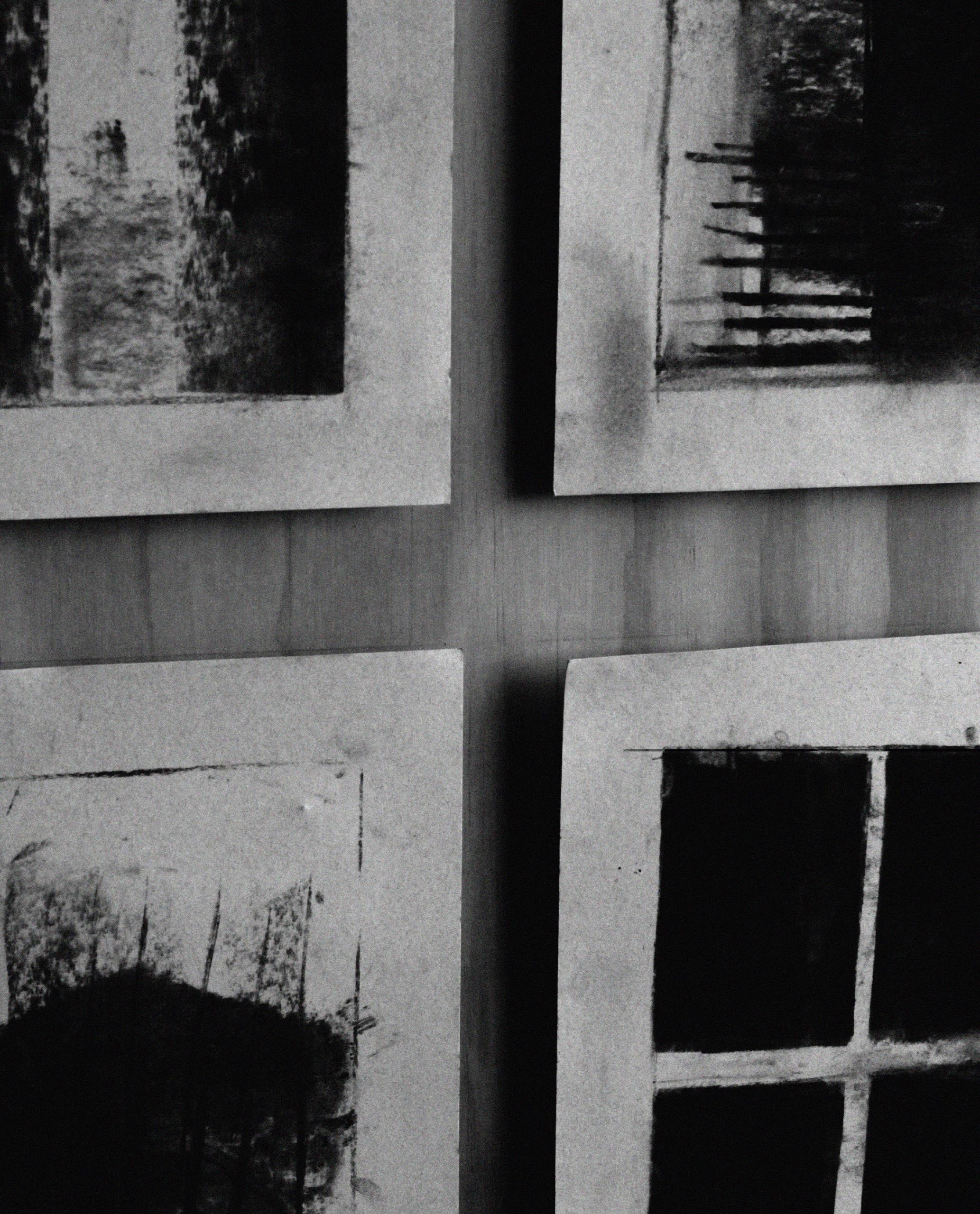
In the design research experiment by author shown in figure 12, a series of charcoal experiments on the back of found certificates translate the allegorical mechanisms of Murakami's novel through the act of mark making. Using both Ralph Hotere and Shane Cotton as precedents, the experiments were produced as a means of interrogating the link between marks on a paper and spatial depth. Utilising Ganoe's theory of narrative design as a platform, the following tactics were applied to the creation of the marks:

+ convergence_oppositions that move toward their progressive mediation

+ transformation_blurring, layering and obscuring

+ multiplicity_motion versus rest, speed and slowness

In the research design experiments the notion of threshold was used as a catalyst. The series of 9 studies were done iteratively within the space of 30 minutes. The idea behind the studies was to investigate the relationship between black and white, presence and absence, the projection and the trace.

The marks varied in degrees of speed and slowness, using the flat edge of the charcoal piece to make broad strokes and the thin edge to add lines of confrontation. In some instances no more than four strokes were used, whilst others, layers were applied, blurred and obscured, and re-applied.

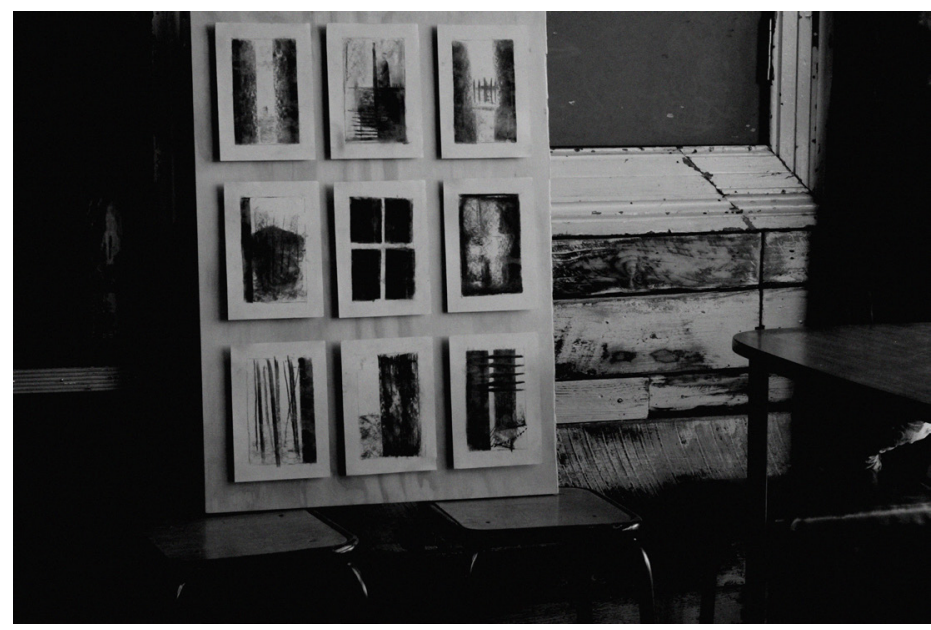

Figure 1.8. Displayed experiments. Image by author. 


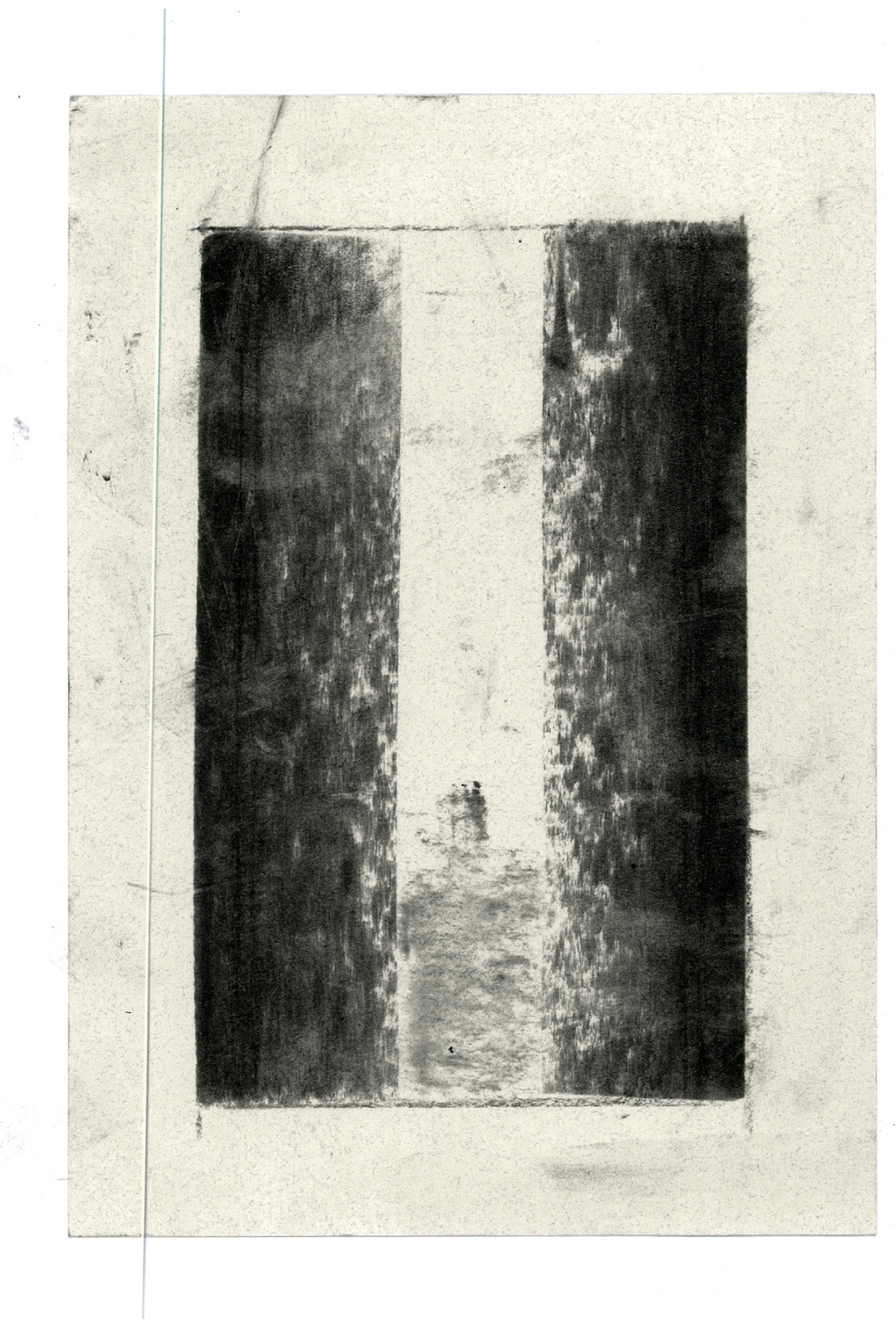

Figure 1.9. Multiplicity. Charcoal on certificate paper. image by author 


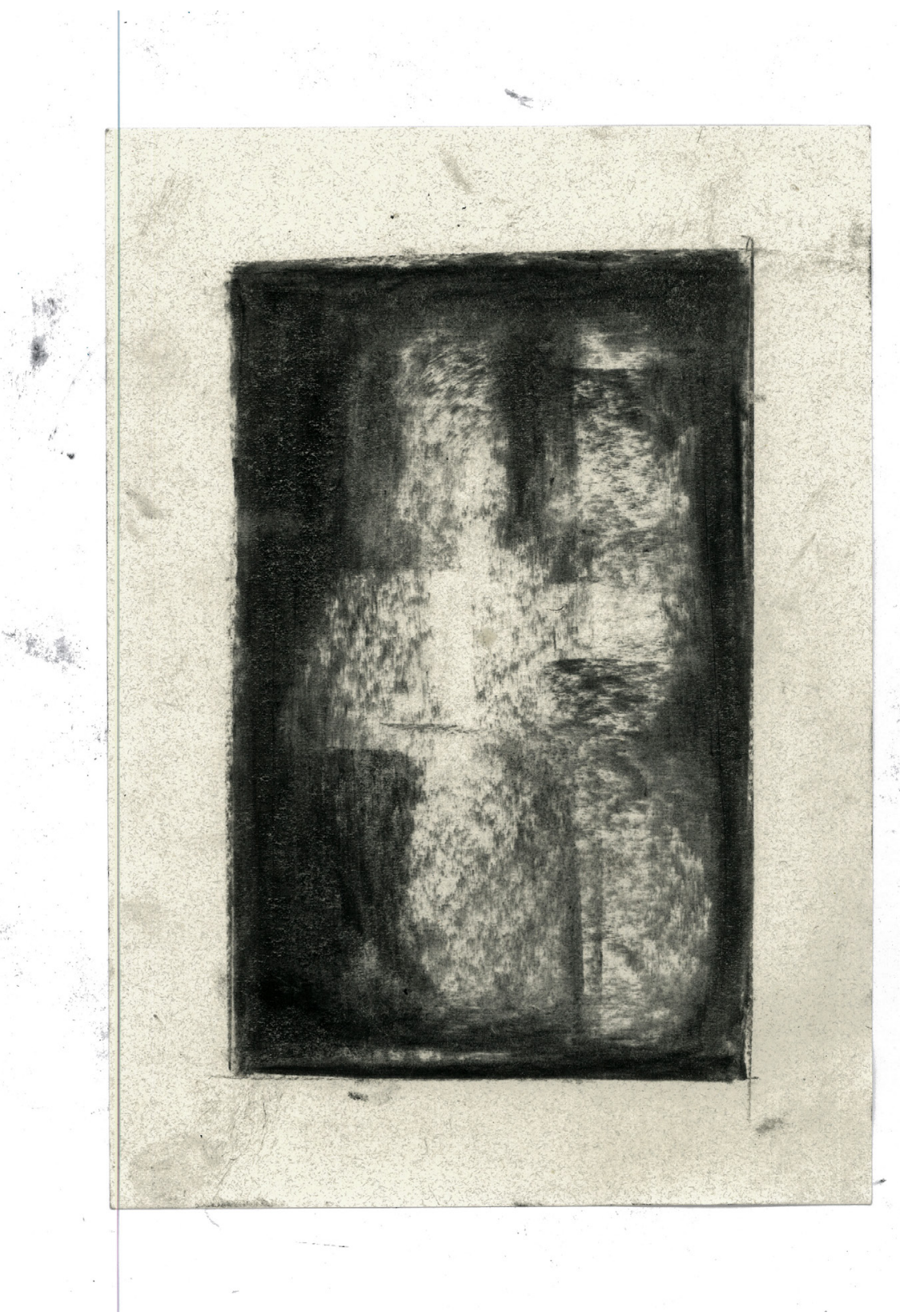

Figure 1.9. Convergence. Charcoal on certificate paper.

Image by author 

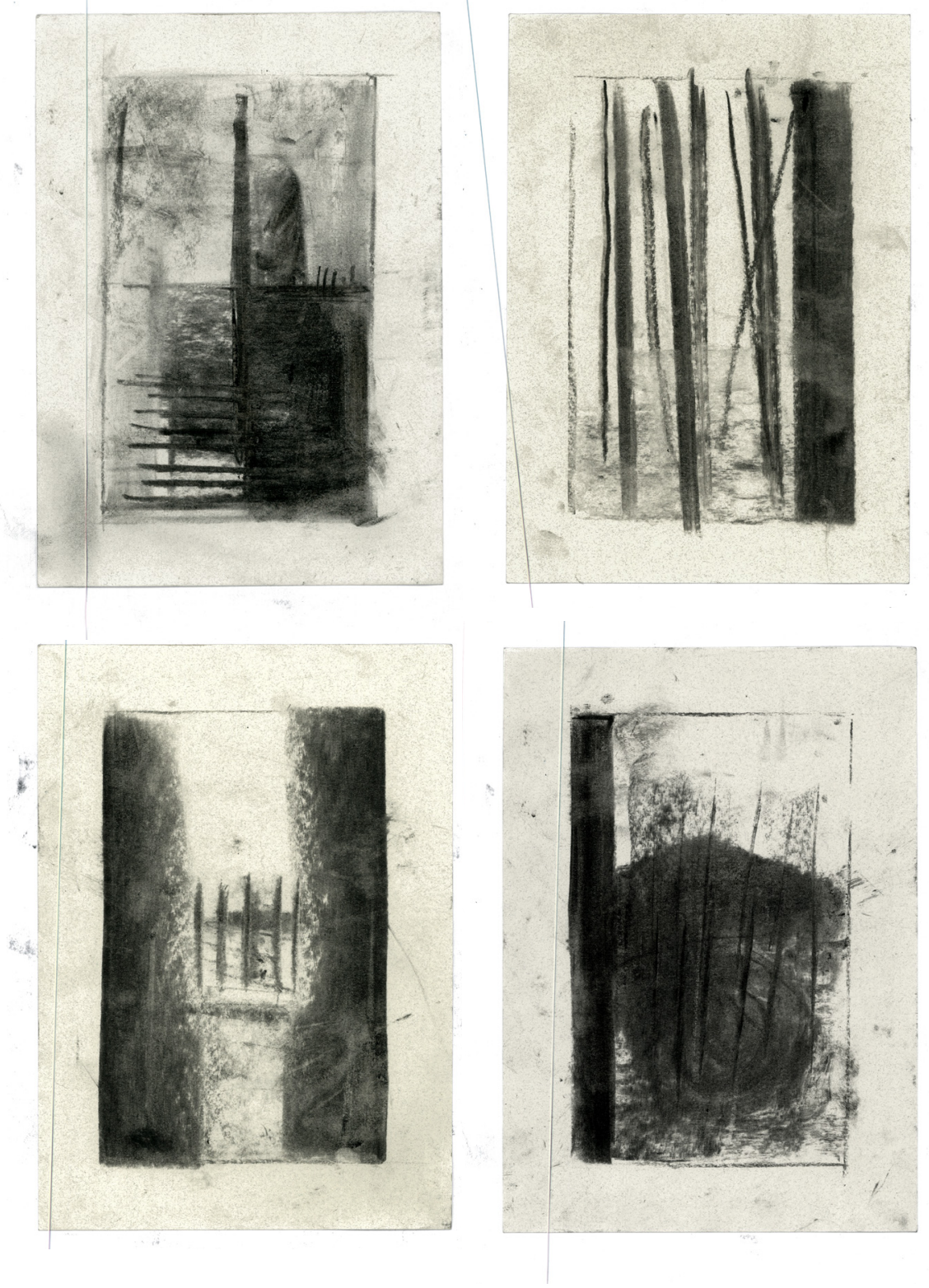

Figure 1.10. (opposite page) In-situ. Charcoal studies on display. Image by author

Figure 1.11. (above) Charcoal studies. Transformation. scanned images by author. 


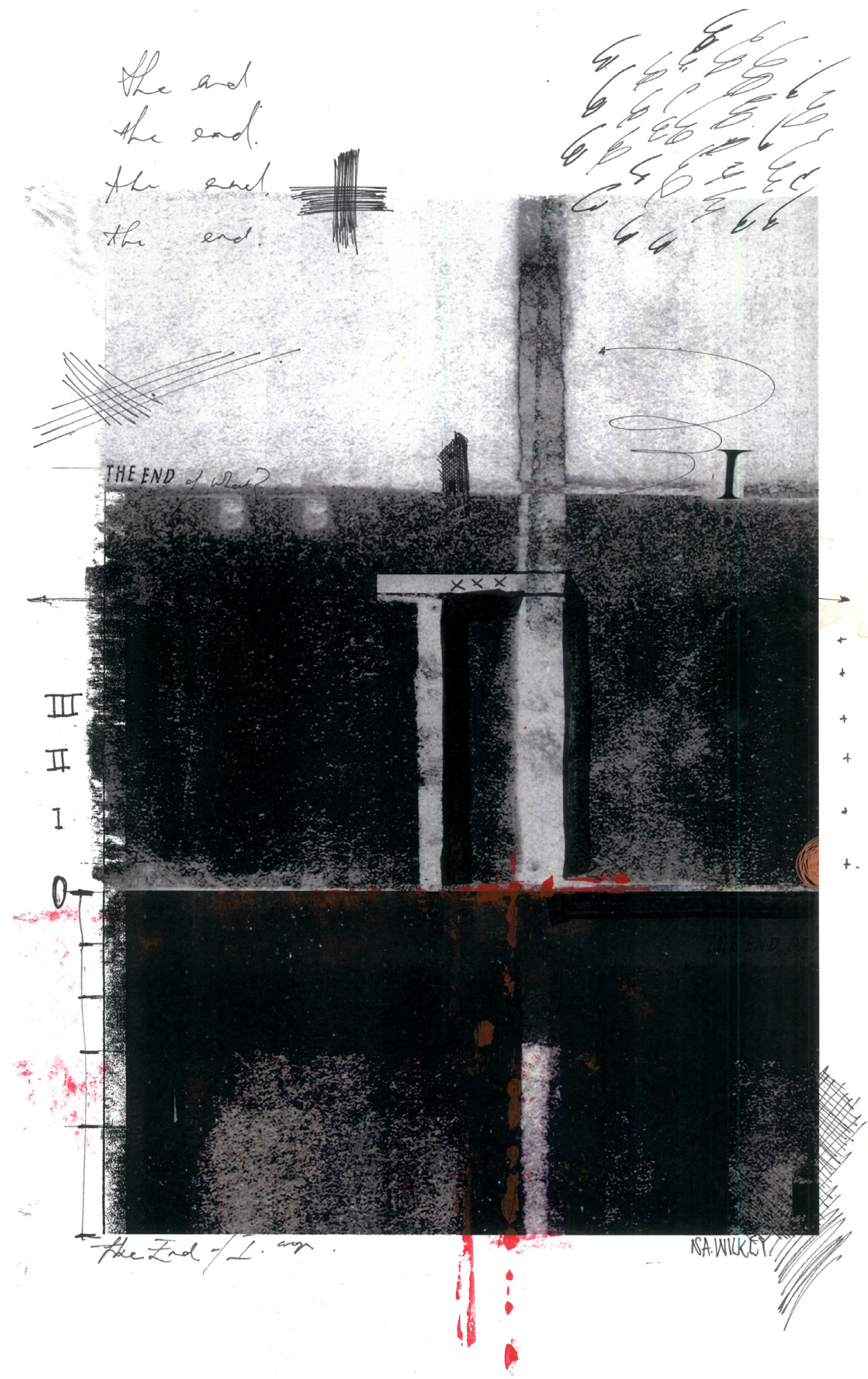

Figure 1.12. THE END? Mixed media collage by author. 
The studies as shown in figure 1.10 were exhibited as part of a Flash Exhibiton organised by Humbugga, a club of artists and architects who seek to connect art and architecture. This provided the opportunity to engage the studies in the public realm. This exhibition and its responses gave me insight into the nature of the drawn artefact as a means of provoking thought and contemplation. The layered, blurred and obscured marks on paper have both a sense of material presence and immateriality to them. At once abstract and figurative, the studies inspired notions of atmosphere, spatiality, form and context. One viewer of the work, commented how they exist somewhere between "abstract and material"-alluding to spaces and thresholds, visual and experiential qualities of the shadow.

Figure 1.12, THE END, re-examines the orignal studies through the cutting, scaling and layering of them. Additonal layers were added, the introduction of ink pen contrasts the blur with the scratch. There is a notion of a threshold that sits between the light and dark areas of the page, text and markers of measurement were introduced, provoking a further sense of mystery.

The idea of layering, obscuring and cutting became key to the development of further experiments. Out of these studies a visual and atmospheric language was derived.

The artifact-city, building, painting, whatever-has then, in the best sense, its own double obligation. It may act as a positive instrument for

the qualification of human association (artifact as in-between 'table') and at the same time it may in itself present an encapsulation of the same uncertain drama of reality which it helps to qualify and stimulate. The artifact, in other words, may operate as both active agent and as a means of record-keeping, occupying a realm which is both 'immediate' and potentially timeless.

-Koetter, Fred. "Notes on the In Between." Harvard Architecture Review, Spring 1980. p 71 


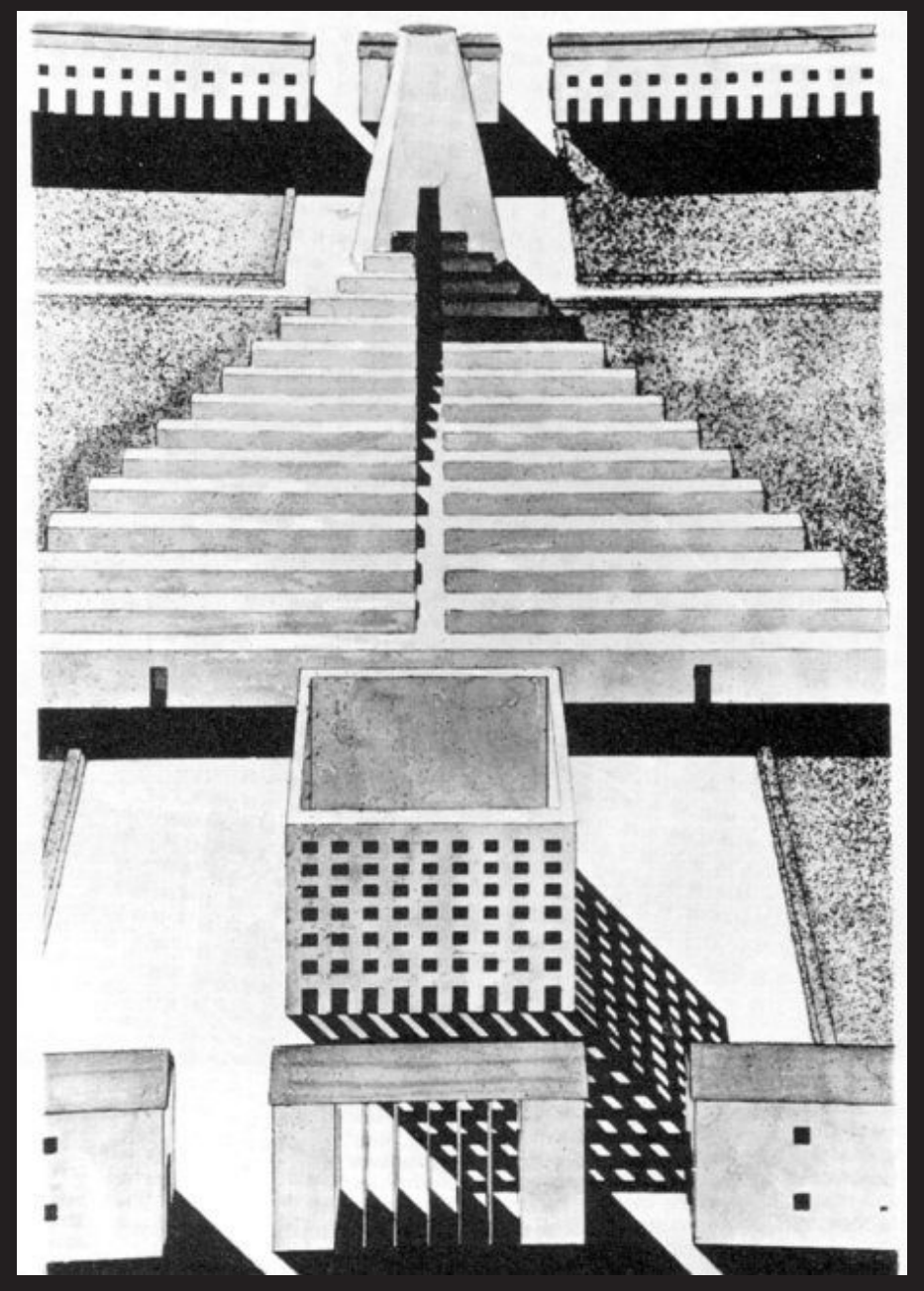

Figure 1.13. Sketch drawing for San Cataldo Cemetery. Aldo Rossi. 


\subsubsection{FIGURATIVE}

\section{GEOMETRY}

figurative

'fig(ə)rətıv/

adjective: departing from a literal use of words; metaphorical
The second of the five principle trait of allegory that Haralambidou invokes, is the notion of "Figurative Geometries". In her definition of 'figurative geometries' she draws from American Literary critic Angus Fletcher who refers to the allegorical narrative as a mathematical equation or geometric principle- which instead of abstract numbers uses personages, everyday or sublime objects and sites to signify structural relationships. These equations however, remain abstract and unresolved, as though emptied of all content by the very structure that governs them. Fineman argues "Allegory is implicit in the idea of structure itself and explicit in criticism". In order to apply figurative geometries within the context of this thesis, we need to look at the principles that govern their structural relationships. Drawing from Diogo Seixas Lopes and his inquiry on Aldo Rossi, he cites the use of the figurative in Rossi's architecture. A reading of figurative geometry in the case of architecture suggests three conditions:

\section{HISTORY}

History as a wealth of knowledge, a disciplinary foundation and a design tool.

\section{AUTONOMY}

Autonomy suggests a self-governing system which is constituted by elementary principles, prevailing as types.

\section{ANALOGY}

Analogy transports the previous terms to a subjective sphere of correspondences between disparate sources. As an operation, it delves into memory and associative thinking to trigger a series of new meanings (Seixas Lopez, 185.

Analogical thought possesses the ability to string together fragments in order to convey or receive new meaning. In a letter to Sigmund Freud, Carl Jung expresses the differences between the logical and the analogical:

... logical thought is the thought expressed in words, which addresses itself to the outside world as a discourse. The analogous or fantastic thought is sensible, figurative and mute, it is not a discourse but a rumination, material of the past, an act of revolt. The logical thought is 'thinking in words' Analogical thought is archaic, unconscious and practically inexpressible in words (McGuire, 298).

As an investigation into the realm of shadow, the notion of analogical thinking seems critical. It is not through the logical or the reductive that the shadow is revealed, in order to delve into the realm of the shadow, one needs to be open to the archaic, the unconscious that guides our being. Aldo Rossi's Cemetery of San Cataldo at Modena project expresses the use of figurative geometry, through both symbolic form and through shadows. 


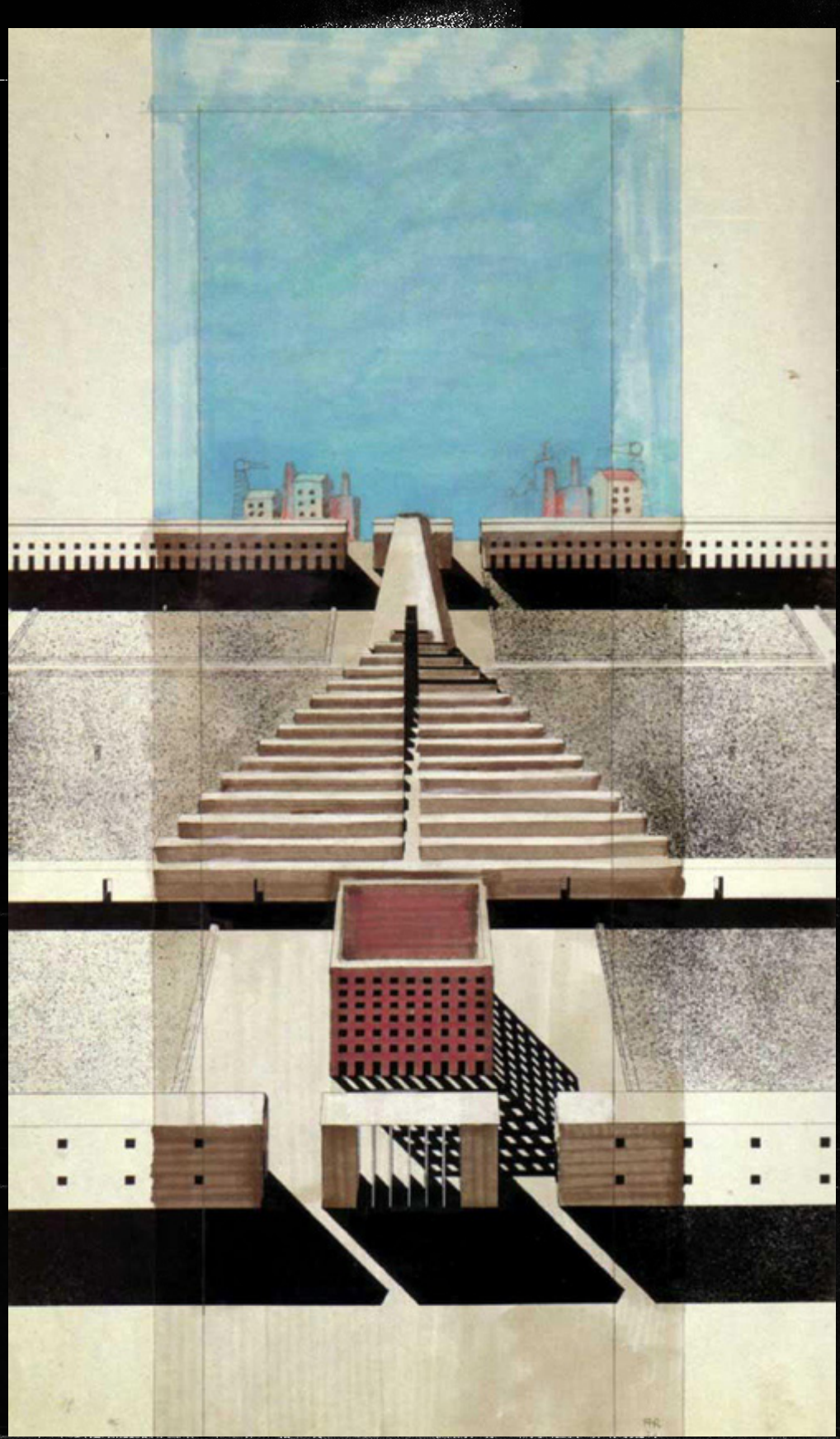

Figure 1.14. Coloured drawing for San Cataldo Cemetery. Aldo Rossi. 
The project for San Cataldo Cemetery is charged with symbolic meaning. Its use of figurative geometries denotes structural relationships that call upon the annals of history to prompt associations. In the creation of the cemetery, Rossi draws upon his personal autobiography, as well as historical symbols to coalesce an analogical composition of fragments. Rossi both acknowledges architecture as a personal process through which one might comprehend the complex and contradictory nature of life, as well as a universal source of symbol and meaning (187). He fuses memories and images in order to set the project in motion; in the words of Aldo Rossi, "image and reality must be intertwined until they are inextricable"(182). Through the reading of sketches for the project, Rossi combines fragments of objects through collage, searching for new associations and relations between symbols and forms. Both poetic and uncanny, the drawings for the project combine both technical and poetical elements. The shadows in these drawings range from the bold and assertive, taking on a corporeal presence, to the layered and hatched, obscuring the boundaries between things and denoting chronological and atmospheric time.

The elements of the funeral complex are seen as a field of geometric shapes between voids. Figurative elements include: a truncated cone-reminiscent of a deserted factory chimney, a house with four walls and no roof-a house for the dead, image of a ruin, and a series of skeletal like passages, inferring both the body and death. This use of figurative elements, fragmented and collaged, triggers new meanings and relations. Rossi subverts the notions of form through analogy and the use of figurative elements.

Figure 1.17 on the following pages applies the use of figurative geometry to the visual language already established in the charcoal studies. Forms and atmospheric qualities were mined from these studies and translated into figurative geometies through assosciation, memory and analogical thinking. Displayed as fragments de-contextualised from any context, the architectural objects are forced to speak their own language. What is it they say? Do they shout across the divide of time? Or whisper along the wind?

\section{San Cataldo Cemetery, 1971}

Aldo Rossi

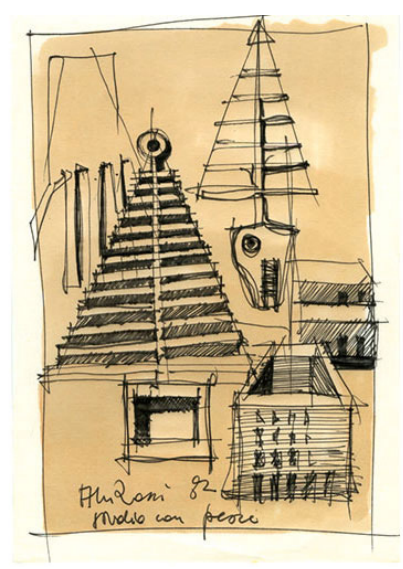

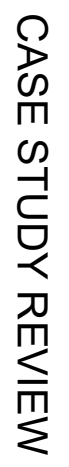

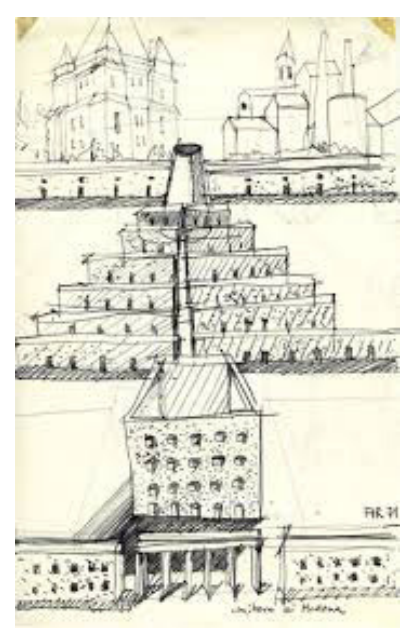

Figure 1.15 \& 1.16 Provisional sketches for the project at Modena. Aldo Rossi 


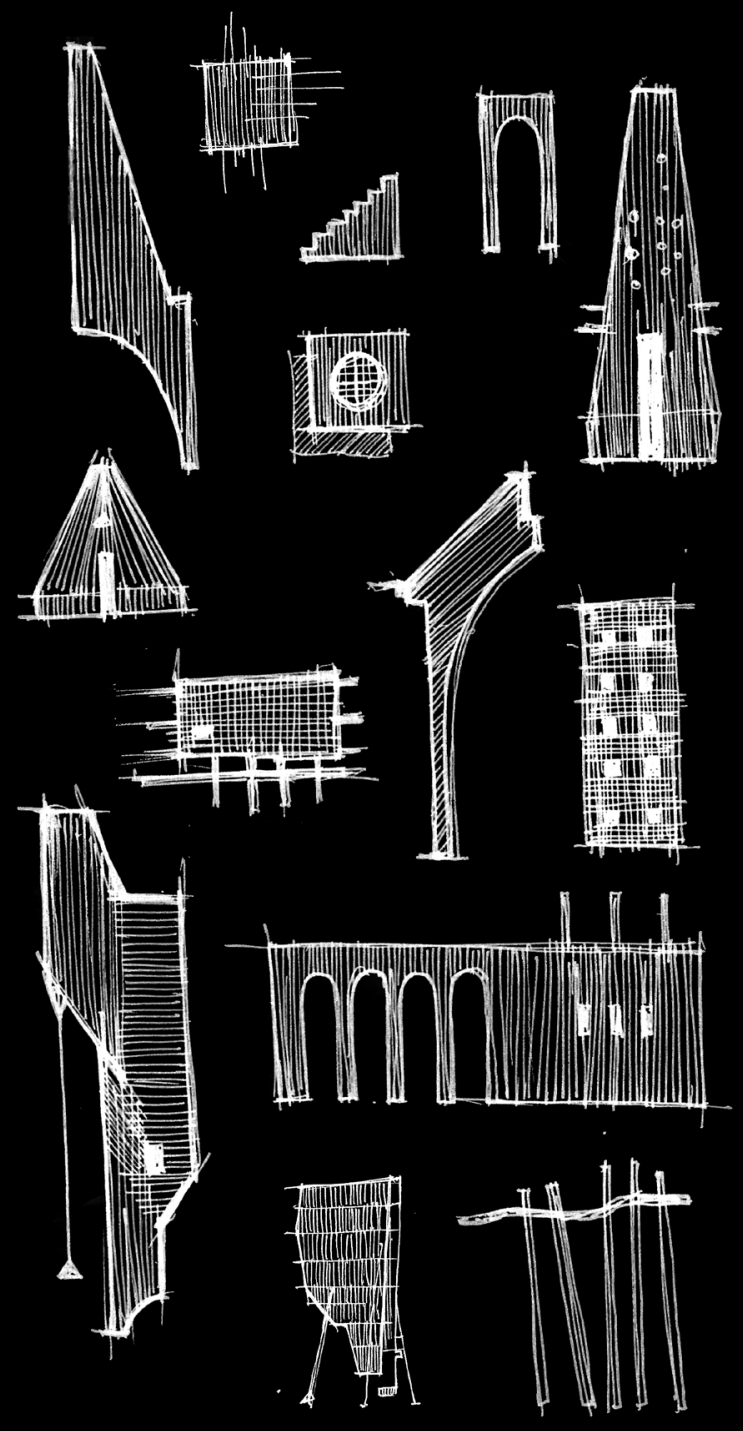




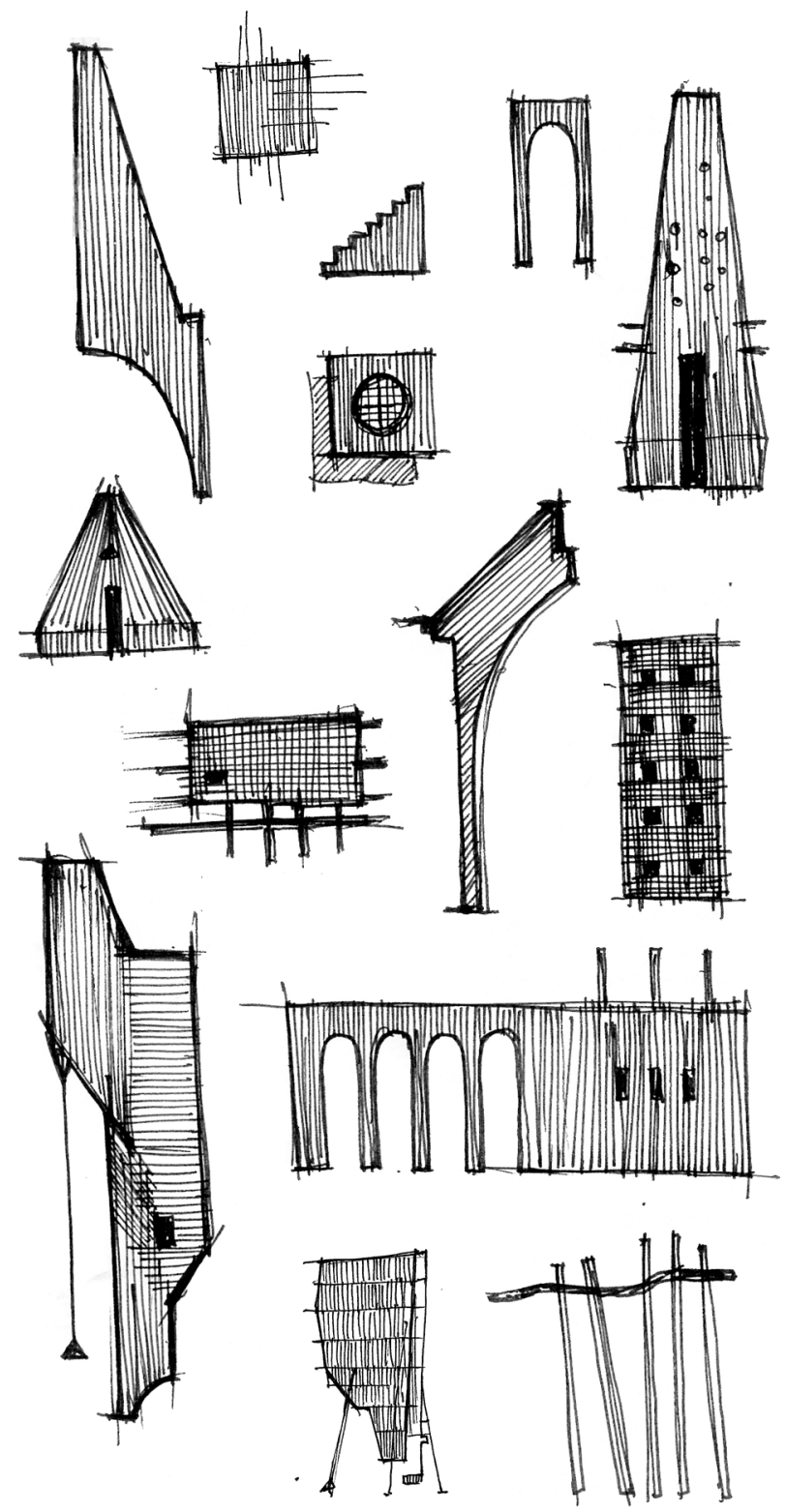


QRl

The Tomb is a vessel

journeying outward on a beam of light emitted from [Earth],

following

an immense and subtle arc through

the stars. For eons it will inhabit

the dominions of space, until

in a distant time

it must return to the world

of its beginning. Thus a cycle

the epicycle of Space and Time

will close. On that remotest day

the dark corridors of the infinite will again

become thresholds for departure, fading

shores on the dark gulf of [eternity].

[E]

The form of the Tomb has always

been known; it existed as a sign

in ancient codices, on countless

ritual maps of exploration.

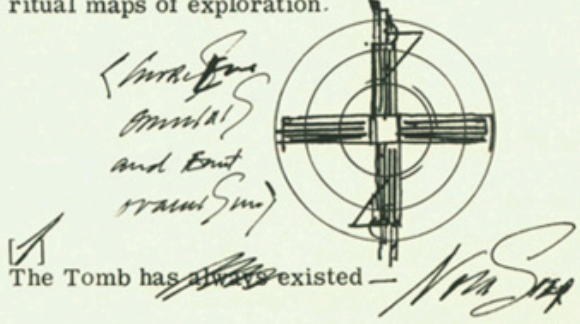

Figure 1.18. Einstein's Tomb. Visual + Verbal. Lebbeus Woods. 

where 'images' derive from personal, psychic activity and a sense of creative engagement with the object (Nigianni).—calling for representation that does not simply recreate reality but reconstitutes it, created out of a hybridity of materiality, narratives and psychic space. This hybridity constitutes an experience. In Walter Benjamin's analysis, the allegory conjures an experience of the world as no longer permanent, but fragmentary and enigmatic: "transforming things into signs is both what allegory does-its technique- and what it is about-its content"(Benjamin, 57) Therefore architectural representation can be reconsidered through associative imagination and subjectivity, acknowledging the creative capacity of the individual to connect disparate signs and therefore generate their own personal meaning. Haralambidou reasserts the relationship between image, space, and text:

Start by looking at the picture, running information on a surface, go behind the picture, fall down in the landscape, study the assemblage, picking up clues placed scattered in time, turn and look towards the door, and build the link back to the top. The text describes a spatial understanding. The architecture is the text and the text is the architecture.(Haralambidou, 33)

The architect's sketchbook reifies this notion; the notes, sketches and diagrams shape constellations of ideas which shift between writing and drawing, verbal and pictorial or analytical and synthetic (234). Within the context of this investigation text ultimately guides the process of drawing, the visual and verbal are intertwined so that the investigatory method reveals and interrogates spatial ideas. The understanding of the text is supplementary to that of the drawing - both the language of writing and the language of drawing reveal spatial constructs and act as memory devices for the imagining of space. 


\section{Einstein's \\ Tomb \\ 1980.}

Existing as an unbuilt speculation, the project is a poetic ode to one of humanity's greatest minds: Albert Einstein. Although merely speculative, the drawings and accompanying text invite contemplation. It is representative of an idea, expressed through architecture that meets the challenge of memorializing the secular physicist. Never to be built, the tomb is an expression of the subjects' ideas around space and time. It is a veneration of his memory, ideas and life. The project provides an example of how architecture might address issues through both the visual and verbal. It shows architecture's latent ability to form thoughts and ideas that are at once both tangible and intangible. Its form is symbolic, relating to archetypal meanings that are pervasive throughout human culture. It exists in its own temporal and spatial dimension, inhabiting the realms of thought and imagination, as well as occupying the pages of the book.

It provides a compelling precedent for the integration of visual and textual description in the formation of provocative allegorical design solutions. 

traces of its theoretical foundation that continue to operate despite its apparent neglect. The challenge then is to produce an architecture that is neither the result of a heroic conflict nor a commercial enterprise, and to try to imagine what architecture would be like if it could, gracefully and gratefully, accept being abandoned to the elements or lost in print.

-Ostwald, M.J., Tucker, C., Chapman, M. Residue: Architecture as a Condition of Loss. Melbourne: RMIT University Press, 2007. p14.
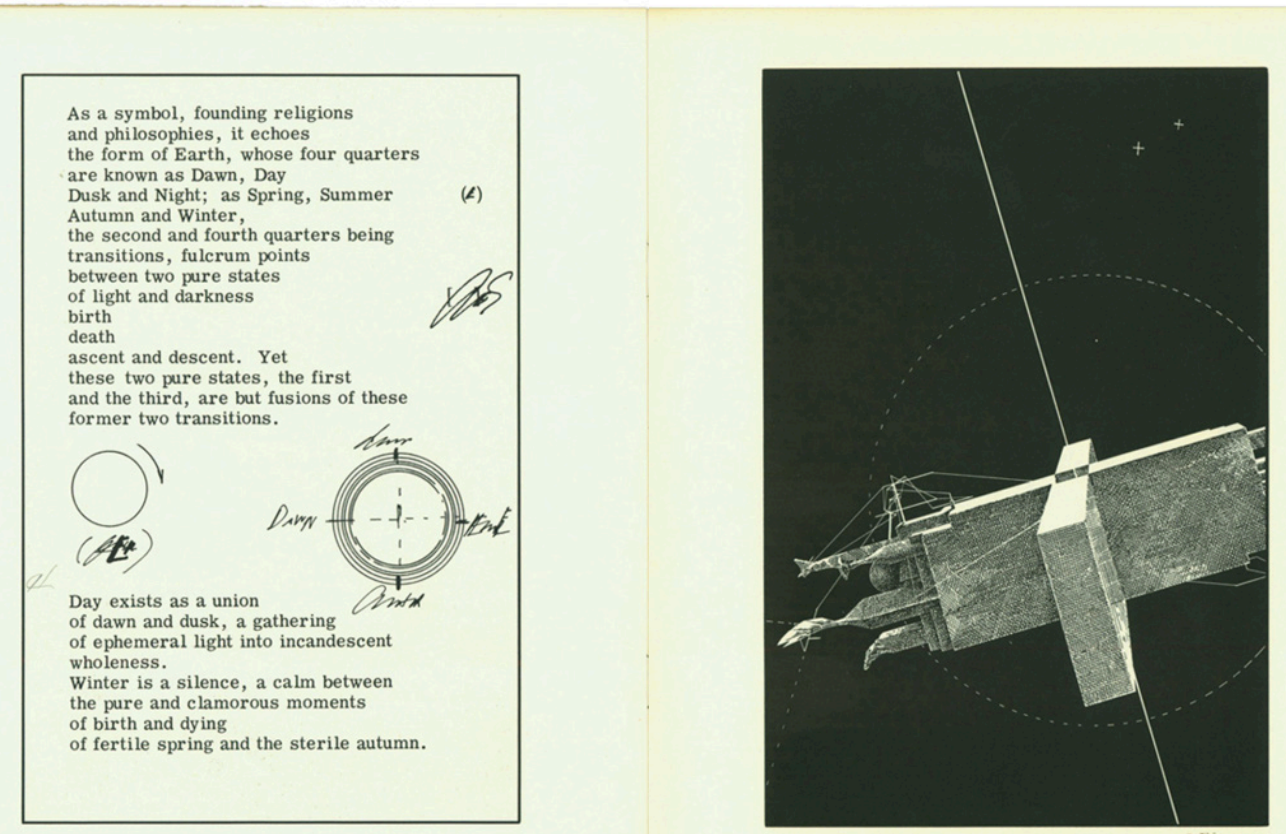
Figure 1.20. Synthesis of textual and visual. Seeking resolution. Notes from the sketch-book. Scanned page by author.

Arawing upow thew nery awe capacitici, eley populate a vality parallec to that of

the neman beilg. Man husocel hos

been lowt with wothing remaing of himi

but ar enosimally charged trace,

bief acmeppreic teprea:

Where thought ruls aganse obje ot. the paysical questioning of th inclusideal.

De-Corporealization.

y." derell is to everantly

fold and unfold in

regueteral hecoming hatwees

sh tawe f rhe Qfer.

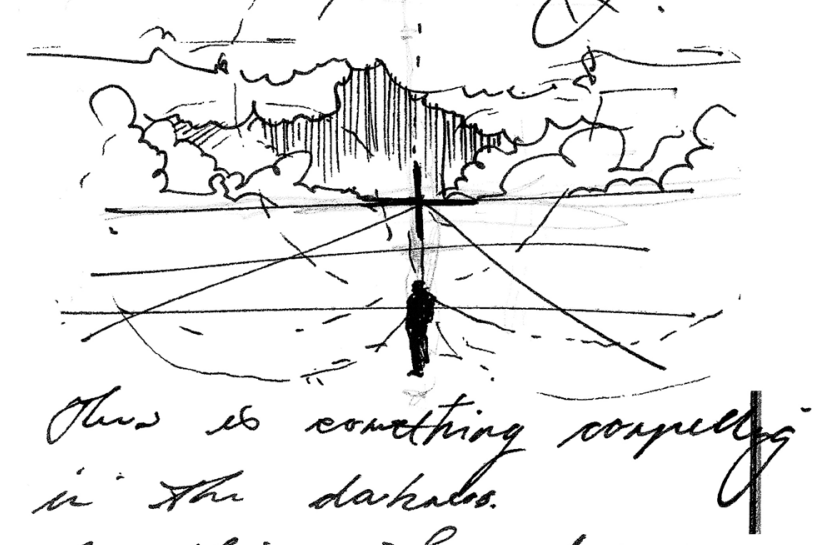

larutting thoc ahaw

ir. lavites is to emb.

10 Nos srancience. 
re-cniagive the to-exfisience

\& relacionstic hefeffece ilabitat

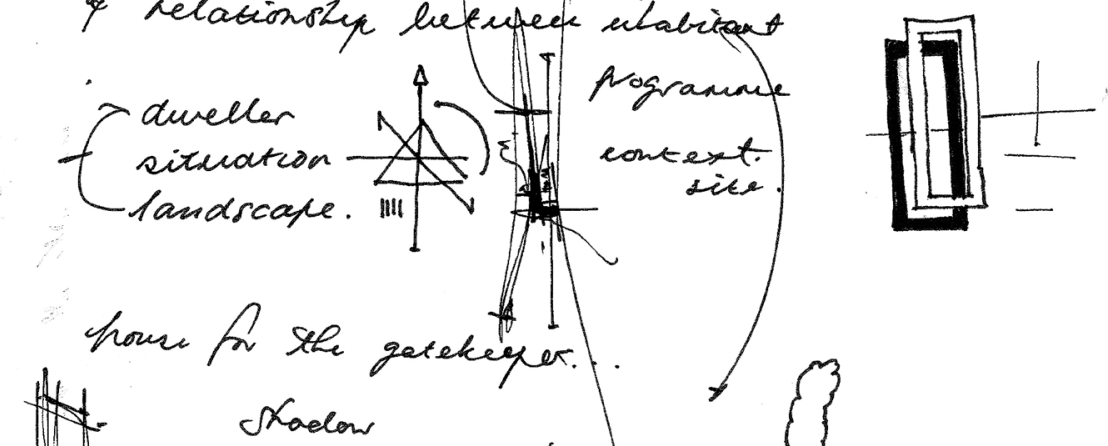

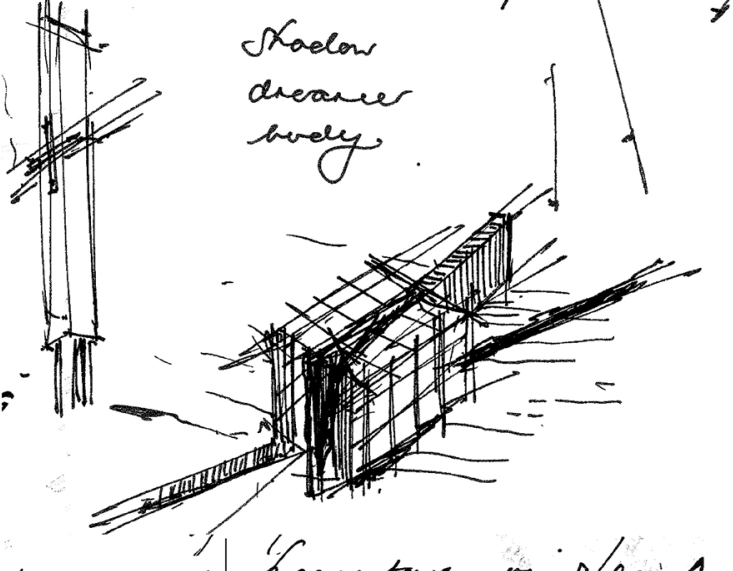

reppt on uigg of postic

thererience. enipatial. Pluting

no quection... -

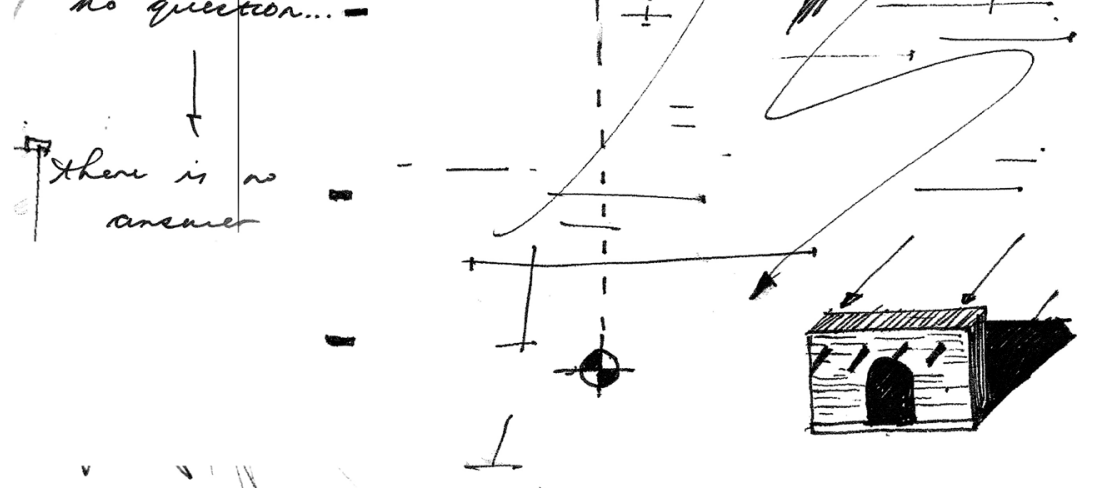



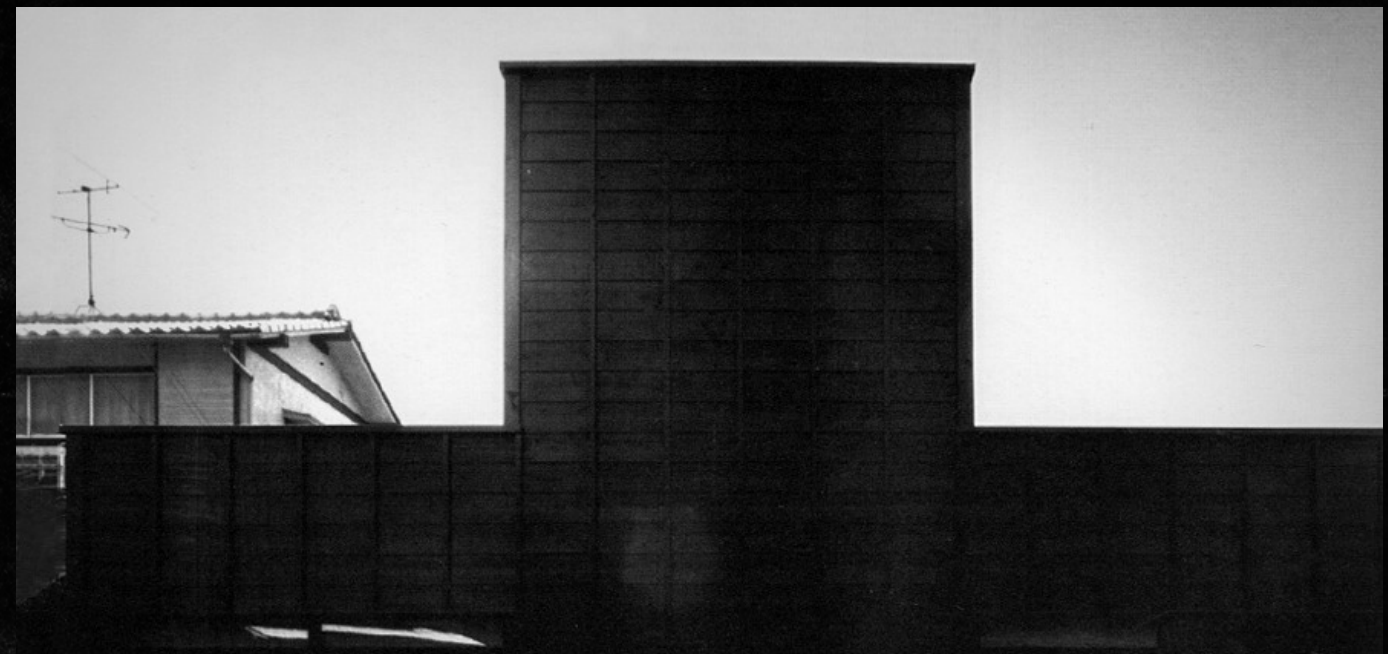

Figure 1.21. Dark Box Bird Cage. Exterior elevation Hiroshi Nakao. 
The conflict or the journey. In his book Allegory: the Theory of a

\section{PROGRESS}

Symbolic Mode, Fletcher defines

two broad categories of allegorical narratives: what he calls 'battle', an opposition between two forces, or 'progress', a description of a sequence of events that often takes the form of a journey across time. Architecture is never experienced in its totality. It is offered through a sequential continuum of manifold appearances in time and space (El-Bizzri, 38). Its visible aspects appear to us as we journey through it. 'Battle' in this thesis refers to the dialectical interaction between light and shadow, it embodies a set of oppositions that are always in conflict, seeking resolution. 'Progress' refers to the evolutionary progression from concept to image. Battle and progress can be attached to most allegorical architecture projects, as a broad definition, it entails both a sequence of events across time as well as an opposition between two forces. The battle as both research method and design tactic leads to a reimagining of dualities.

Figure 1.22. (right-top) Dark Box Bird Cage. Exterior courtyard. Hiroshi Nakao.
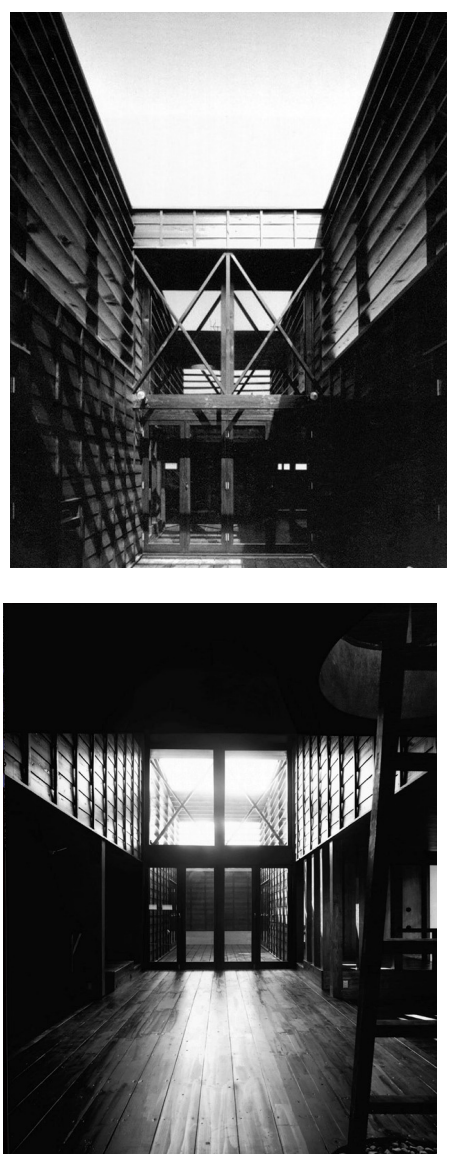


\section{Dark Box, Bird Cage 1993.}

Hiroshi Nakao.

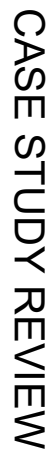

this image can be viewed in the print version of this

issue 
This building by Hiroshi Nakao, uses blackness the architectural driver. A conflict in the process of design, Nakao himself, professes, "The idea here was to generate a variety of types of darkness, which of course also means distinct types of brightness". At first seemingly monolithic, the interior uses shadow and light to create a feeling of expansion. The house reveals and conceals itself through the journey. Battle is evident in the spatial configuration and in the arresting stir of blackness. The interior spaces clearly registers the transitions of light and dark, a conflict. The deep courtyard exchanges depth with the internal void of the central living room, another opposition. Nakao's blackness is not a 'nothingness', but 'everything', it is not a silence but a ceaseless stir (Nakao). In Japanese culture, as expressed in Junchiro Tanizaki's In Praise of Shadows, darkness is charged with deep meaning. Clarity is not achieved through radiant brightness but through the sublte interplay of light and shadow, causing the true nature of things to be subtly percievable (Janson, 21) The continual conflict between light and shadow, reveals the true nature of reality. The idea of Nakao's darkness provides clues into how to reconcile this conflict.

Figure 1.25. Dark Box Bird Cage. Ladder to the mezzanine. Hiroshi Nakao. 
Allegory is consistently associated with the incomplete, the fragmentary, and the unfinished. According to Fletcher, the unfinished form and fragmented nature of the allegory must be considered in fluid terms: "all analogies are incomplete, and incompletable, and allegory simply records this analogical relation in a dramatic or narrative form" (Fletcher). As allegorical architectural projects are, by their definition, unfinished, they occupy the realm of the imagination. The incomplete nature of the work allows new possibilities to be received.

Although the thesis investigation exists in the form of a two volume codex, it is in the sketchbook that a true reflection of the fragmented yet iterative nature of the design process is evidenced. Haralambidou cites the importance of the contradictory and fragmentary essence of the sketchbook; "the sketchbook is not just a representation of the project, but its site and the medium through which it is developed" (233). The pages of my sketchbook reveal the true nature of the research project, not as a finalised design proposition but as a fragmented research method, where exploration is conducted through the notion and allegory of the Shadow.

Without the ambiguity of the unfinished, little room is left for the reception of new possibilities. As we have seen in the contemporary sphere of architectural production, these possibilities are often evaded for the sake of efficiency and constancy. The ruin can be seen as a physical manifestation of the unfinished. Ruin assumes the continuity and presence of history; it suggests a 'redemptive' metaphor that invokes a future world of potentiality. Incompletion suggests the rupture and emptiness of the void (Eisenmann,6). In her text Critical Architecture, Jane Rendell attributes incompletion to criticality, "As the user's experience depends on complex juxtapositions of many moments and many conditions, whether a building is critical may depend not on instantaneous shock but enduring ambiguity, the ability to appear ever-changing, resist resolution and remain open to interpretation." 
if A common strand from the ninth century to the twenty-first century has been the idea of the ruin as the vehicle, or 'an allegory of memory... fragmentary, imperfect, partial and thoroughly incomplete. ... There is an excess of meaning in the remains: a plentitude of fragmented stories, elusions, fantasies, inexplicable objects and possible events which present a history that can begin and end anywhere, and refuses the master narratives of history...

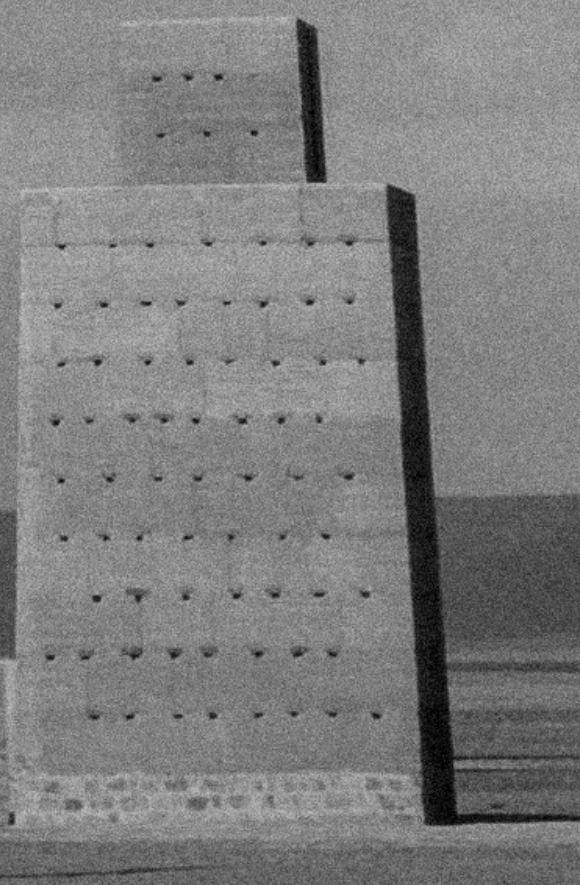




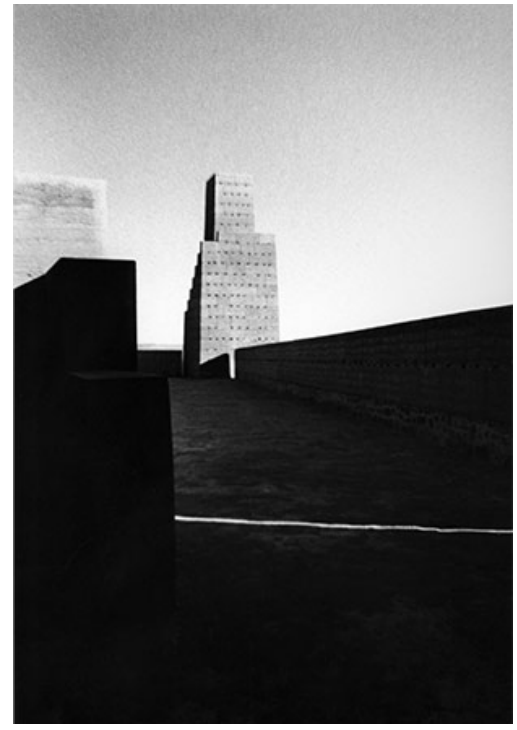

Figuer 1.28. Hannsjörg Voth. City of Orion.

\section{Stadt des Orion, 1998 - 2003.}

Hannsjörg Voth

Conceived as a three-dimensional representation of the constellation of Orion, the City of Orion project by Hannsjorg Voth, represents the notion of a ruin. Not immediately graspable to the viewer, it is through the enduring discovery and ambiguity that it provokes emotive experience. From afar, the structures appear as ancient temples, abandoned to the elements. On closer inspection, monumental forms begin to reveal themselves through materiality and shadow. Seven towers relate to certain celestial bodies, through their arrangement and orientation, these celestial bodies become clearer to the viewer. Without this notion, the structures remain ambiguous, it is only through progressive discovery that we are able to relate this construction to something larger.

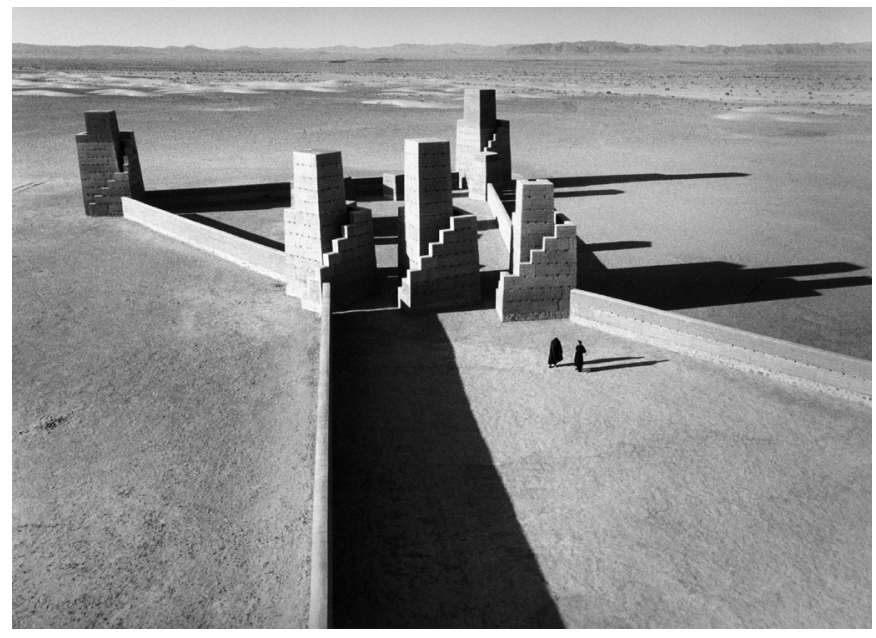



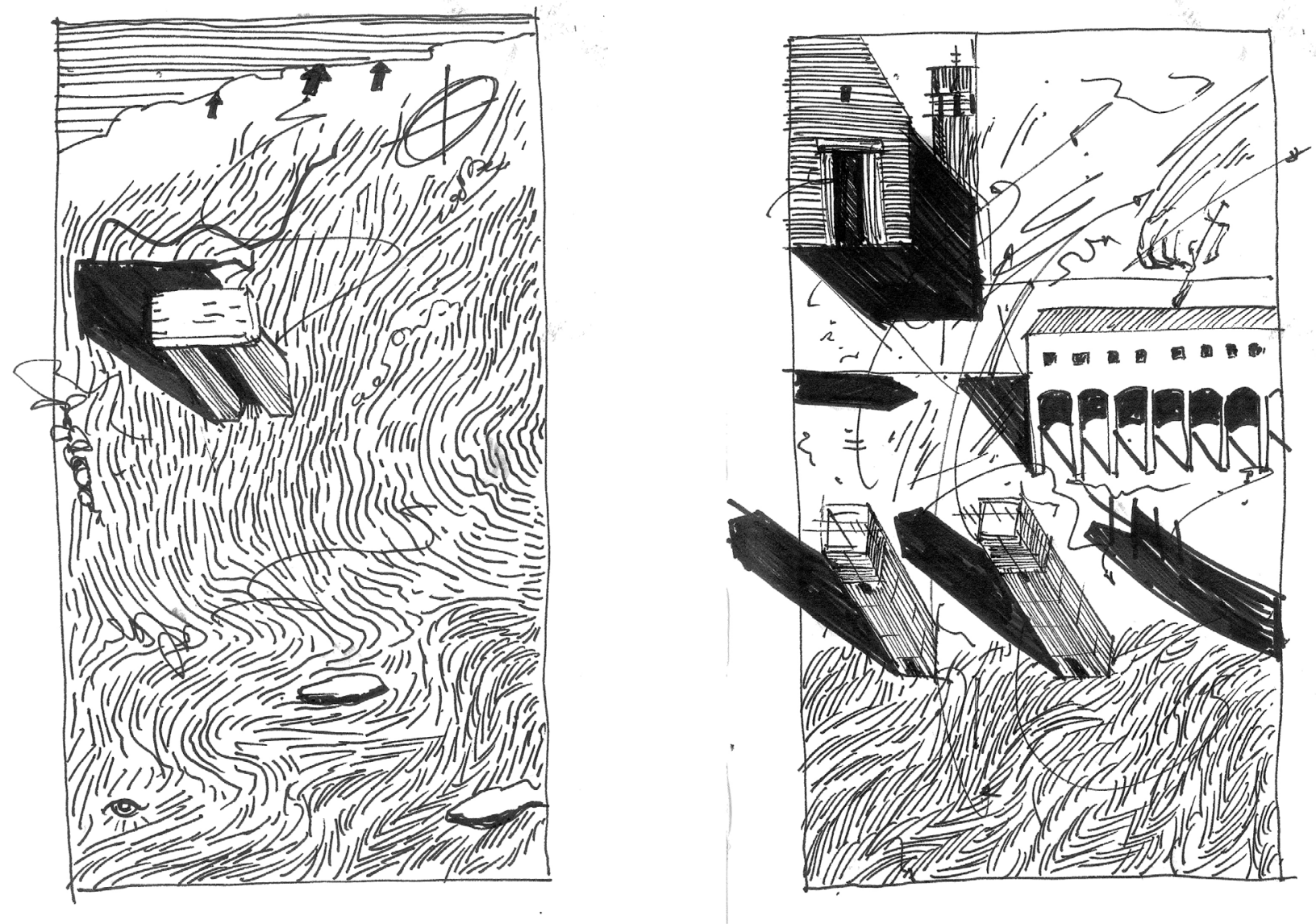

Figure 1.29. Fragmented montage sequence exploring the use of figurative geometries, battle and progress the state of being unfinished. 

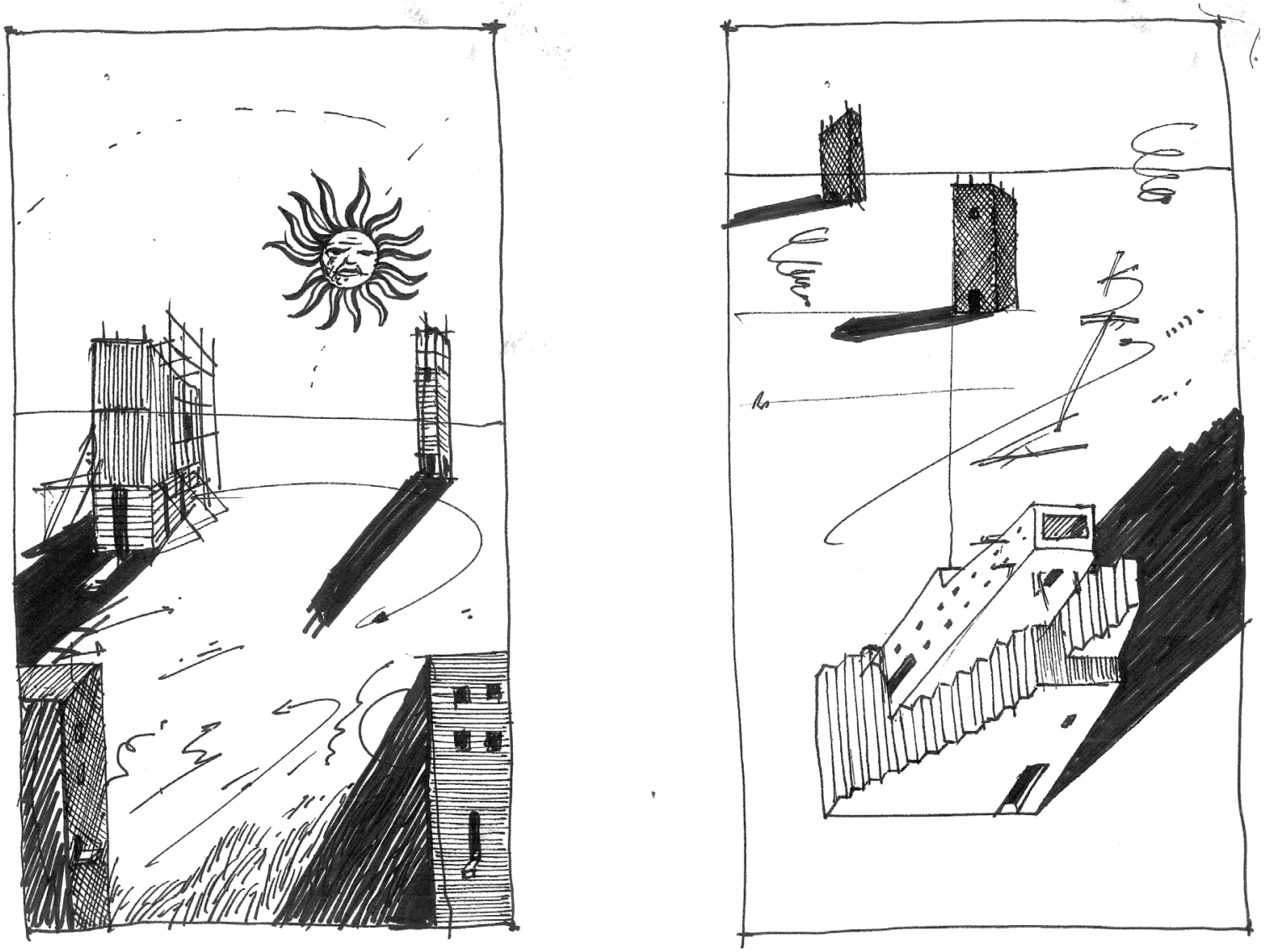



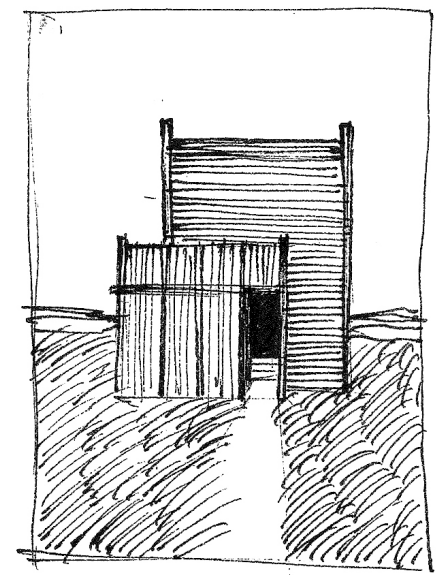

Figure 1.31. Conflict and Journey. Sketch vignette by author. 


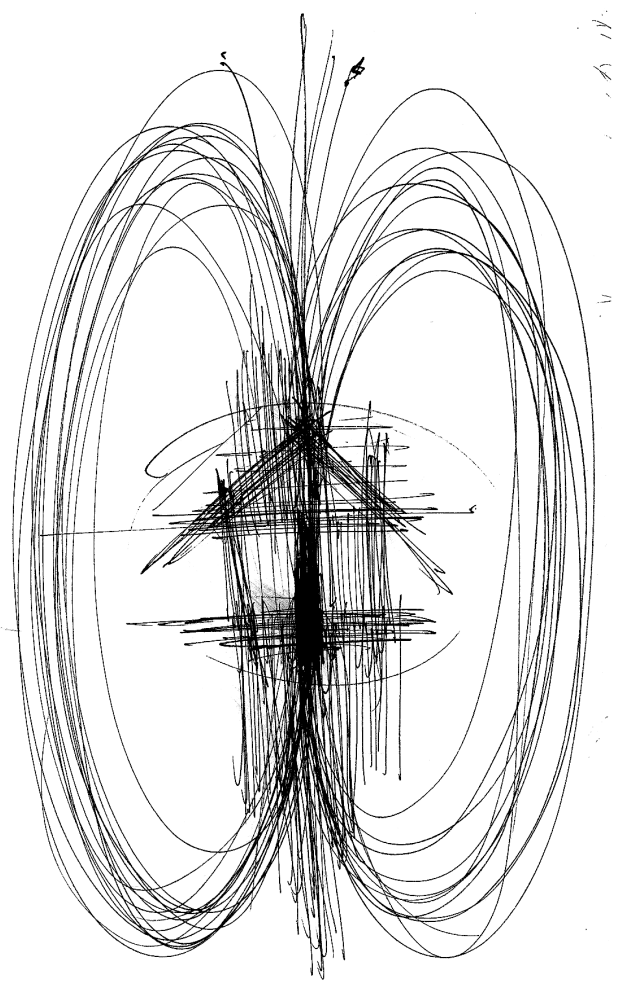

Figure 1.32. House as Threshold. Sketch by author. 
In this chapter, Jerome Bruner's essential characteristics for a succesful narrative provided insight into the construction of a fictional narrative in literature. Through the application of Cathy Ganoe's theory of narrative design, key features of the literary allegory, as provided by Murakami's provocative novel, were defined:

\section{INNOVATION}

\section{TRANSFORMATION}

\section{MULTIPLICITY \\ CONVERGENCE}

These characteristics, became catalysts for shifting normative modes of design thinking. The chapter identified the use of Penelope Haralambidou's proposition for "Allegorical Architectural Project as Critical Method" as a critical framework within which architectural and spatial concepts can be reexamined and redefined. The traits: double meaning, figurative geometry, visual and verbal, battle and progress and the state of being unfinished, provided useful insight into the nature of the allegorical architetcure project. They revelaed the physical characteristics of a critical allegory and engaged narrative as a form of design thinking.

Utilising the design tactics as mined from the narrative, sketch design experiments were conducted in relation to relevant allegorical precedent studies. These experiments started to develop a formal and visual language for the project, mining the case studies for their implications and applicability to the allegorical programme, the Shadow Grounds.

In the following chapter, METAMORPHEUS, notions of the shadow will be presented and discussed. The ideas generated out of this discussion will propose integrating the learnings from METAPHORMOSIS into design experiments that further explore the realm of shadow in architecture-aiming to propel the development of the design into new and unexpected directions. 


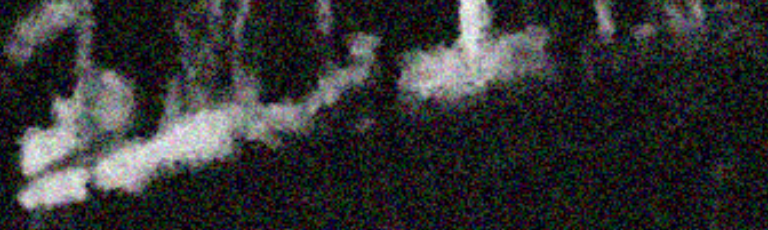

2.

Figure 1.33. Into the Darkness. Image by author.

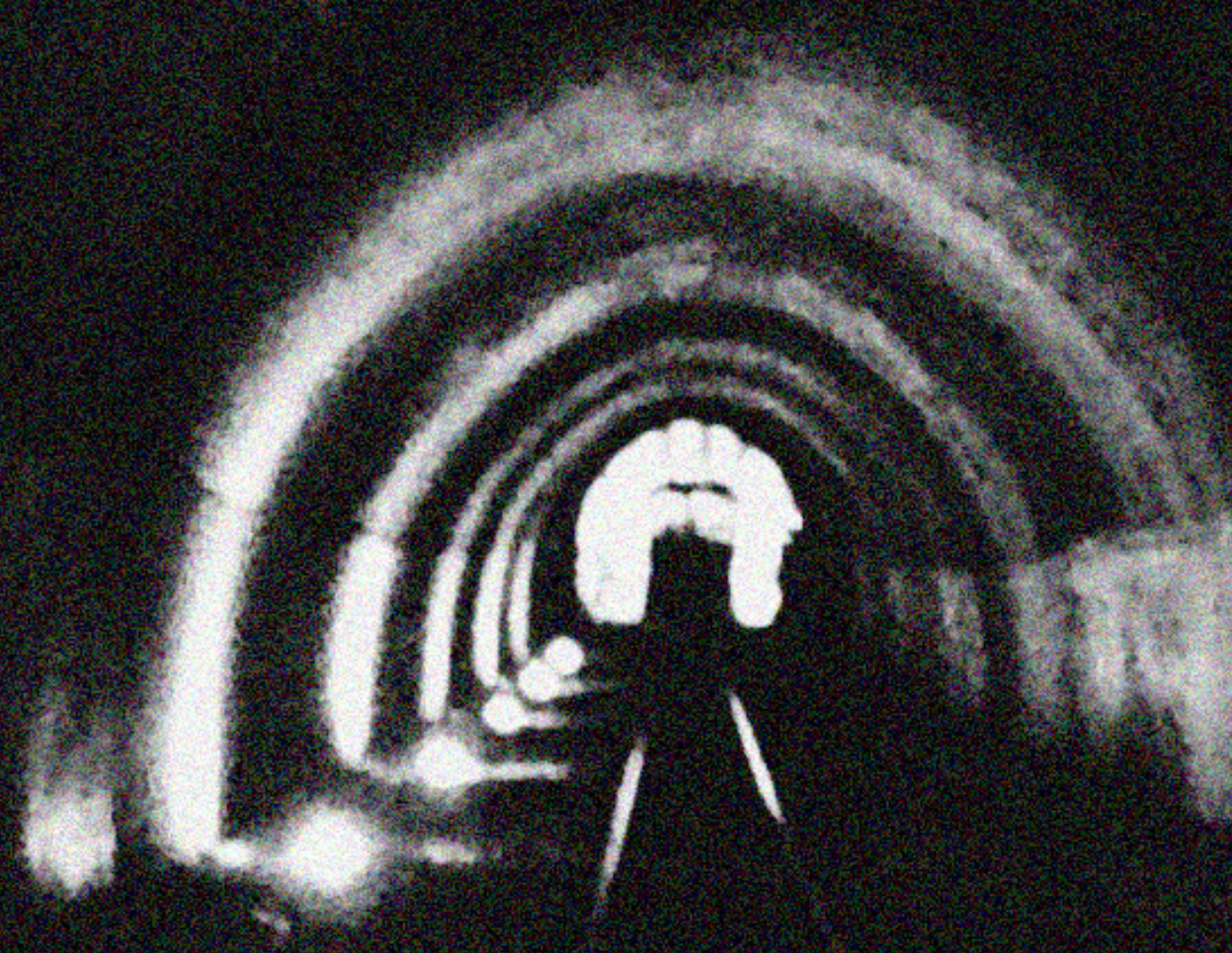


Things need not have happened to be true. Tales and dreams are the shadow-truths that will endure when mere facts are dust and ashes, and forgot.

Neil Gaiman, The Sandman

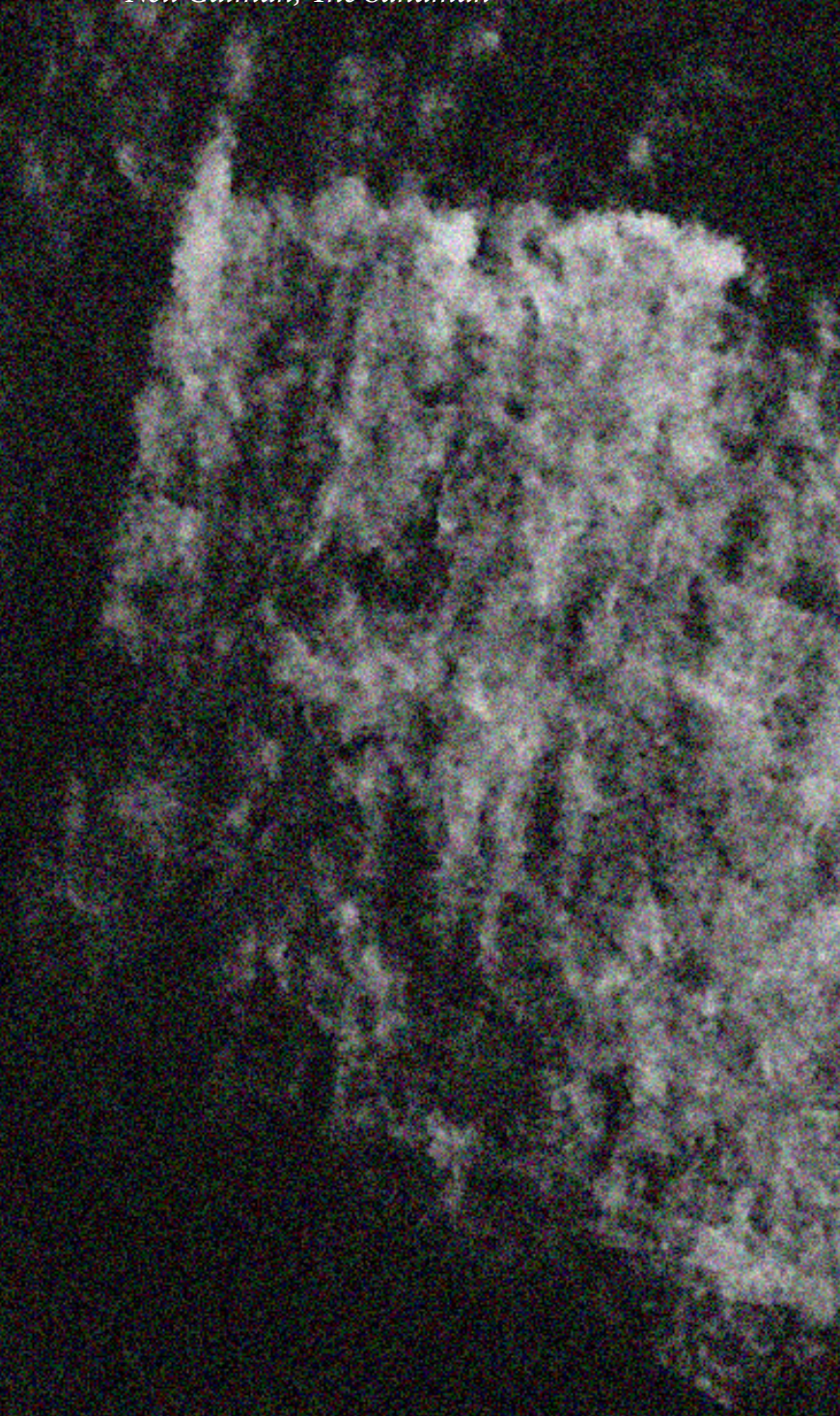


Part 2

\section{METAMORPHEUS*}

\section{Architecture \\ of Shadows}

RO2 to identify historical and mythological notions of the shadow in relation to architecture, exploring them through the language of the drawing.

\section{*orpheus \\ /òr -fē-əs /}

noun: a poet and musician in Greek mythology who almost rescues his wife Eurydice from the underworld by charming Pluto and Persephone with his lyre. It is an allegory of the redemptive powers of the human soul 
In effect, we retrieve in the symbolism of Shadows the note of atemporality, of 'eternity,' of the suspension of becoming. Time begins with the apparition of Forms, thus with the Light... . The return to Shadows implies then the immersion into the pre-formed, contact with that which was not worn away by Time. 
Shadows are pervaded with mystery. For art historian Michael Baxandall, "it is a real material fact, a physical hole in light, but it has neither stable form nor continuity of existence; on the other hand the metamorphoses it goes through are determinate, and though it is discontinuous it can recur"(Baxandall, 20). Along with the physical perception of shadows, Roberto Casati proposes that shadows are "remnants on earth of cosmic darkness" (Casati, 10), the antithesis of light. This points to the shadow as the experience of something other "something different, of something coming and going"(10). The Shadow in this thesis draws from both definitions, acknowledging that to concretely define the shadow is to deny its very nature.

As a response to the rationalist tendencies of architectural modernism, VIA 11: Architecture and Shadow, is a collection of essays that arose out of an ongoing examination of the "other" in architecture. It offers many points of departure for the study of shadow in architecture, this investigation proposes to use these, as well as Arden Reed's classifications in "Signifying Shadows" as generators for drawing experiments into the shadow. These include:

2.1 SHADOW AS REFUGE

Perceptual_chiaro/oscuro

\subsection{SHADOW AS THRESHOLD}

Temporal_space / time

2.3 SHADOW AS TRACE

Ontological_shadow / substance.

2.4 SHADOW AS PROJECTION

Logical_difference / repitition

2.5 SHADOW AS SUBLIME

Affective_threat / protection 
Reed argues that, due to its multiplicity of readings, meaning and interpretations, the shadow cannot be fixed nor defined. The drawing becomes the mode with which to investigate because the drawing allows for duplication and multiplicity of interpretation to occur. As Arden Reed argues, shadows avoid direct signification; theyoccupyaposition ofambiguitybetween the aforementioned classifications, forever being altered, composed and recomposed by the perception of the viewer as well as by the passing of time and shifting of the seasons. He argues that we don't just see shadows but we read them. Marco Frascari reasserts this notion: "[s]hadows are the indices, the icons, and the symbols which mark the presence of architecture; they are the no light necessary for seeing the light" (Frascari, 35)

The principle aim of Part II is to develop ideas about the shadow in relation to architecture and actively translate these through drawing, using the allegorical architectural experiments as generators for studies into shadow.

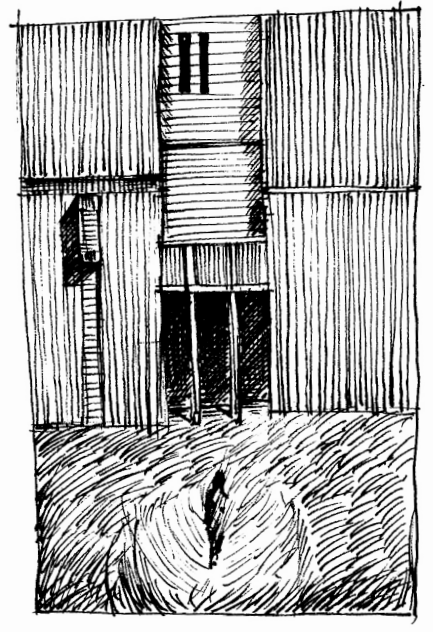




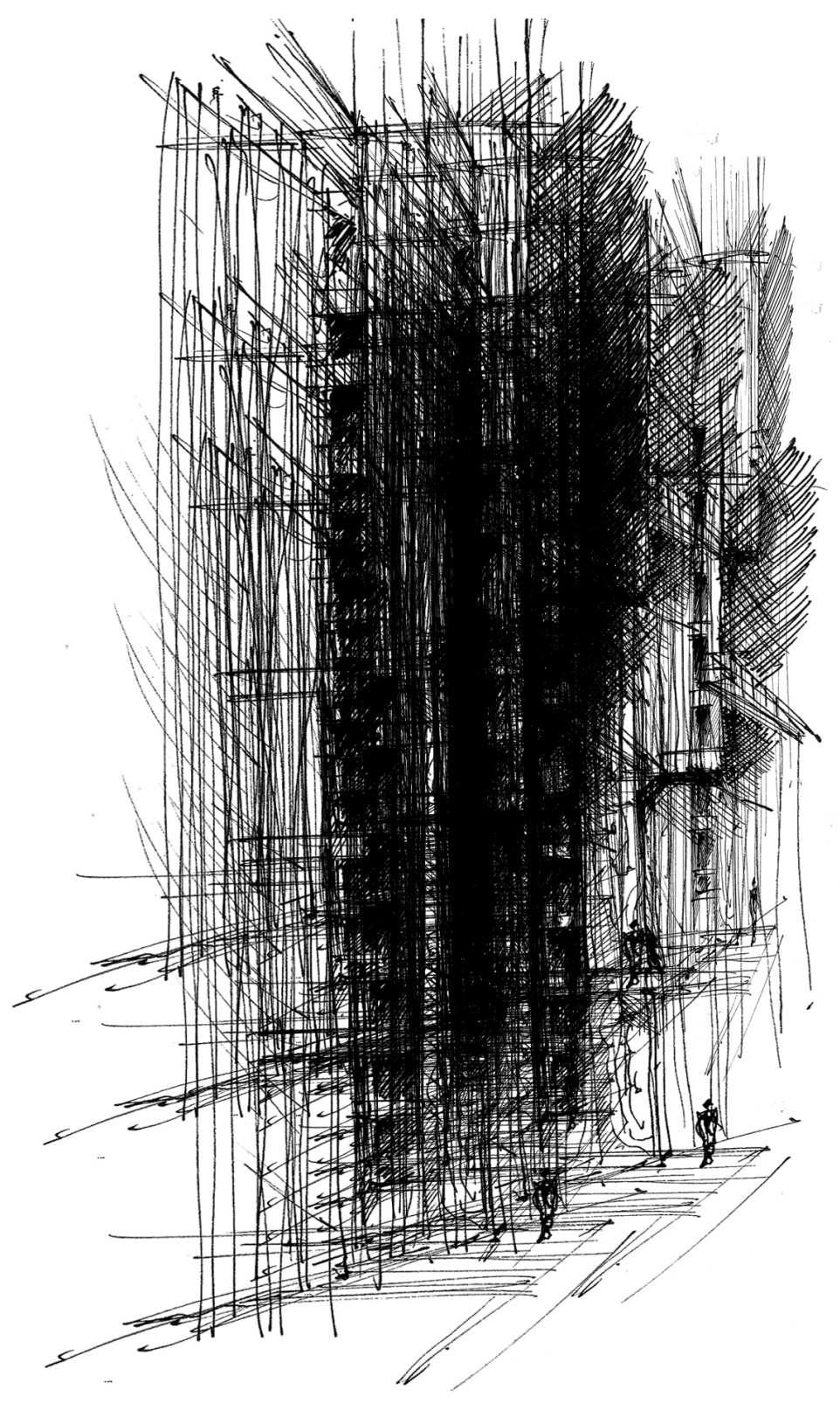

Figure 2.2. Shadow as refuge, illuminating vs obscuring. When does the darkness become impenetrable? Sketch experiment by author. 


\subsection{SHADOW AS REFUGE}

Perceptual_chiaro*/oscuro*

*chiaro

/chià·ro/

noun: luminosity, brightness

adjective: clear, light *oscuro

los'kuro/

adjective: dark, obscurer, shadowy

When we perceive a shadow, what is it we see? Shadows both illuminate and obscure. A shadow is considered both part of the object and disconnected from it. According to art historian Thomas Kaufmann, we can look at shadows, into them, or through them. (Reed, 14) The visual perception of shadows and its effects is ambiguous and slippery. Roberto Casati posits that they are "holes in light"; in this sense, to look at shadows is to see nothing at all. However, we talk of seeing shadows as we do the objects upon which they are cast. It is through the shadows on a surface that we denote its qualities, the surface material disrupts the light energy, thus revealing its secrets, its form. As such, it is the shadow that relieves objects of the banality of visible illumination.

Figure 2.2 investigates the interplay between chiaro / oscuro through layering and multiplication. Based on the use of figurative geometry and notion of the unifinished, vertical lines were drawn with hatching and shading added to create depth. Moving from the physical sketch to the digital collage, notions of the blur, layering and obcuring were applied to test shadow as both illuminator and obscurer. 


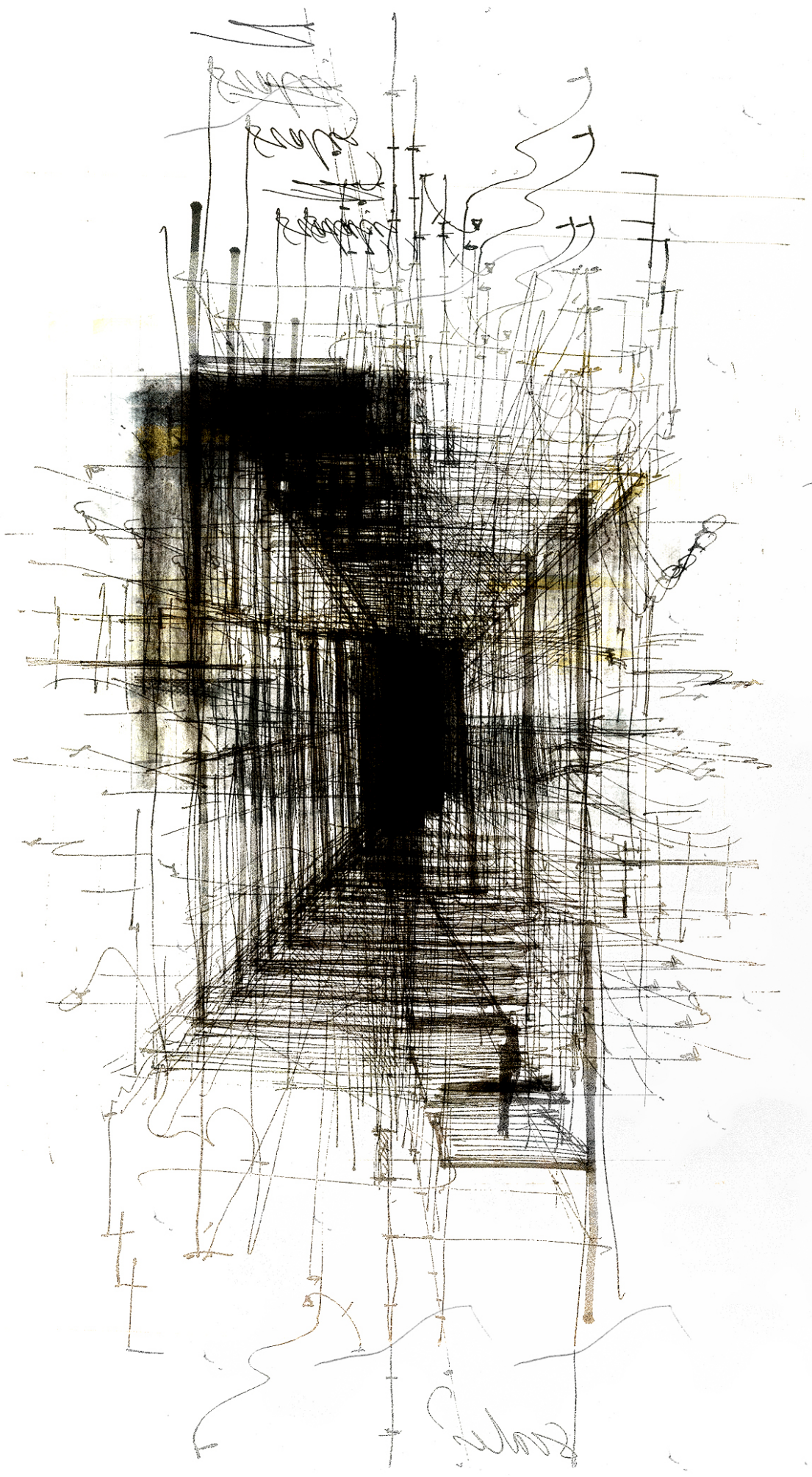

Figure 2.3. Shadow as threshold, spatial and temporal. There is something compelling in the darkness, something that draws you in. Hybrid sketch experiment by author. 
2.2 SHADOW AS THRESHOLD

Temporal_space/time
The continual mirroring between light and shadow creates a holistic image that gives dimensionality and life to the illuminated structure (Suman) thus providing a sense of spatial depth. This mirrors the act of shading in drawing, where the addition of shadow adds depth and a sense of a third dimension. Thus, spatial depth is ultimately provided at the threshold between light and dark. As well as the illusion of space, the shadow also denotes the passing of time. The movement of daylight continually generates its opposite, shadow, leading to a reconciliation of opposites.

A definition of shadowy regards it as "transitory, fleeting", a notion of time passing. The shadows on a sundial literally signify the passing of day. The shadow is always transitory, fleeting, shifting with the passing of time and with the movement of the viewer. Because a building as a material artefact is always at rest, the motion of shadow across its walls and surfaces reflect an eternal timepiece. The shadow in architecture relates us to the physical cycles of earth, sun and moon. As well as this notion of the shadow and time, Reed argues that "a shadow is always adjacent to and verging on, but not precisely where one stands, it delineates the spot where at present or in the present one is not." Metaphorically speaking then, the shadow "signifies the obscurity of what is yet to appear or of what is already out of sight" (Reed, 15) Paintings by Goirgio de Chirico manifest this state of mystery or enigma. Empty squares and classical arcades, shadows cast from things beyond the frame of view and lonesome figures with long shadows define these images. Shadows speak of absent objects, objects which belong to memory and therefore to the power of the imagination (Frascari, 36) Shadows fall either side of past and future, revealing the true place of human existence, the limina between light and dark.
Figure 2.3 adds the element of spatial depth through transformation of vertical and horizontal line work. Formal qualities were derived from previous sketch experiments and layers of obscurity added. The repition of elements and their convergence on a point of darkness, signifies a notion of the temporal. Evidenced in the experiment are ideas of: multiplicity transformation layering Figurative geometry is eschewed for a more experimental investigation. 


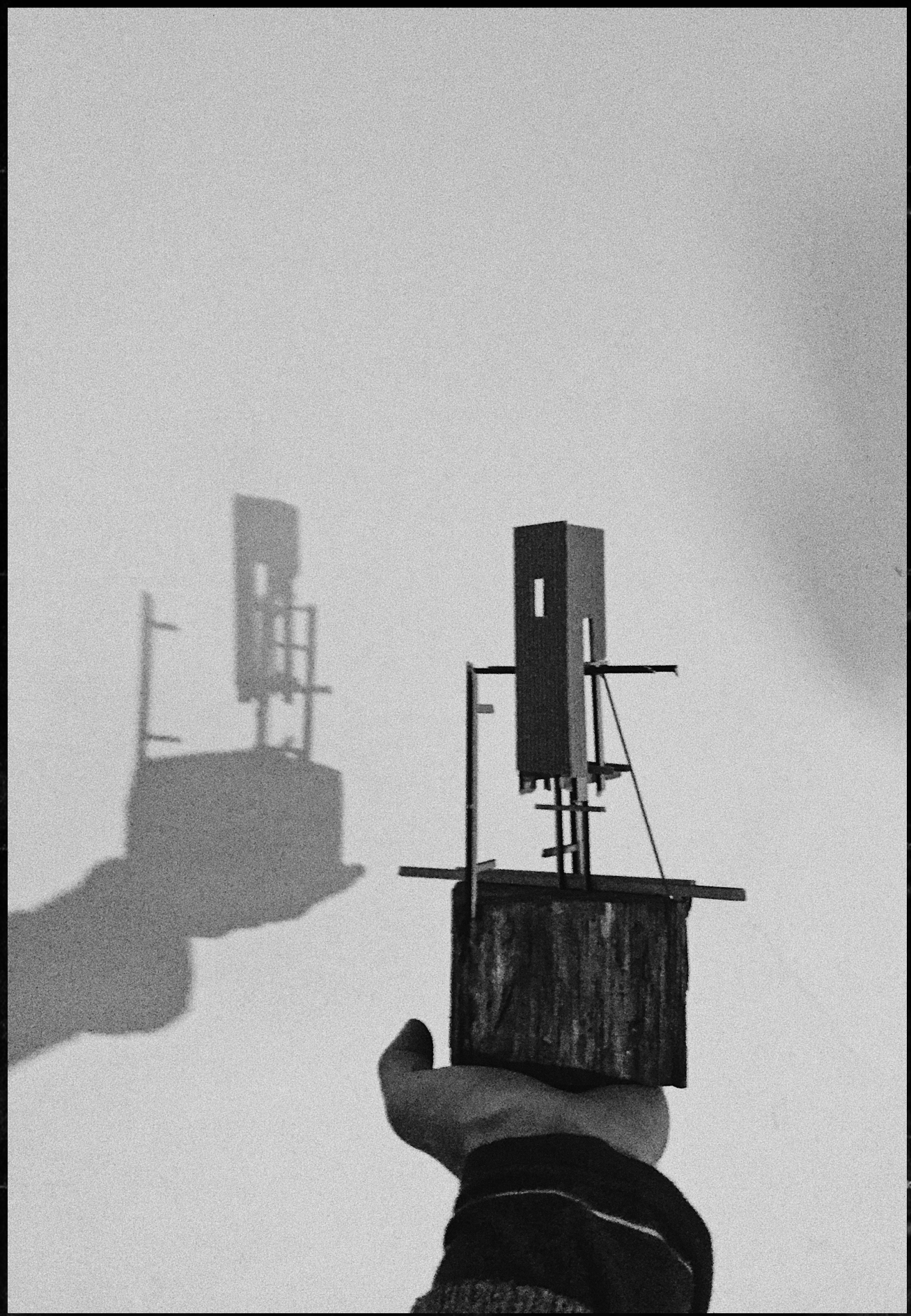

Figure 2.4. Shadow as trace. Artefact held in the hand of the maker. shadow vs substance. Digital photograph of model casting shadow by author. 


\subsection{SHADOW AS TRACE}

Ontological_shadow / substance

Object and shadow are doubles, twins in two separate realms-the three-dimensional and projectable realm of objects (projective space) and the non-projectable realm of shadows. That shadows denote the physicality of substance is a case of optical perception, metaphysically speaking, shadows stand for what is hidden in architecture (Kunze, 66) - what is hidden is the presence of "other" that exists beyond the physical presence of momentary habitation: the past and future, the worlds that could have, would have or might have been; the immutable reality behind the screen of fragmentary illusions; desires, guilt, fear and ecstasy (66). This is what separates architecture from building, the building stands for what is projectable- the optical. Architecture on the other hand, is a matter of experience and imagination, a felt presence or absence (67). It is a matter of shadows.

Figure 2.4 depicts a sketch model experiment. Physical modelling was used as a way of interrogating the physcality of the shadow in relation to shadow as trace. Seeking to formalise and spatialise previous sketch experiments, the model was treated as a three-dimensional drawing. Frame, enclosure, mask, aperture and threshold are all evident in the artefact, yet it remains incomplete. Photography was employed as a means of interrogating the artefact from multiple viewpoints and cast it in different light. Searching for something in-between shadow and substance. 

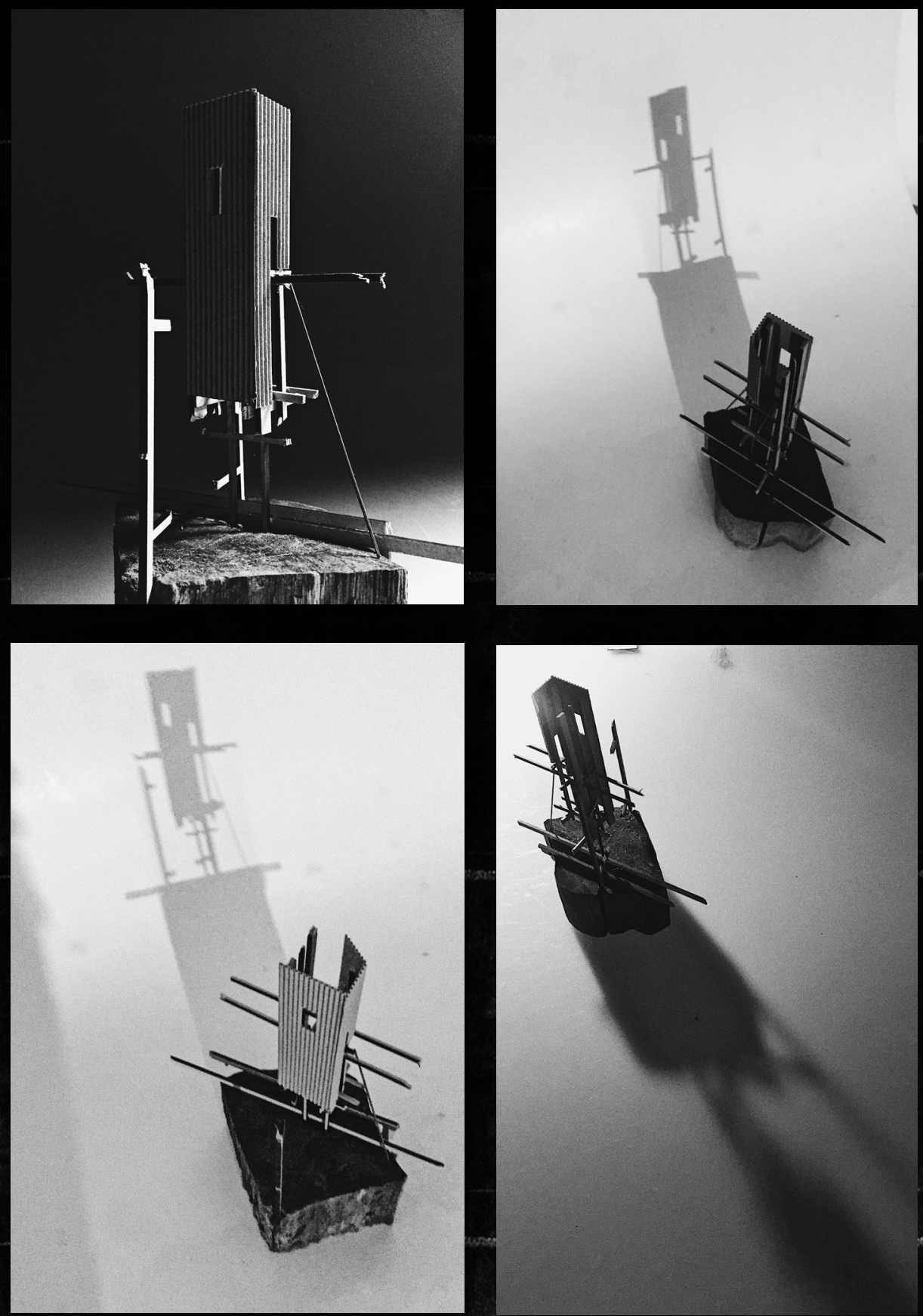

Figure 2.5. Shadow as Projection. Difference vs repitition. Digital photographs by author. 


\subsection{SHADOW AS PROJECTION}

Logical_Difference / Repitition

Shadows can signify both the repetition of an object and difference. It can create an "imitation, copy or counterpart" of the body that cast it. Although, parallel to this idea, the difference between shadows and their body can at times be mysterious, almost demonic (Casati). This characteristic of shadow can undermine the identity of the thing that cast it. As a verb 'to shade' is defined as "to change or make pass by imperceptible degrees into something else", in this sense shadows can both produce meaning and abolish it. Through the difference and repetition shadows give the ability to discern the spatial dimension of architecture, their continually movement perpetually alters our perception of space and form.

Figure 2.5 re-presents the sketch model in a different light. Viewed from multiple angles and under different lighting conditions, the tests were forays into the notion of shadow as difference and shadow as repition. Seeking to find the relationship between the body and the shadow.

Figures 2.6 and 2.7 (next page) re-examine the model studies and apply the process of layering to disrupt normative thinking and challenge the linearity of the process. These collaged photos create further ambiguity through obscuring and multiplication. Spatiality starts to become suggested. Spaces that are libreated from reason, allowing the eye to wander through and the mind to dwell in them. 


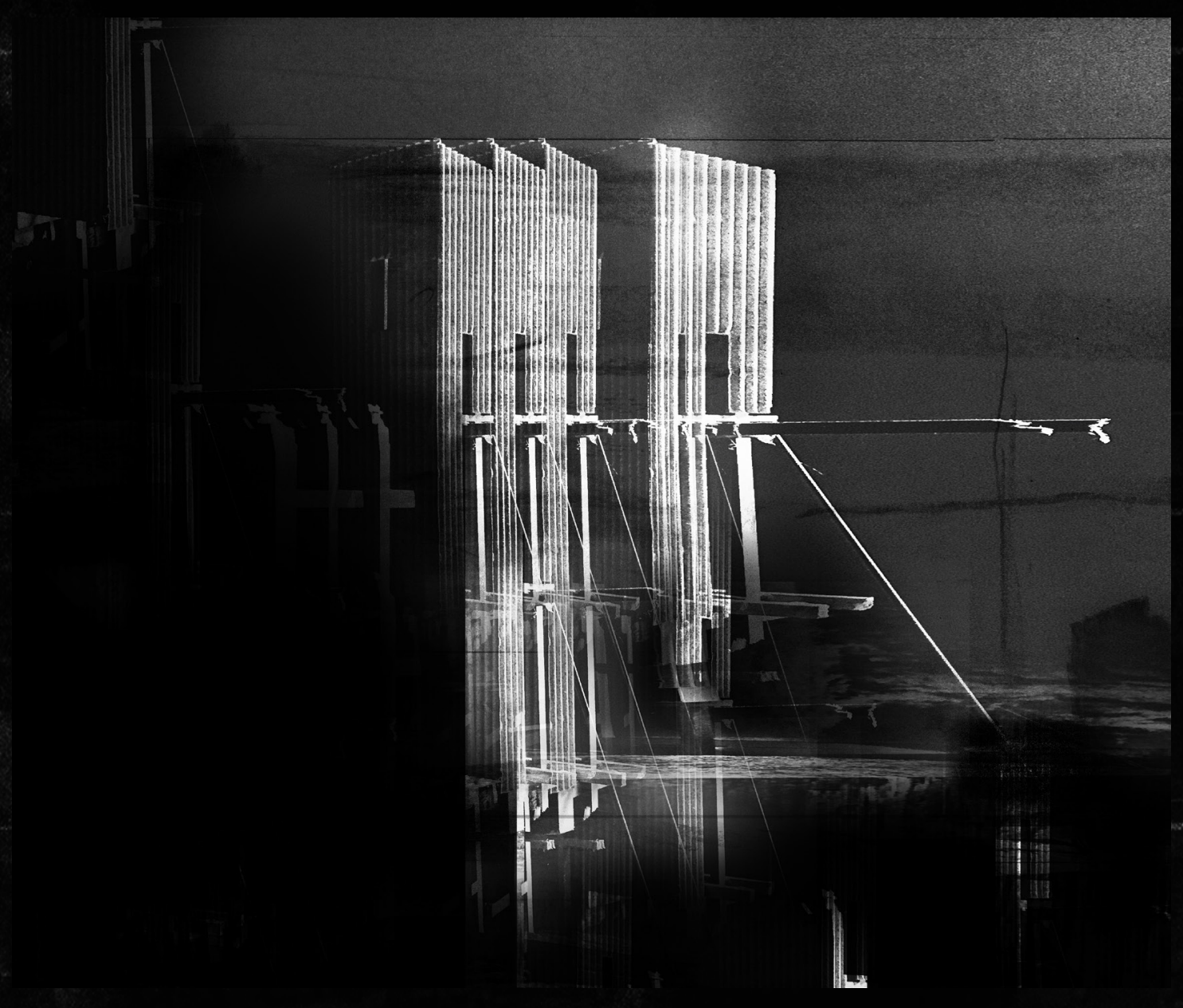

Figure 2.6. Shadow as projection. Multiplicity studies.

Digital. photographs by author. 

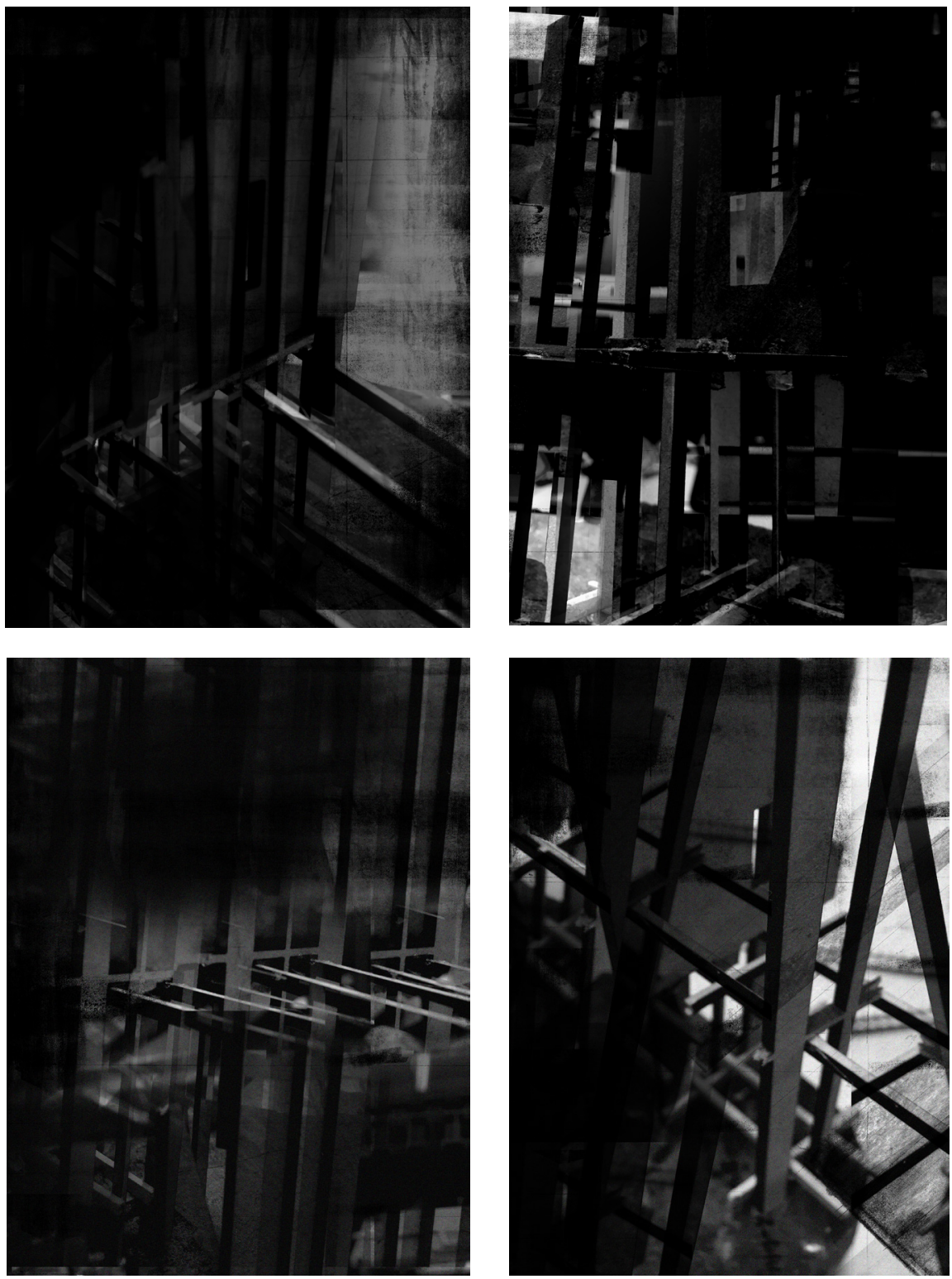

Figure 2.7. Shadow as Projection. Repitition and multiplicity. Digital photographs by author. 


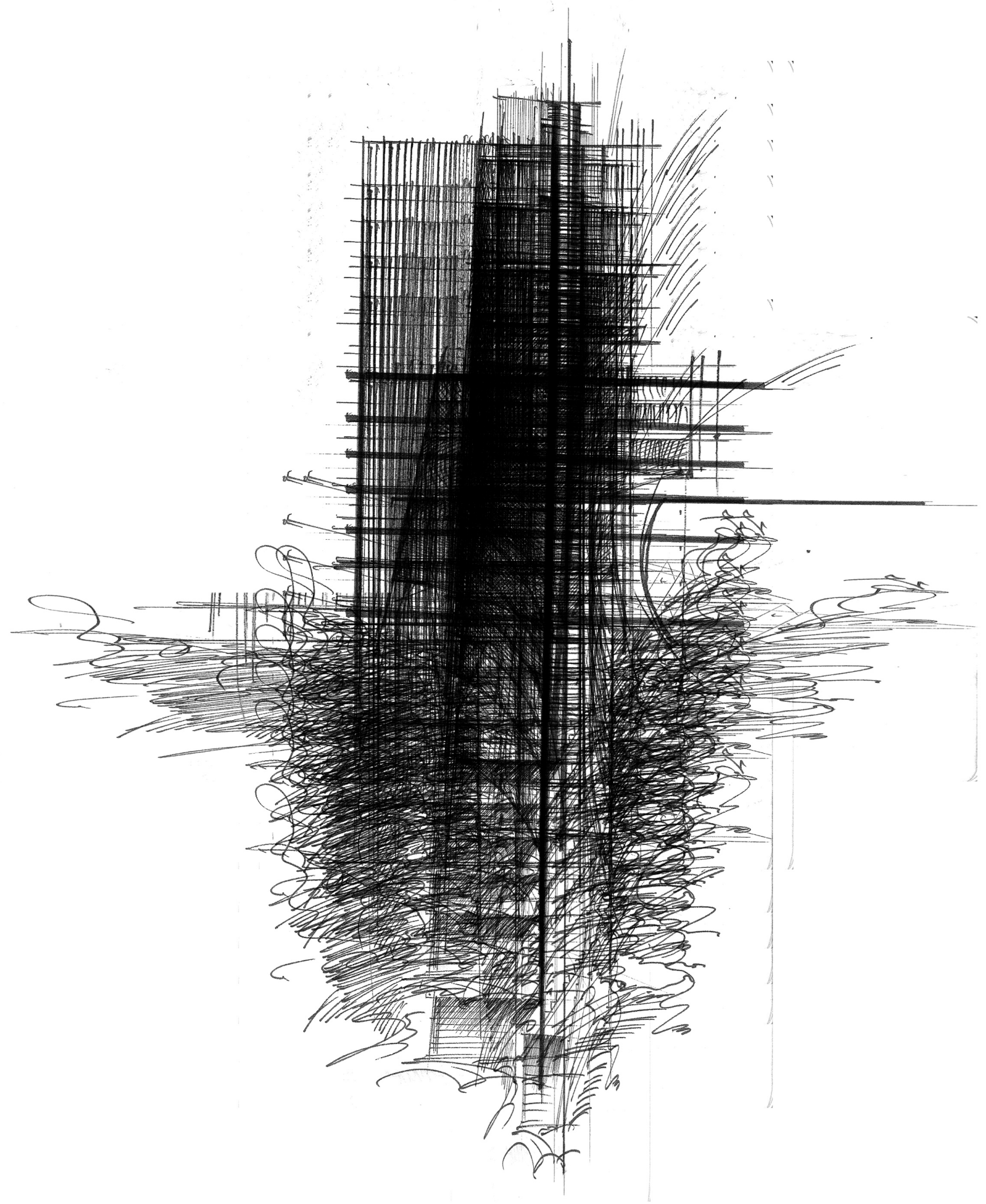

Figure 2.8. Shadow as Sublime_threat vs protection. Experimental section drawing. hand drawing + digital collage 
Shadows can offer either the presence of something unknown or the promise of shelter. The notion of the sublime shadow as something both protective and threatening is offered in Edmund Burke's influential book A Philosophical Enquiry into the Origin of Our Ideas of the Sublime and Beautiful, where he states: "the first, is that darkness itself on other occasions is known by experience to have a greater effect on the passions than light" later he argues that darkness "is terrible in its own nature" (Burke, 47). Japanese novelist Junchiro Tanizaki, in his essay In Praise of Shadows, also offers us shadows as a means of shelter and as an uncanny presence that might represent something "other":

... [W]hen we gaze into the darkness that gathers behind the crossbeam, around the flower vase, beneath the shelves, though we know perfectly well it is mere shadow, we are overcome with the feeling that there reigns a complete and utter silence; that here in the darkness immutable tranquillity holds sway (Tanizaki, 20)

The layering and interplay of shadows creates subtle differences between light and darkness. In the dark alcoves of the Japanese tea house, the true nature of things becomes realisable, no longer are things gleamed in pure light, but in the play of shadows hard boundaries dissolve. In that way the shadow moves, melts and obscures the differences between light and darkness, revealing the interconnectivty of things, flows, objects and people.

In the Critique of Pure Reason, Immanuel Kant "argues that perception requires a synthesis of what appears in space and time." The obscurity of the shadows and the depth of darkness in architecture begins to hinder this synthesis, contrary to a space filled with light, 'darkness is filled, it touches the individual directly, envelops him, penetrates him, and even passes through him' (Vidler, 175). The notion of the shadow as both threat and protection is used in this thesis as a confrontation. There is something compelling in the darkness, something that draws us in, and invites us to embrace our own transience, collapsing the duality of inner and outer, past and future. 
II . 1 (I)

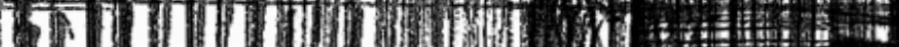

$1+4 .+10+1$

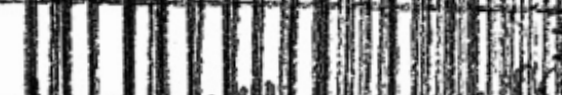

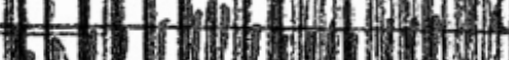

-1 (1)

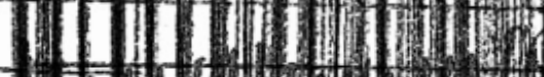

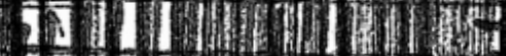

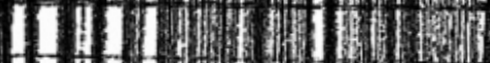
$13 \mathrm{~m}(\mathrm{~m}) \mathrm{m}$

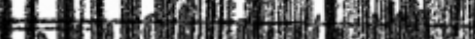
1. 6) 17) 1 I (H) 1 (t) 1. 1 (1)

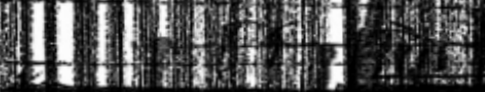

(1) (1)

7)

110

H)

inIII

end

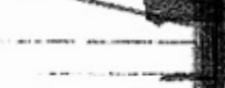

Af 1 -

III

con

\section{U1II IX:}

1.

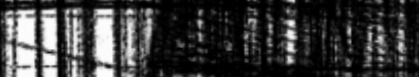

(1)

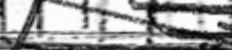

\section{2 \\ 5} (1)

ath

Nis:
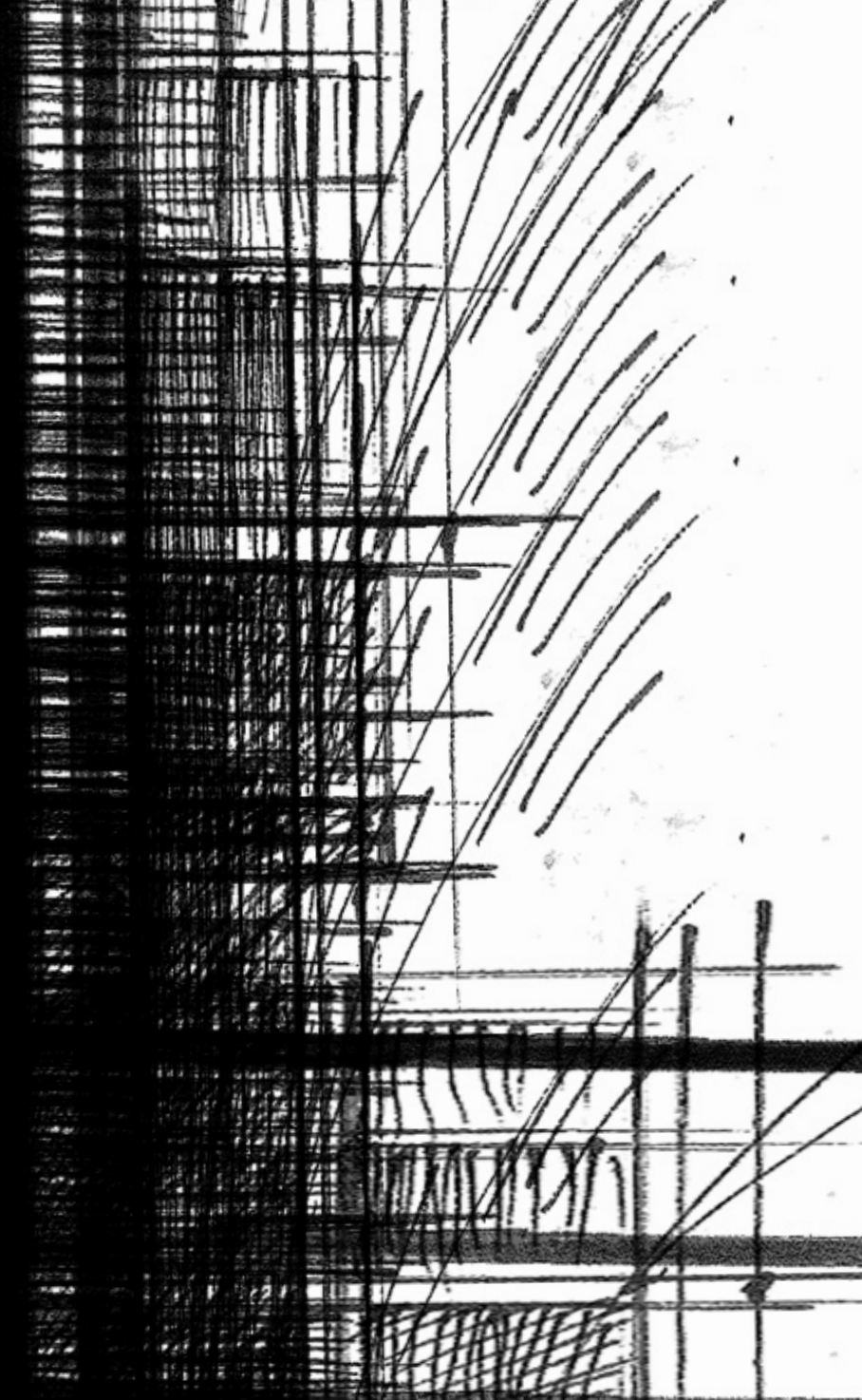

19:4:

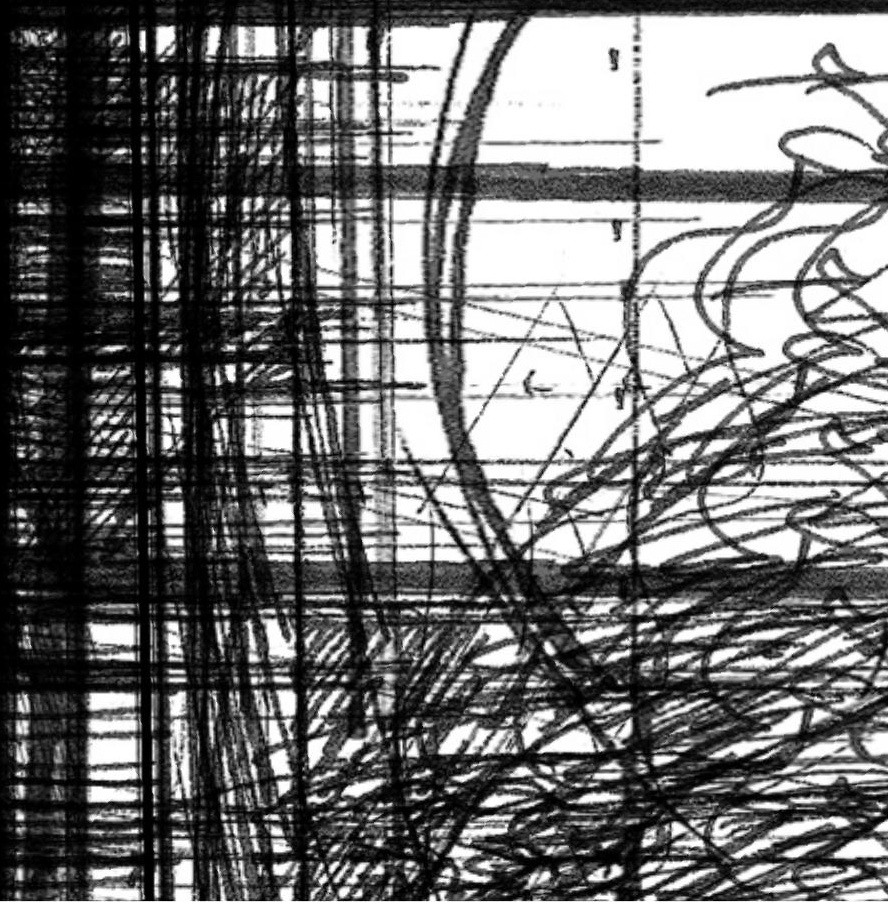




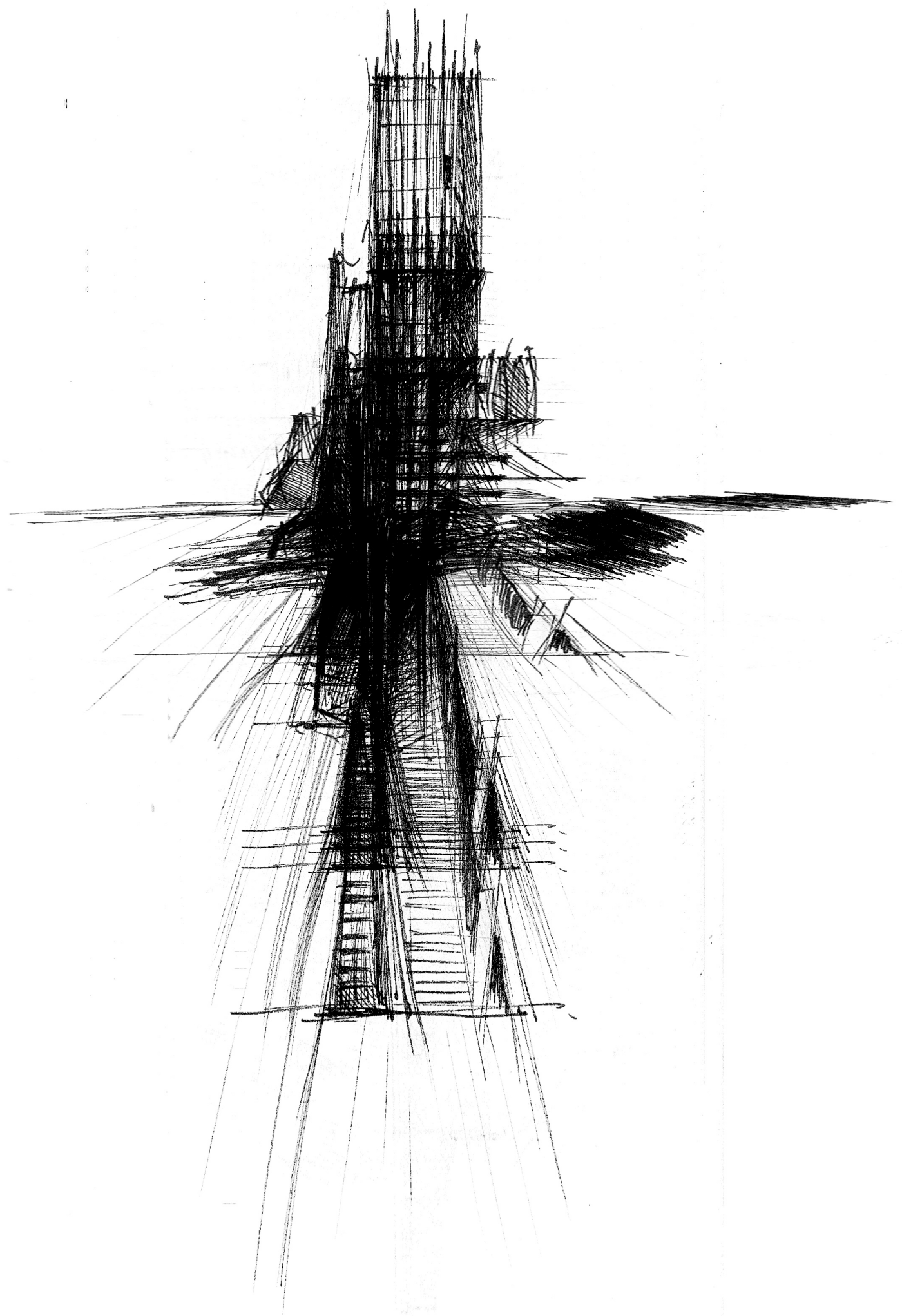



SHADOW BELONGS TO THE EARTH.

A WORLD WITHOUT IT IS A PLACE WITHOUT MATERIAL.

IN DEATH THE SHADOW IS A DREAM

HERE THE MASK IS ABSOLUTE.

THE SPIRIT IS MASTERED

SHADOW. THE DRAWINGS

OF A CONVERGENCE

FILLS WITH WATER

ITS LINE ON THE

IF WE REPLACE

THOUGHT, THE

MAN OFFERS

THENATUREOF

TO DISCOVER

THE CAVE

UNABLE TO

FROM THE

IN HIS OWN

TOKEN OF PLACE.

OUTSIDE, THE

HORIZON.

TIME WILL ALLOW IT ITS ROOM.

THE TREE MOBILIZES LIGHT

EARTH, A REALIZATION OF

THE TREE, YOU] ARE PART OF
OF THE NON-EXISTENT.

ITS EMBRACE IS WITHOUT LIMITS.

BY A LIGHT THAT CASTS NO ON EARTH ARE THE RESULT OF MASS. A CAVITY THAT AGAIN DRAWS EARTH'S SURFACE. THE WATER WITH LINE BECOMES A CONSTRUCTION EARTH.

ARCHITECTUREIS THIS THOUGHTCONSTRUCTION. DWELLER IS FREE HIMSELF MASS, BUT LIVES SHADOW AS A

TREE FRACTURES THE TO GROW AND ADD TO

AND CASTS ITS SHADOW ON PLACE. [WHEN YOU REST BENEATH ANOTHER'S SHADOW,

AND YOU ARE NO LONGER ALONE.

IT IS HERE THE STORY IS TOLD. 


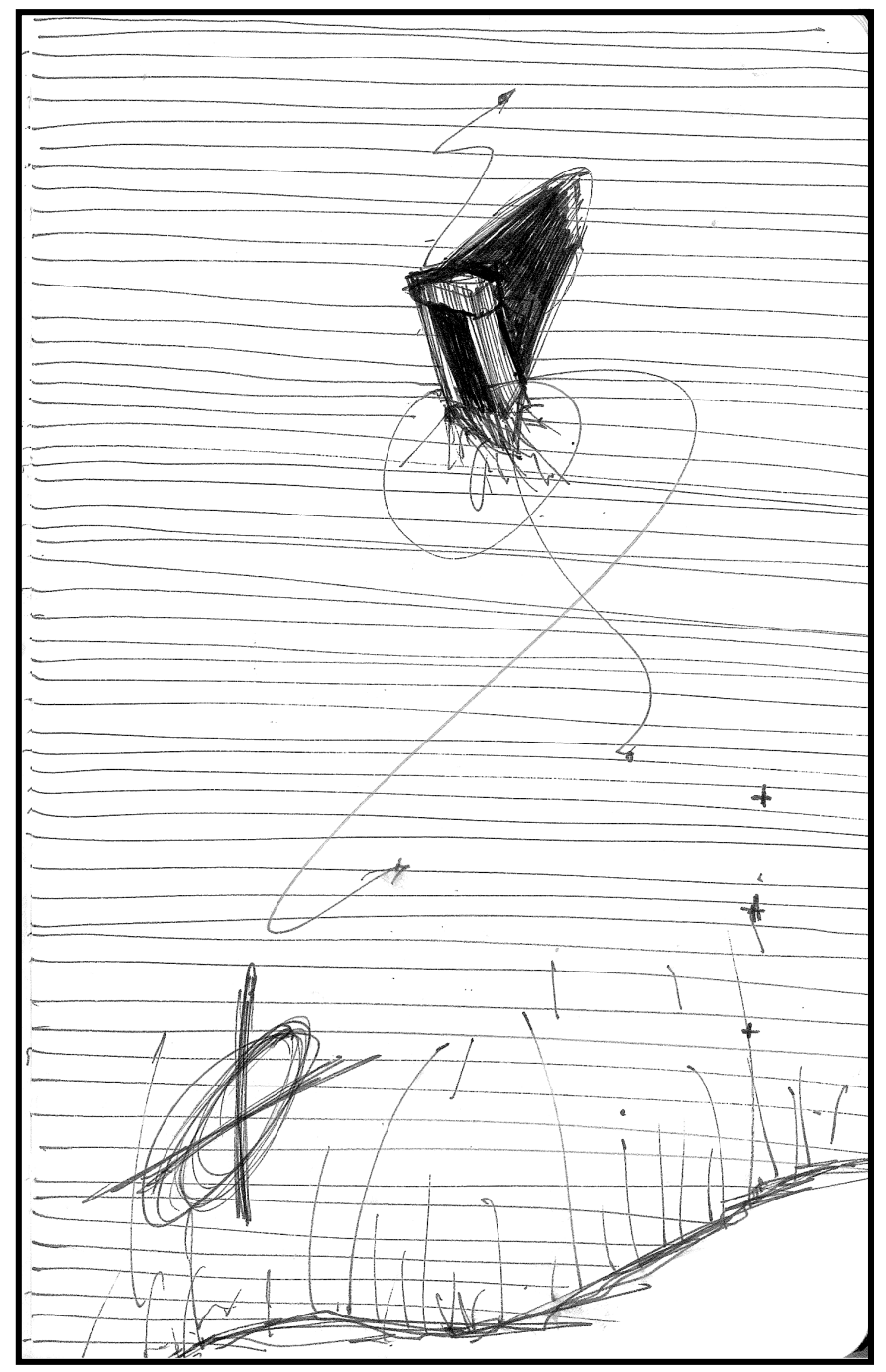

Figure 2.11. threshold upon a field. sketch by author 
This chapter delved into the realm of shadow. Using Arden Reed's theory of the shadow in his essay "Signifying Shadows", it identified and examined five characteristics of the shadow:

\section{SHADOW AS REFUGE SHADOW AS THRESHOLD SHADOW AS TRACE SHADOW AS PROJECTION SHADOW AS SUBLIME}

These characteristics, and their associated operations, were further interrogated through relevant literature and critical engagement. Each of the characteristics were interrogated through the language of the drawing. Propelled by the deisgn experiments in Part 1, these studies drew out qualities of the shadow through expressive and iterative design experiments. This gave a greater understanding of the role of the shadow in architecture and its ability to convey or obscure meaning.

The experiments generated further insight into architectural and experiential qualities of the Gateway and Shadow Grounds. Reflecting upon Jerome Bruner's key features of constructing a narrative, the series of design experiments evidenced the following:

INNOVATION_use of a 'breach' to disrupt normative design process

TRANSFORMATION_blurring, layering and obscuring

MULTIPLICITY_motion versus rest, speed and slowness, diversity in methods, hand sketch+digital manipulation

Moving forward, METAMORPHOSIS transforms the ideas and learnings generated in Part 1 and Part 2 into the drawing. Seeking Bruner's final feature CONVERGENCE, part 3 will aim to work toward the progressive mediation of oppositions through the speculative drawing. 
This image can be viewed in the print edition of the issue 
When darkness is so deep that it provides a foil of black nothingness, the beholder receives the compelling impression of things emerging from a state of non-being and likely to return to it. Instead of presenting a static world with a constant inventory, the artist shows life as a process of appearing and disappearing. The whole is only partly present, and so are most objects. One part of a figure may be visible while the rest is hidden in darkness... [t]he frightening existence of things that are beyond the reach of our senses and yet exercise their power on us is represented by means of darkness. 


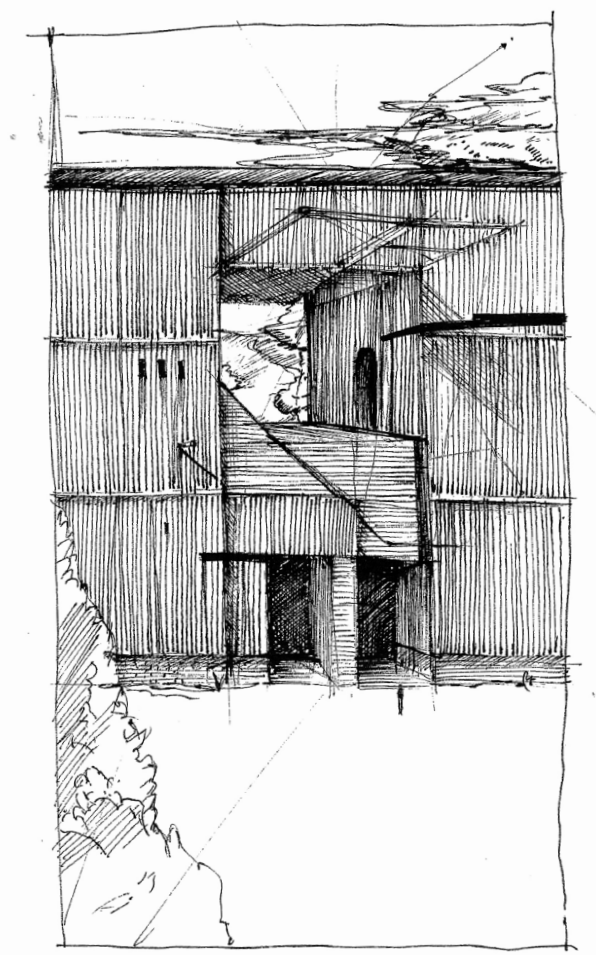

Figure 2.13. Gateway. Sketch vignette by author 


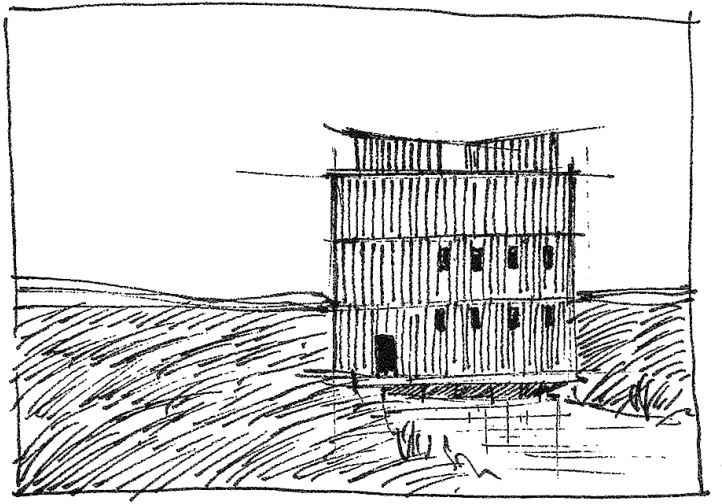

Figure 2.14 The Gatekeeper's House. Sketch vignette by author 
Part 3

\section{METAMORPHOSIS*}

\section{Architecture \\ as drawing}

RO3 to interrogate the architectural drawing,

exploring its potential for inviting an

allegorical architetcural project. 
...ARCHITECTURE. What is architecture, and can it be held within a drawing/model as well as a building? Architecture is the 'mother of all arts'. It is a-synthesis of poetry, fine art, sculpture; it flows over time like music and its spaces have establishing vignettes, oscillate across the scales (from macro to micro) - and have a dénouement, as in film or prose. One could go on. Above all, architecture is the manipulation of space in all its manifestations. Space can be both imagined and graphically represented. 

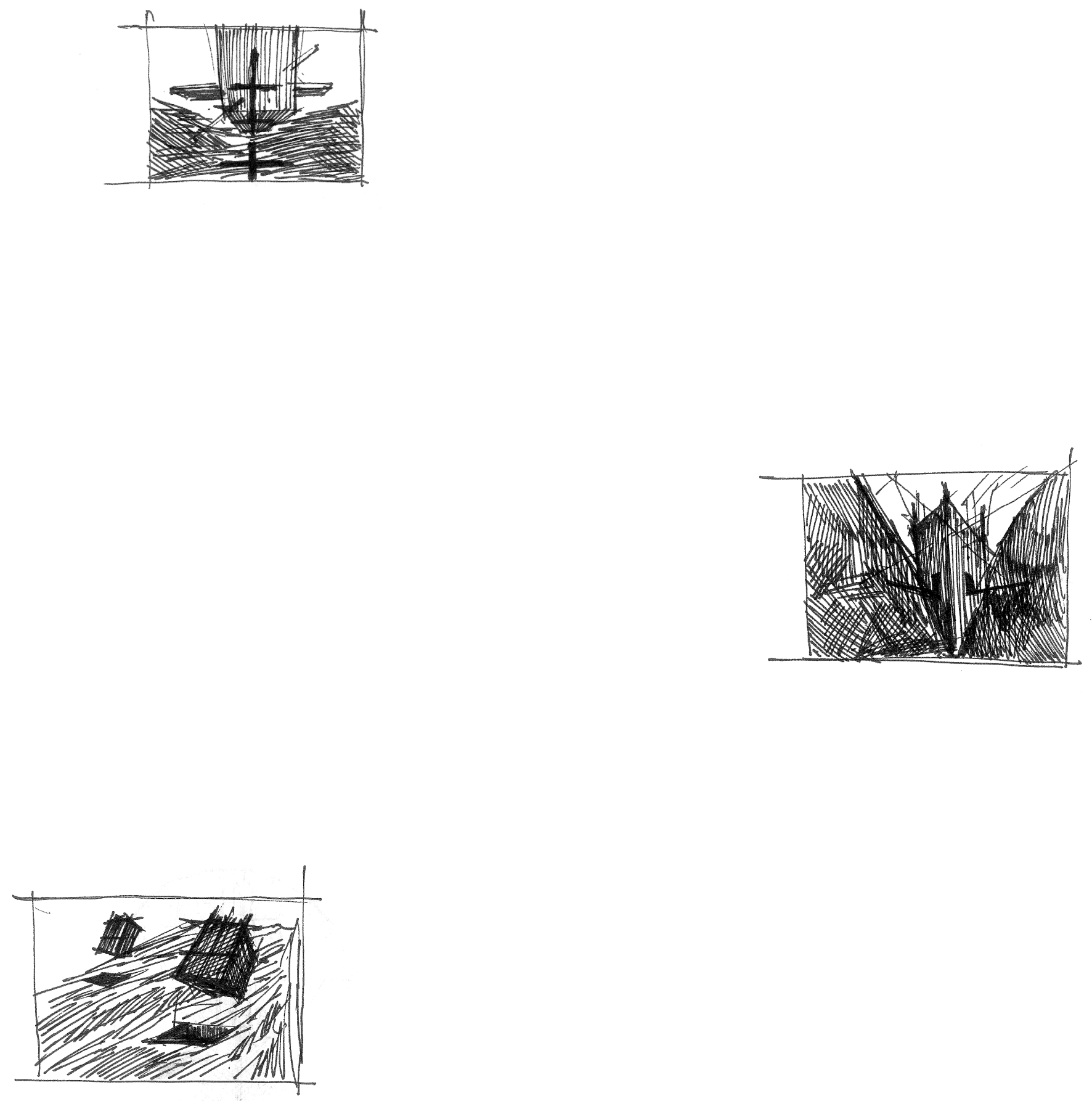

Figure 3.1. Touching down. Sketch vignettes by author. 
In this thesis investigation drawing is seen as the shadow of architecture. It denotes the presence of memories, intentions, desires and dreams in the creation of the architectural constructs. Within the drawing lies the very essence of architecture. Architect and Educator, Raimund Abraham proclaims that the principle of drawing reveals the origins of architecture, "the act of interfering in, and shaping space. For the piece of paper is the space and the pencil is the tool with which to shape and intervene"(Abraham). Drawing then reveals a critical impetus for architecture, which poses the question to technology of what to build and how. It is through the creation and manipulation of space within the two-dimensional field that ultimately gives us insight into the nature of three-dimensional space. This thesis argues that the act of drawing must be reconsidered within a contemporary technological sphere. Through the act of drawing, one transfers the physiological (intangible) into the physical (tangible). It is a repository of thoughts, emotions and ideas.

In order to expand on this idea of the drawing, this thesis refers to Marco Frascari's Eleven Exercises in the Art of Architectural Imagination as a way of solidifying and engaging with reviewed notions of drawing. Three sections outline three key ideas laid out by Frascari, additional theoretical grounding and case studies expand upon these sections:

\subsection{DRAWING AS LOCI FOR THOUGHT}

3.2. TRACES AND ARCHITECTURE

3.3. COSMOPOIESIS OF ARCHITETCURAL DRAWINGS

The aim of Part 3 is to metamorphoses the expanded learnings from the previous two sections, engaging the drawing as both creative act and projective reality. It seeks the analogous links between the constructing of a drawing and the constructing of architecture. If the drawing is purely a visual medium, how does it imply something more visceral, more experiential? 
porcessof architecunt

creation as. an unbid oscillates

hecmeeh nequecis and

reconciliation: like a ocatericous

arfrowtatio

mat

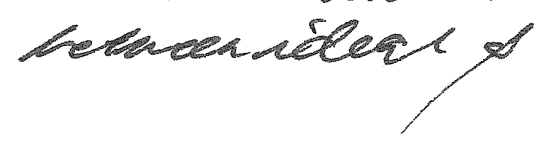

architedfue as monument to the carnal. commenosaticain keith the queerer of thence of oven

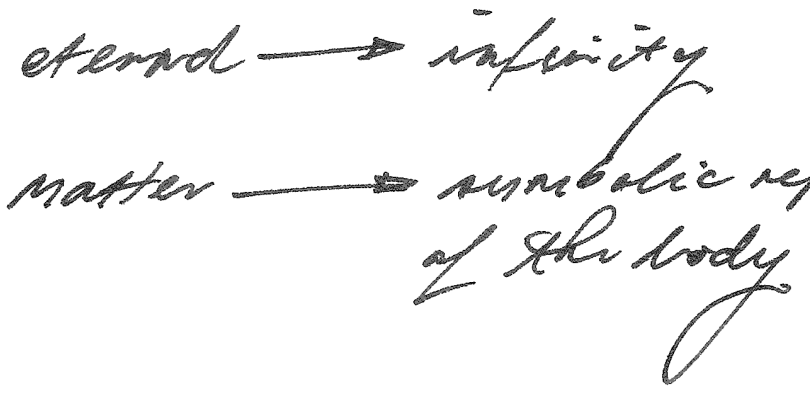

architachur as medicate lessee the realer of the of mate-

Process of archietctural creation as one which oscillates between negation and reconciliation: like a continuous confrontation between ideal and matter

Architecture as monument to the eternal. Commemorating both the absence and presence of man.

eternal: infinity

matter: symbolic representation of the body

architecture as the mediator between the realm of the eternal and the realm of matter.

— Author's notes from Raimund Abraham, [UN]BUILT 


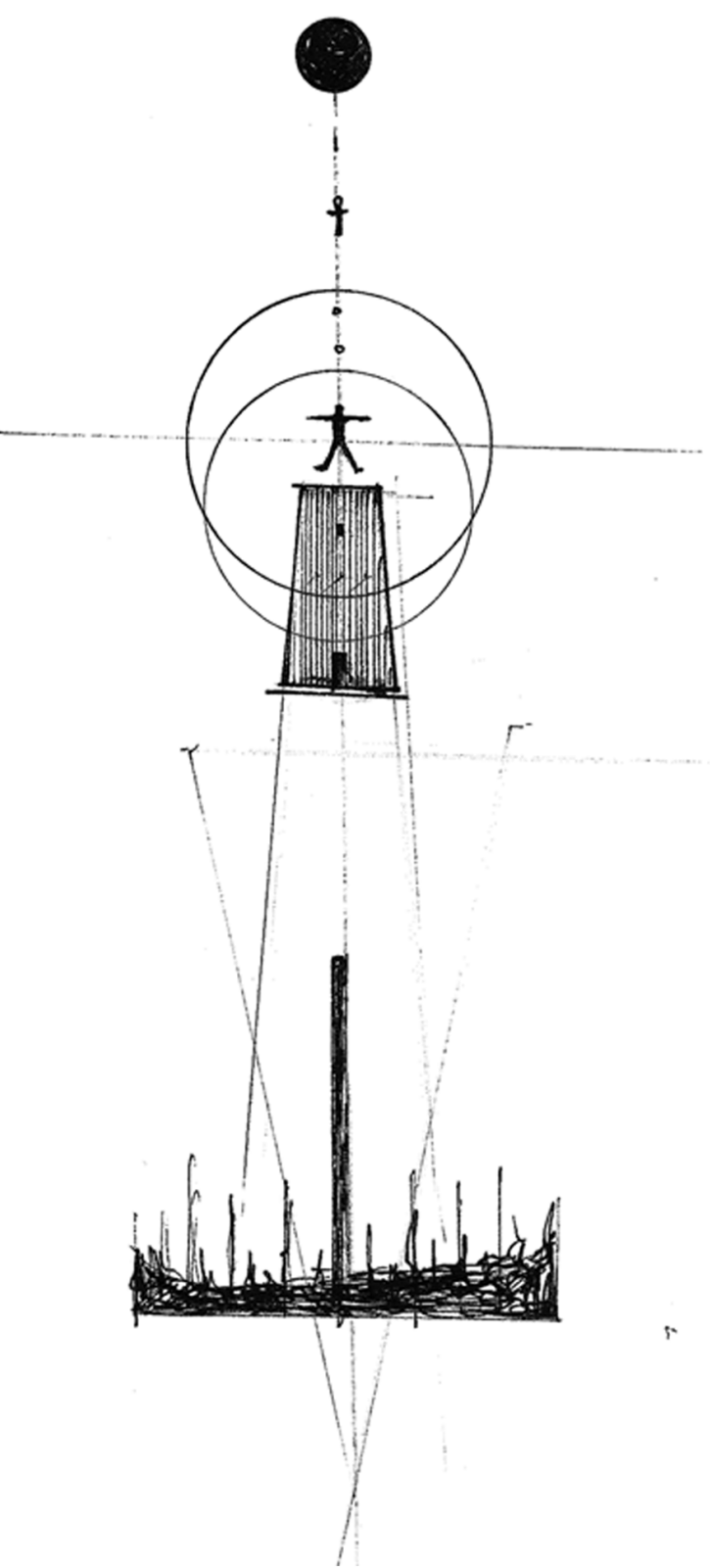

Figure 3.2. Schematic sketch diagram. Architecture as mediator between the realm of the eternal and the realm of matter. 


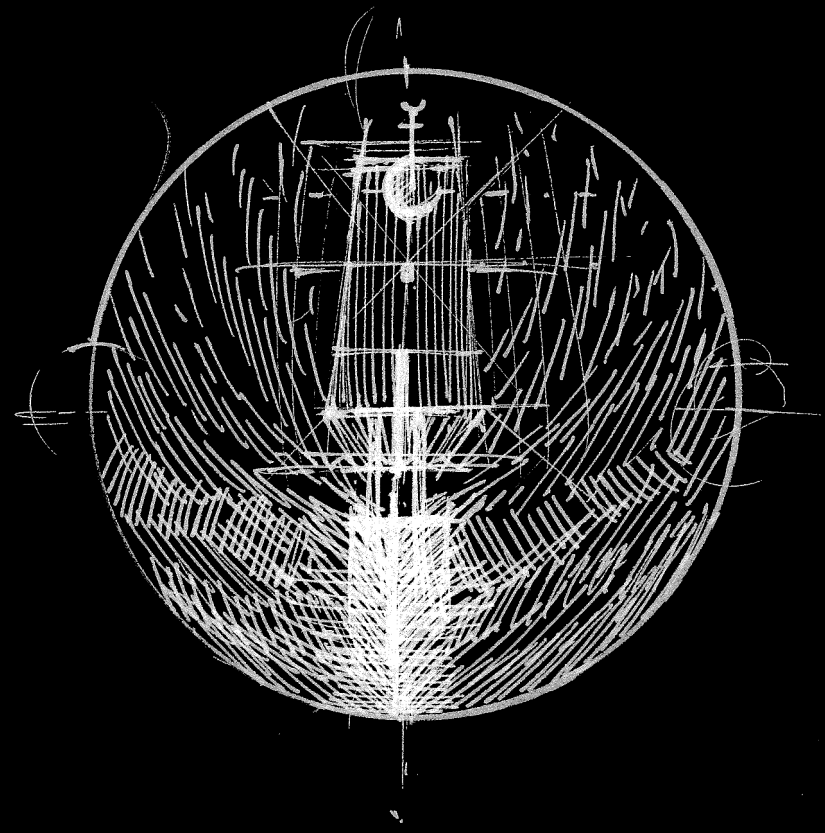

Figure 3.3. Centrality. Sketch by author. 
"Architectural drawings are metaphors, not in the literal meaning, but factually they are a carry over, a moving of sensory information from one modality to another modality, from one set of emotions to another set of emotions."

-Frascari, Marco. Eleven Exercises in the Art of Architectural Drawing: slow food for the architect's imagination. routledge, 2011. p. 147-148 
My line wants to remind constantly that it's made of ink, I appeal to the complicity of my reader who will transform this line into meaning by using our common background of culture, history and poetry.

-Saul Steinberg, All in Line, London: Penguin Books, 1945.
Figure 3.4. Convergence.

Experimental plan. Sketch + digital collage by author.

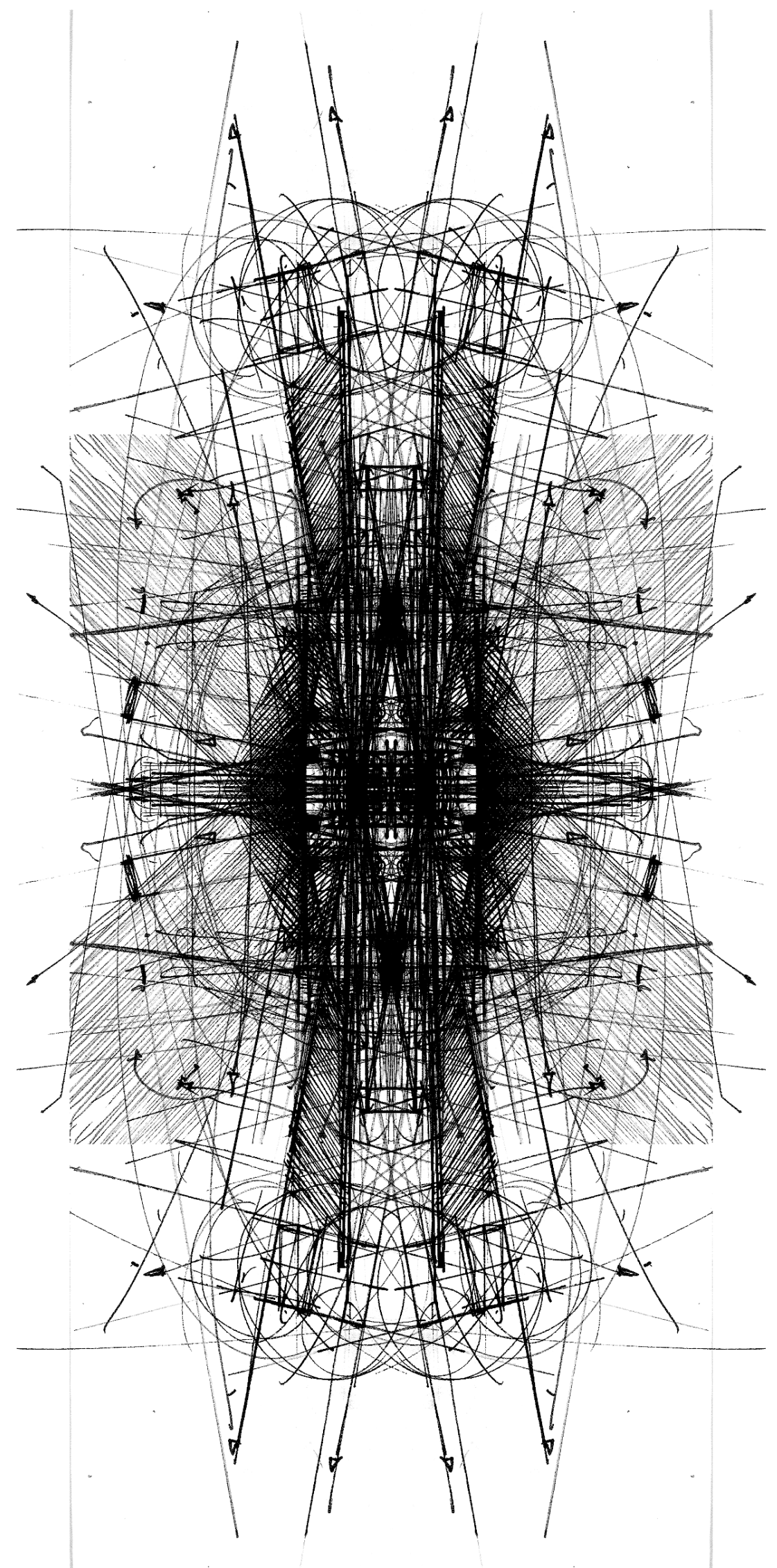




\subsection{DRAWING}

AS LOCI FOR THOUGHT
Architectural drawings are forms of being, expressions of complex states of mind and experience (Frascari, 35). They reflect the multiplicity of thought and mode that is born out of direct engagement between the thinking hand and the paper. Frascari, professes "the materiality of the lines become the carrier of fluid, and generates invisible lines that become lines of thought." In this regard, drawing links the tangible with the intangible. They become loci for thought.

In the present age, the prevalence of CAD and BIM in the architectural design process has reduced architectural drawing to a flat plane of homogenous computer generated lines and superimposed photographic renderings (Temple) "The density of the fluid world is muted, anchored and jammed into rigid lines and inert surfaces"(Hill). This reduced and inert condition of contemporary representation removes all substantial foundations of the drawing, resulting in architecture that is merely sheer graphic configuration. This mode of drawing reduces architecture to merely "solid stuff", but as made clear elsewhere in this thesis, architecture is concerned with shadows (dream stuff). Frascari argues for drawing that can also transmit metaphysical conditions, embodying myth and invoking imagination.

Drawing, then, blurs and delineates, excludes and includes, contests and accepts; in expressing, it suppresses (Hamel). In the recognition of drawing as an emerging visual field of ideas that are discovered in and through its processes, one imagines drawing as a site of ongoing negotiation, a process of crossing defined limits, perpetually crossing, perpetually oscillating (180). In order to challenge normative presumptions of architectural design and shift an awareness, this thesis engages drawing processes that go beyond defined conventions. It recognizes that in order for innovative and novel experience to occur, one needs to "make drawings that lubricate the process of developing tacit knowledge about uncertain engagements, we therefore need to develop methods of drawing that are outside of architectural conventions."

Understanding the nature of projections as ephemeral, dynamic and endowed with shadows may generate an architecture once more experienced as a flowing musical composition (PerezGomez). 


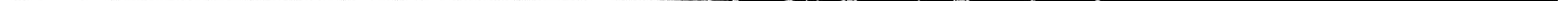


The density of the fluid world is muted, anchored and jammed into rigid lines and inert surfaces... it is important to trust in the unfolding of the idea, to be receptive to the growth of the image, to allow drawing to lead, but at the same time be able to select, discard or further build upon uncovered possibilities. To do so, one has to allow half resolved forms which in their ambiguous state may provoke alternate possibilities.

—Edward Hill, The Language of Drawing, New Jersey: A Spectrum Book, 1996
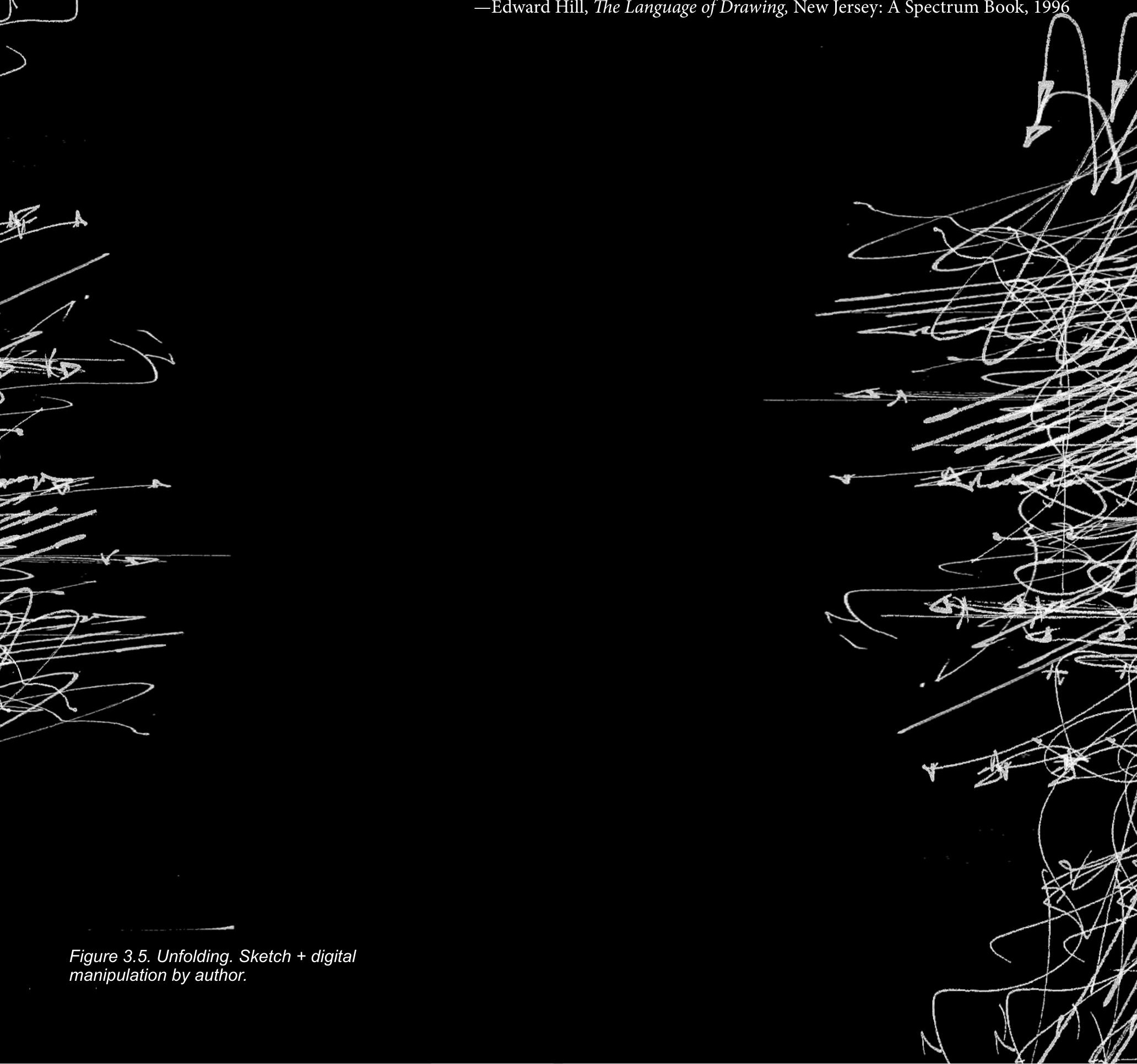


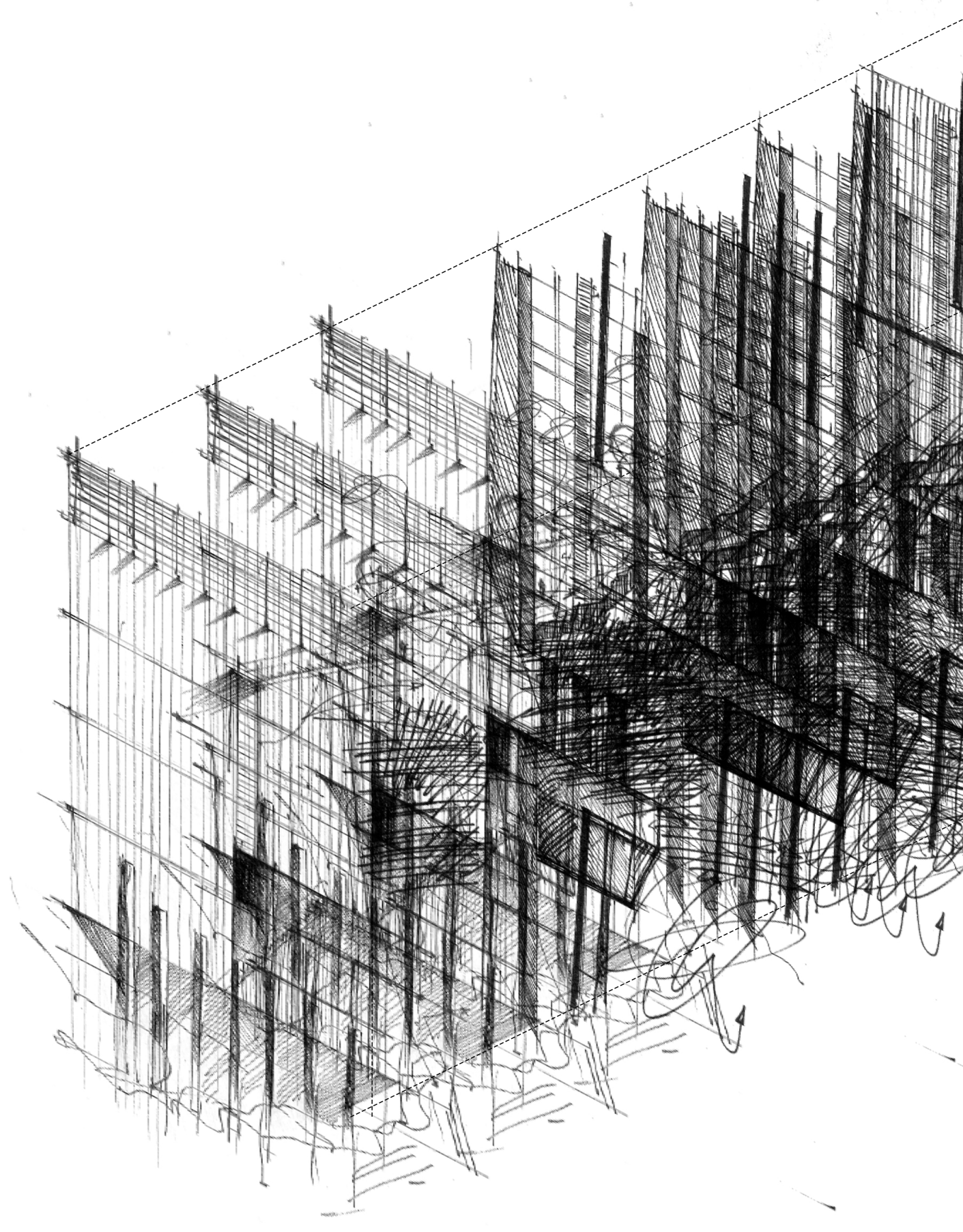




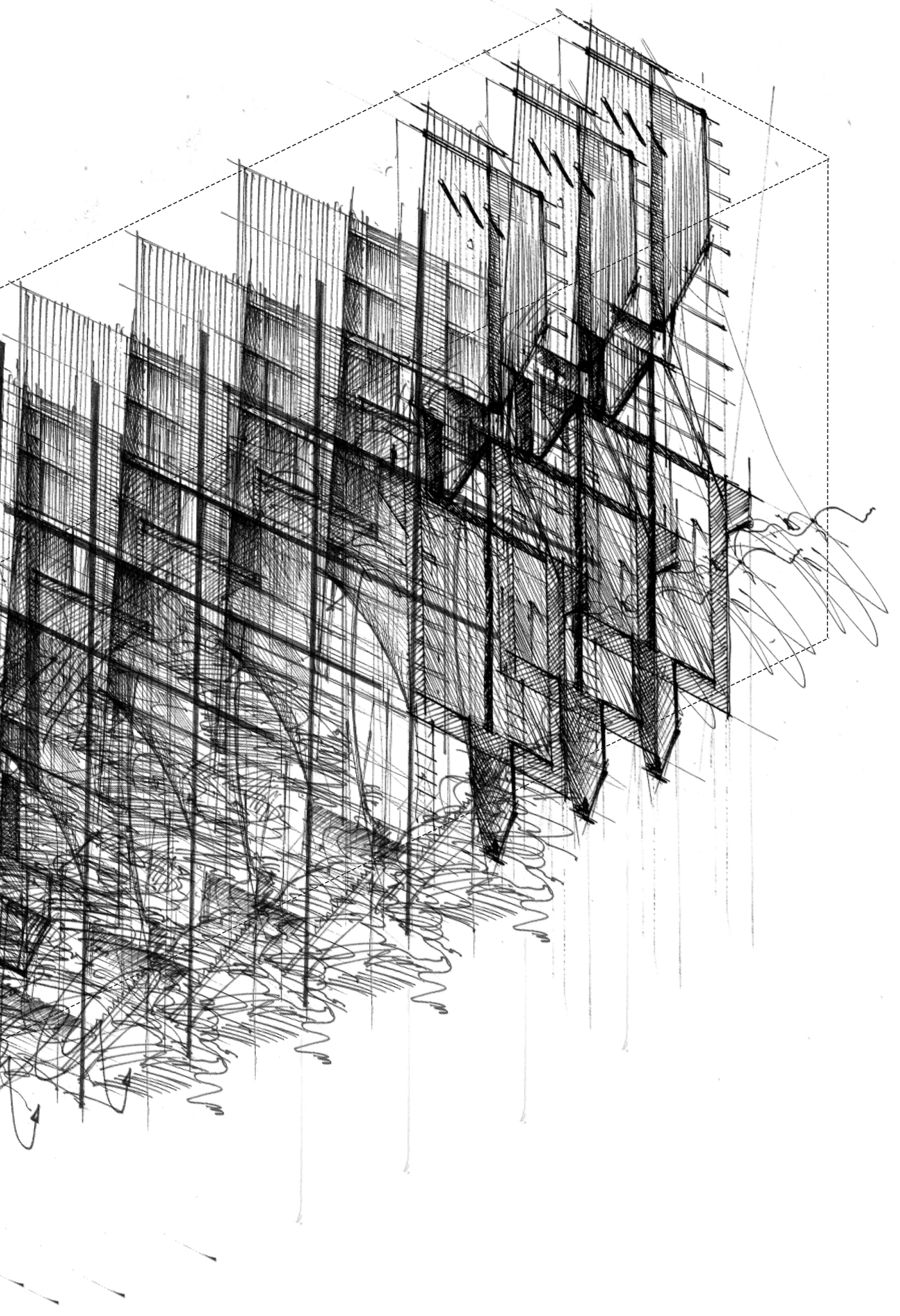

Figure 3.6. Experimental axonometric section. Hand drawing + digital manipulation by author. 


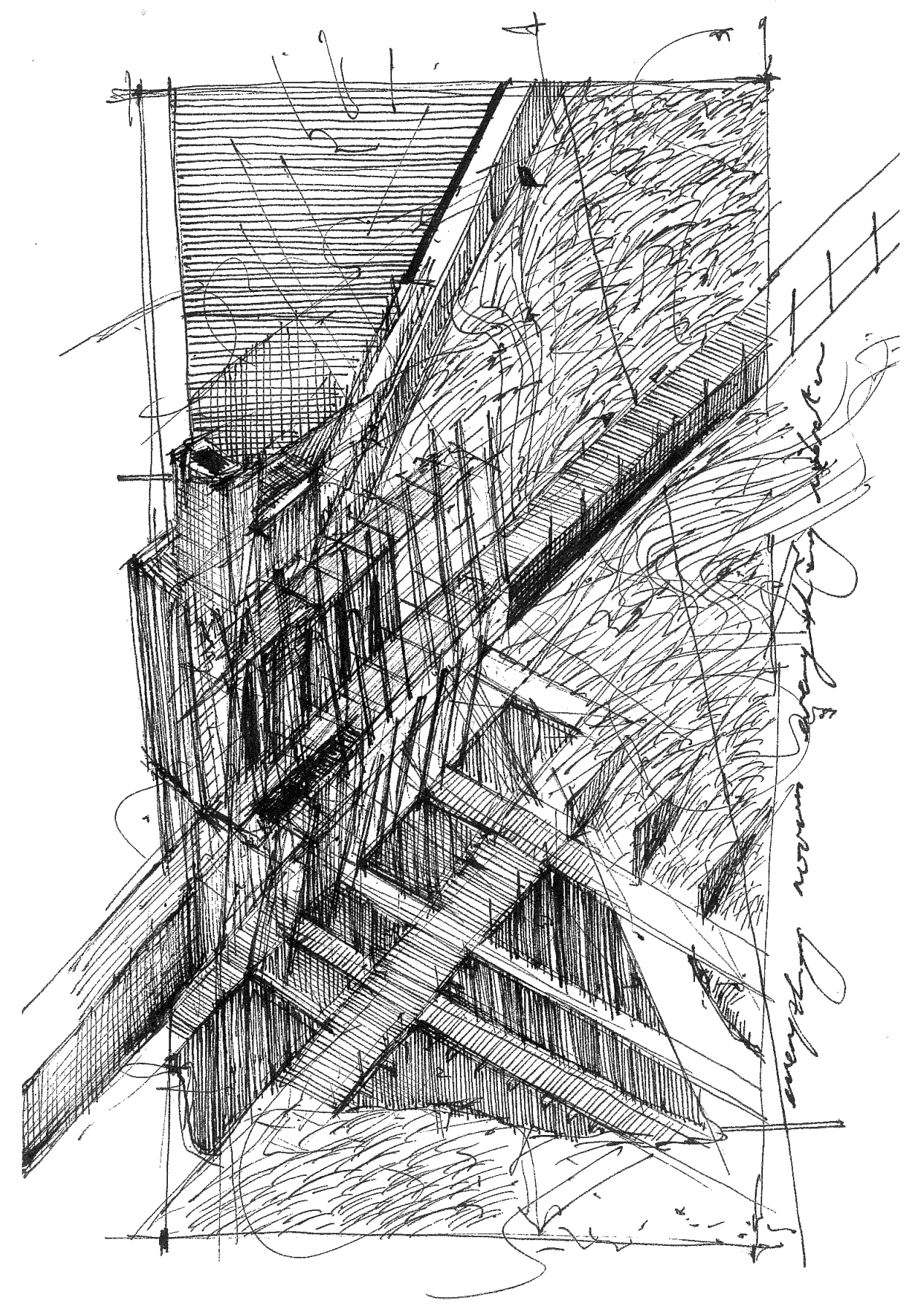

Figure 3.7. Threshold study. Sketch by author. 
If architecture is primarily presence - materiality, bricks, mortar - then otherness or secondarily would be trace, as the presence of absence. Trace can never be original, because trace always suggests the possibility of something other as original, as something prior to.

Eisenman, P. (1996): 569.

For Eisenmann, the traces of a drawing, point to something 'other'. It is the possibility of something other that propels the imagination toward new possibilities. The architectural drawing, through its operations based on composition and decomposition, weighting, ordering, deletion and deformation etc. rely on the trace as a repository of desire. The graphic processes employed by the architect to construct a drawing acts as an invitation for the construal of their constructive possibilities (Frascari). In this invitation for interpretation, between the presence and the absence, the imaginative gaze is enabled 'to proceed beyond the visible into an infinity, whereby something new of the invisible is encountered' (Merleau-Ponty) Just as shadows are the traces of architecture, so too is the drawing, so the drawing of the shadow is a trace of a trace. This multiplication of signification, belies the logical structure of the material world, it opens up a rupture in conventional thinking. Trace in the context of this thesis is used to shift the linearity of the design process and eschew the finality of the digital model, therefore develop deeper understandings of shadow, form and space. Always positing, always questioning,

\section{"Architectural drawing is thus the tracing of a 'metaphysics of presence'.}

-Marco Frascari 


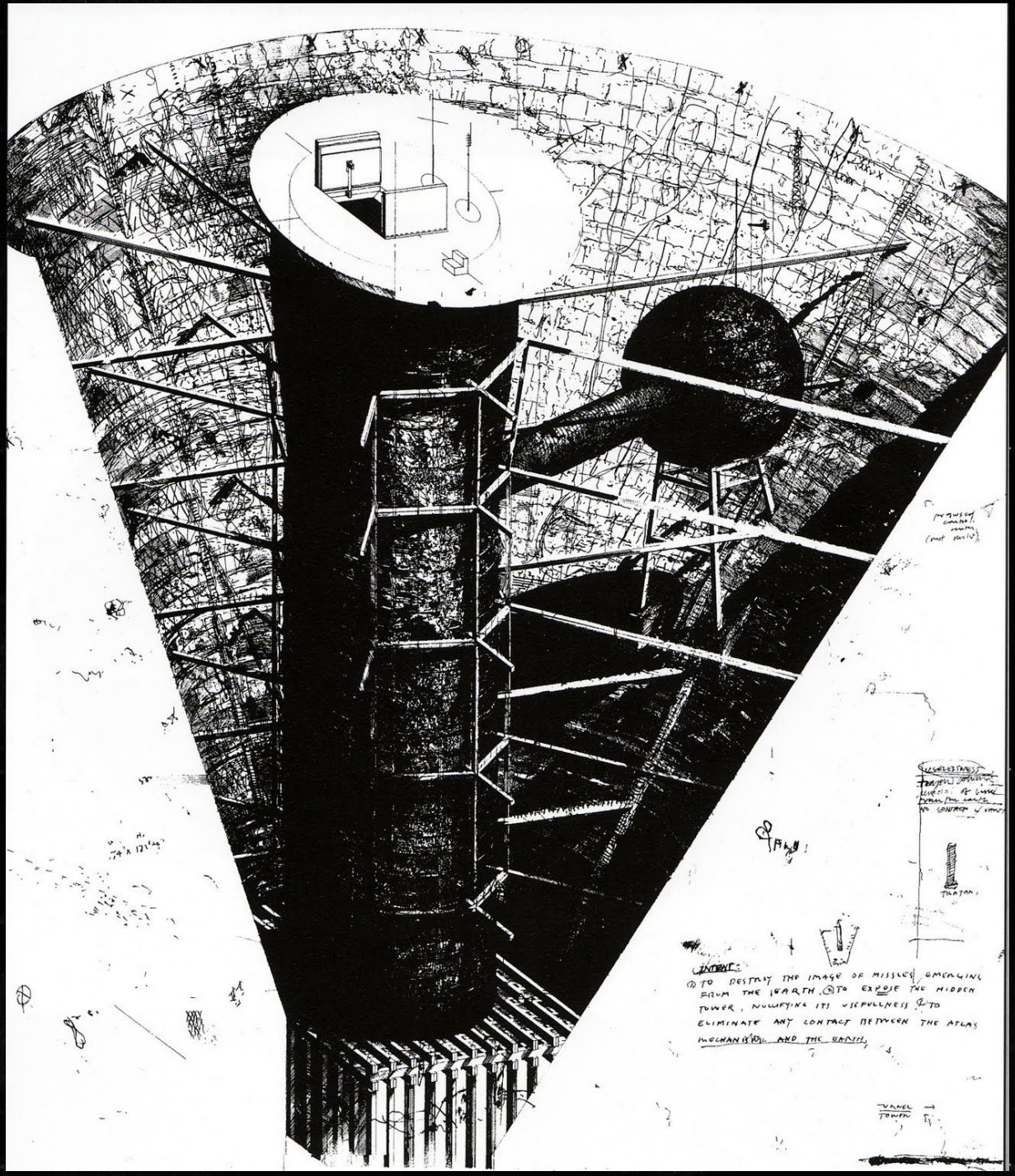

Figure 3.8. Vessels of memory. Wellington Reiter. 


\section{FIELDS.}

Wellington Reiter

Wellington Reiter deals with traces and architecture in his idiosyncratic and provocative book Vessels and Fields. In her reading of Reiter's work, Patricia Philips expresses, "characters and stories unfold, intersect, and overlap, creating an atmosphere from which a vivid... depiction of the city emerges... Reiter draws to complicate and question" (Phillips, 4) Reiter traces both the physical and intangible events of the city. He excavates the fleeting glimpses, restless vectors and transitory nature of the physical realm through the act of drawing. The drawings exhibited in the book exist somewhere between the real and the imagined, creating an atmosphere that is both familiar and uncanny. Reiter's drawings do not simply represent the city, they re-present it, constituting a woven matrix of dynamic forces, vectors, intersections among which artefacts exist. The idea of the trace is the excavating of presence from absence, constructing the tangible out of the void. It challenges the 'given' in architecture and posits 'what if?'.

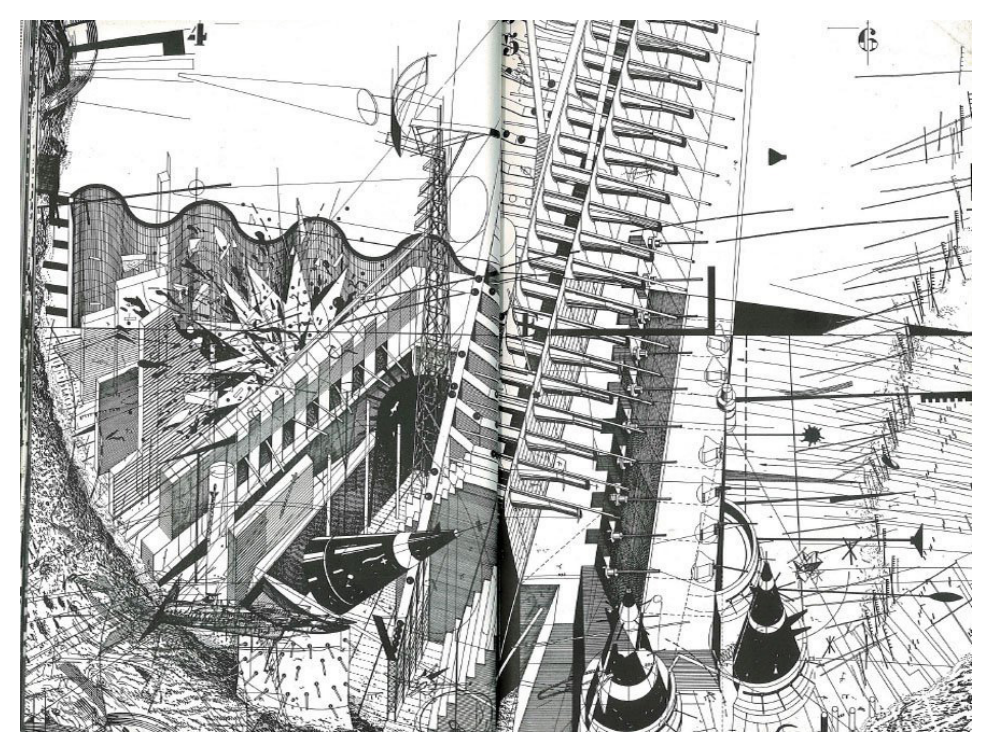




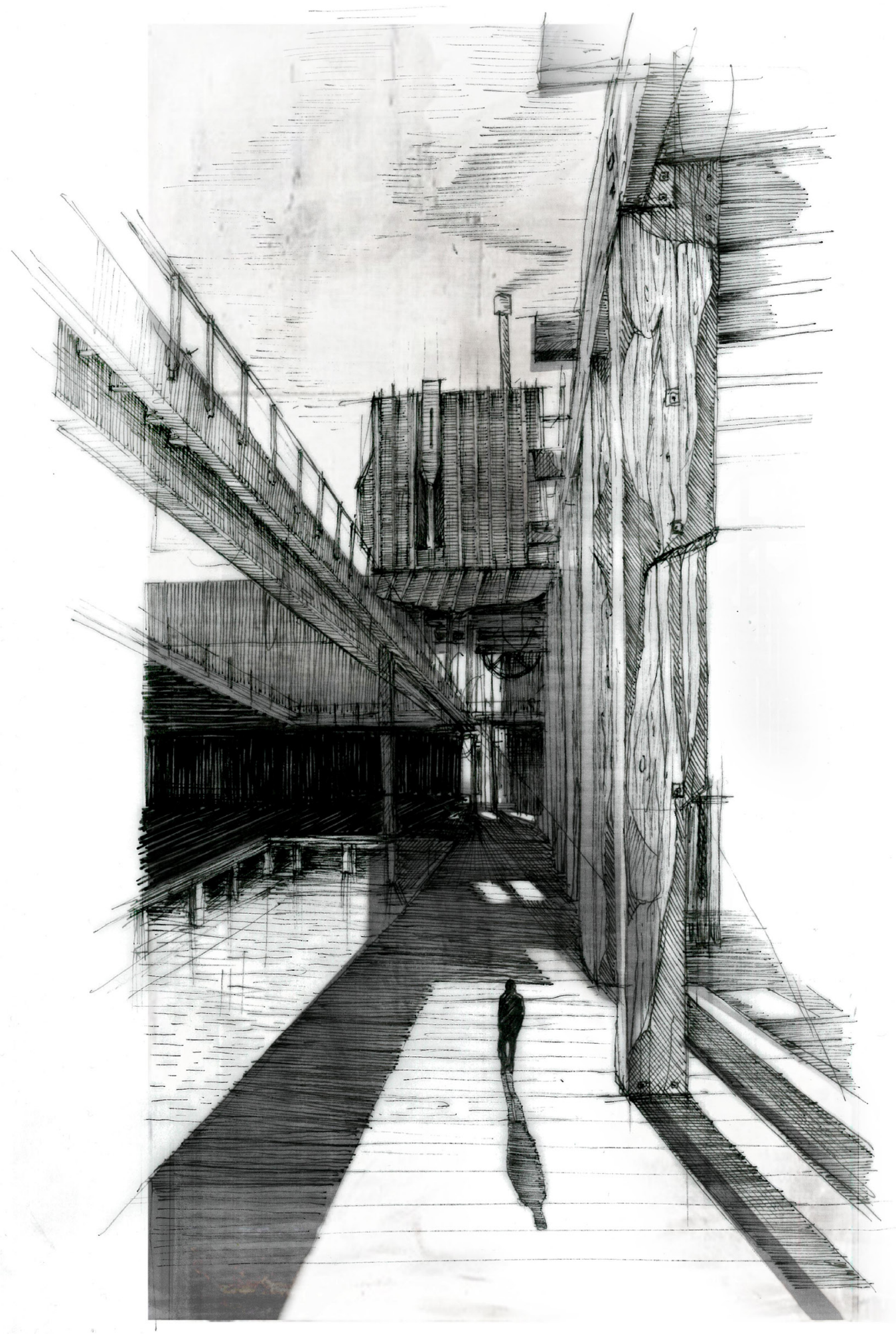

Figure 3.10. In the shadow of the Gatehouse. Hybrid perspective study. 
Drawings constitute, therefore, an integral part of any built building simply because the same cannot be conceived without an initial human intervention of ideas and emotions. Aware of this belief of mine, I let my mind dwell in the silence of the making. In so doing I do not give an architectural form to an image; instead I let the image find its way in a sort of existence that stretches itself next to my own. From this angle, drawings coincide with my inner being beyond program or specific use or materials application. In a drawing, in architecture, a double presence is to be observed and witnessed --that one of the "place" we see and experience, and that one of the mind with emotions in the process of 'conceiving it'.

To think is to see, to see is to draw, to draw is to be, to seek and remember an already visited and inhabited place. 


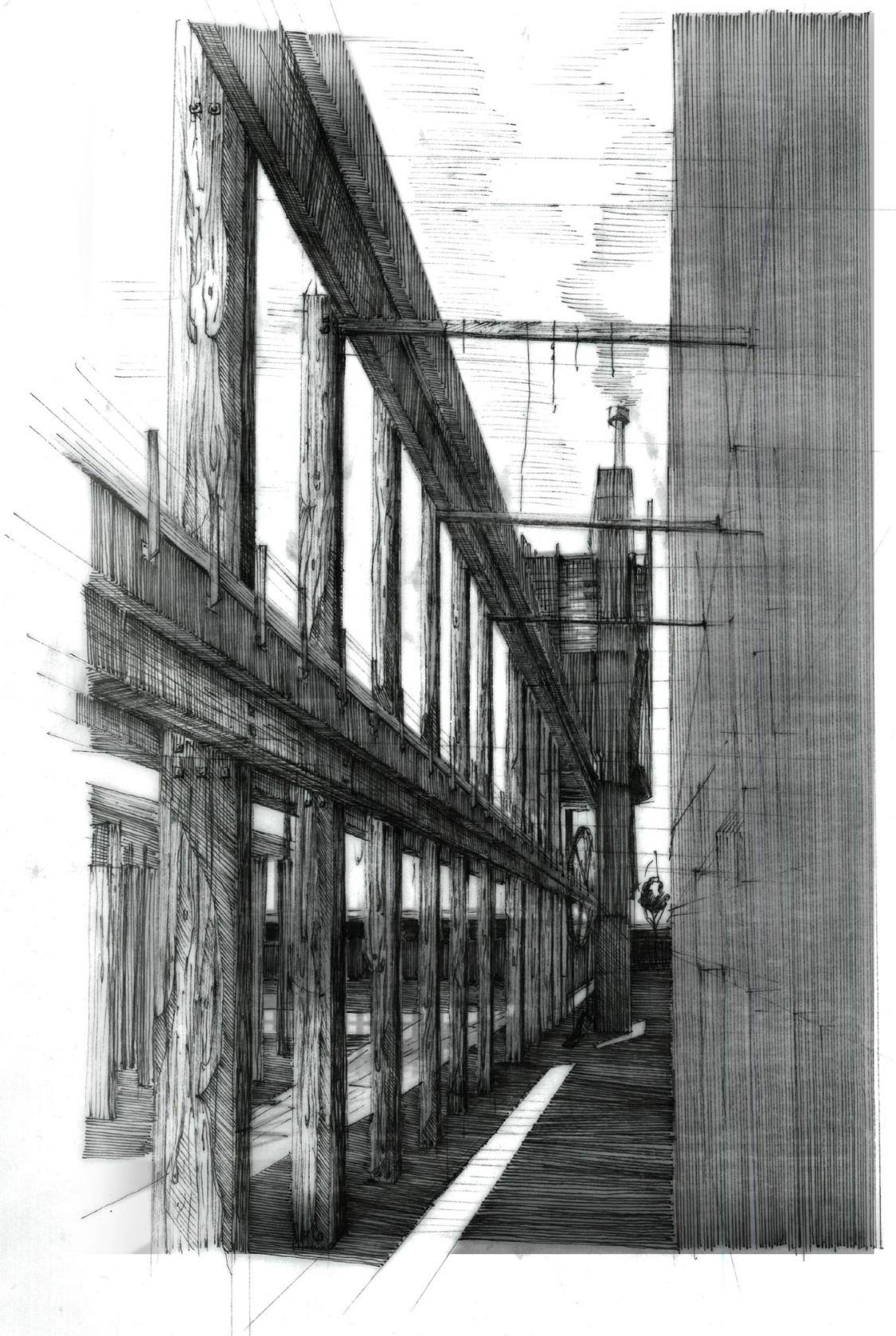

Figure 3.11. Across the unknown bridge. Hyrbid perspective study. 
Hybrid drawings are a method of mediating between the digital and the hand, utilising both the tactility of the hand and the immediacy of the computer. Typically, in the contemporary age, architectural drawings are computer generated using the likes of BIM (building information modelling) and CAD (computer aided design), with hand drawing relegated to a mere incongruent part. The hybrid method incorporates the merits of both tools in order to better interrogate architecture in the two-dimensional realm of the drawing. Marco Frascari states "because the hybrid imagination is incongruous with the unfluctuating banality of common sense." (ref)

Hybrid drawings are by their very process temporal, they have a "past", indicating the evolving nature of architecture. This process allows a re-construing and re-construction of the drawing, providing a sound method for mediating between, what Frascari terms, the 'immediate rational' in favour of the 'mediate sensual'.

Figure 3.10 (previous page) and 3.11 were hybrid perspective studies. A three-dimensional digital model was created using Revit software (BIM technology). Based on the ideas explored in figures 55 and 56, digital modelling became a way of spatialising ideas that were evident in the drawings. Although Revit is a software prized for its accuracy, it was used here as a mediator between the sketch experiments and digital design process, in this way scale, dimensions and construction logic was eschewed. Subverting the use of the tools lead to speculative and poetic outcomes. From the previous experiments a notion of an above and a below was derived. The Gatehouse becomes the threshold between above and below.

Perspectival studies were created from the model, a digital render was made and then printed out and traced over using ink pen. The introduction of the hand became a way of adding materiality, shading, hatching and blurring. Rather than seeking to trace the exact forms of the model, the movement of the hand was allowed to create and construct new possibilities out of it. Whilst these studies were relatively succesful from a point of view of the sublime, they became too static and finalised. Notions of convergence are evident in the interplay betwen light and dark on the page. Transformation is not as evident, the shadows are too defined presenting a snapshot in time rather than a fluid and dynamic interplay. 


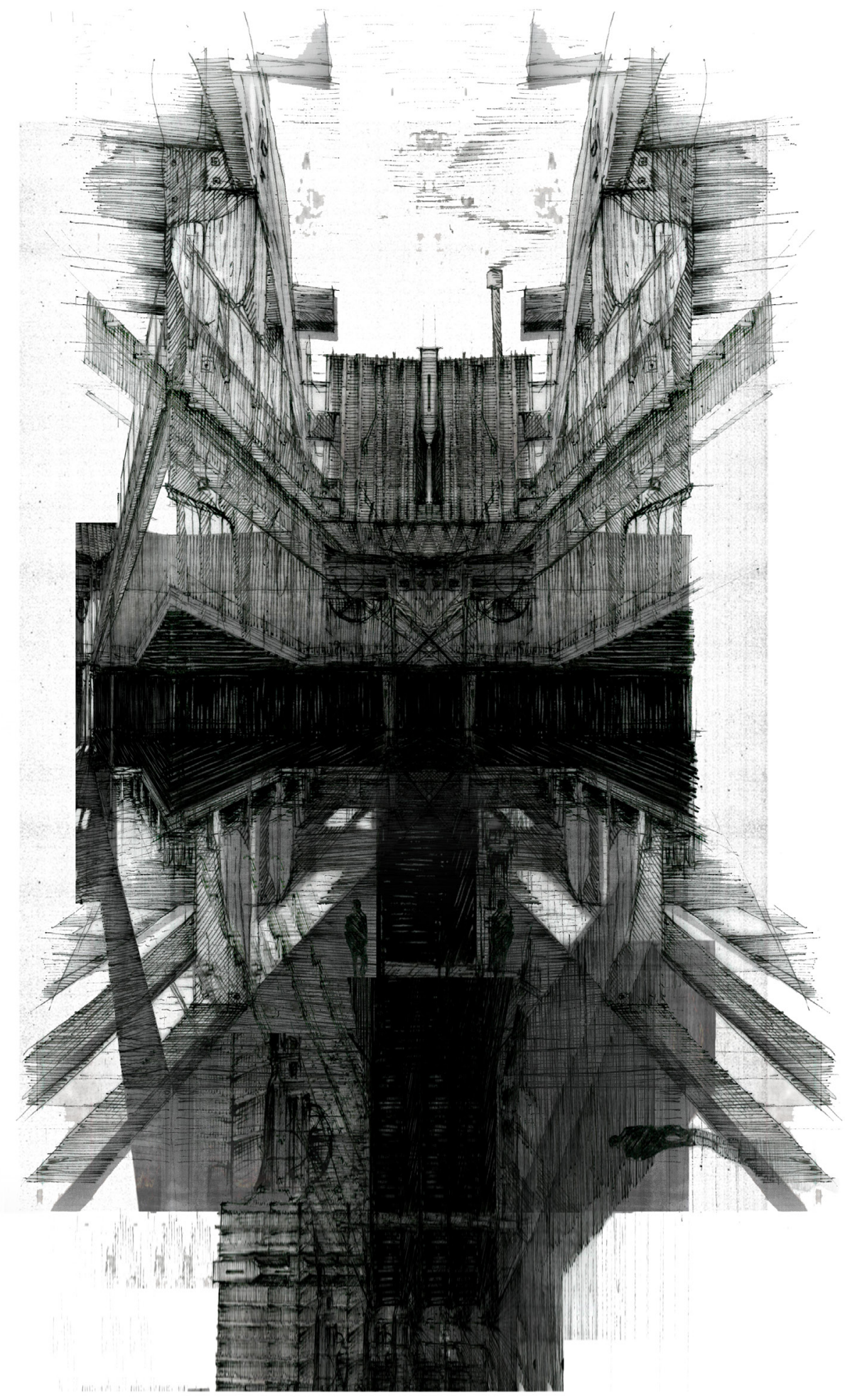

Figure 3.12. The Fall. Mixed media + digital collage 
In order to 'breach' the norms, a process of transformation was undergone. Figure 3.12 and 3.13 (over page) transform the familiar image of their origin into something more mysterious. Layering, blurring and obscuring became a way to re-imagine the previous perspective studies and subvert normative drawing conventions. The drawings become more speculative, more ambiguous and open to interpretation. Rather than two horizons, one of the above, and one of the below, the drawing alludes to a fluid and dynamic spatiality. The darkness draws you in and perspectives overlay, distort and melt into one another, one tries to find a semblance of stable ground to rest. However, the drawings never reach resolution.

Evidenced in the drawings are:

INNOVATION_use of a 'breach' to disrupt normative design process

TRANSFORMATION_blurring, layering and obscuring

MULTIPLICITY_motion versus rest, speed and slowness, diversity in methods, hand sketch+digital manipulation

CONVERGENCE_the progressive mediation of oppositions

Allegorical traits are also present:

DOUBLE MEANING_Open to interpretation

FIGURATIVE GEOMETRY_History, autonomy, analogical, symbolic

BATTLE AND PROGRESS_similarity to a journey and a conflict

UNFINISHED_incomplete, fragmentary, unresolved 


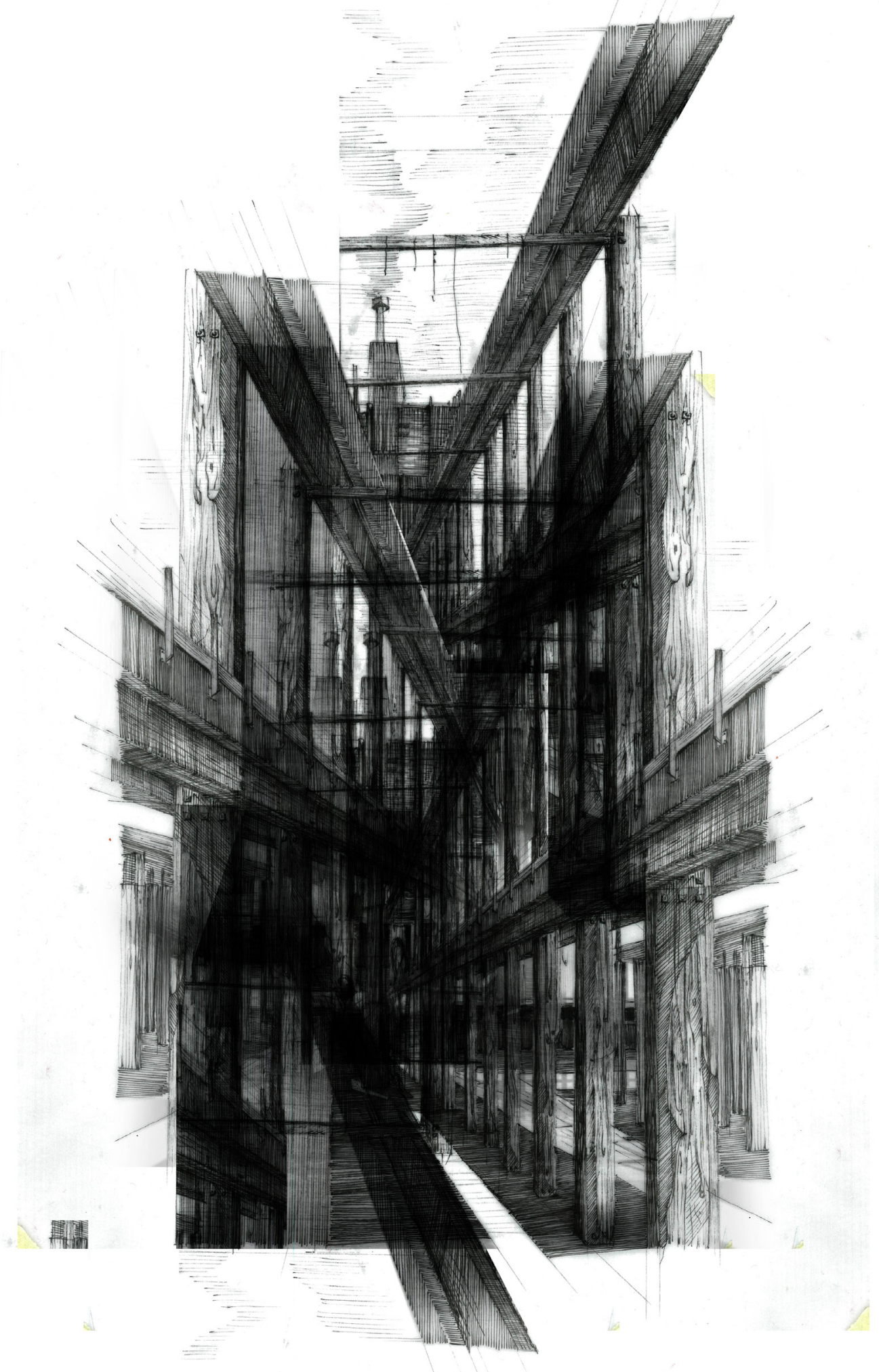

Figure 3.13. The bridge to nowhere. Mixed media + digital collage 
THOUGHTS OF AN ARCHITECT

Another manifesto...

"1 That architectural tracings are apparitions, outlines, figments.

They are not diagrams but ghosts.

2 Tracings are similar to $X$-rays, they penetrate internally.

3 Erasures imply former existences.

4 Drawings and tracings are like the hands of the Blind touching the surfaces of the face in order to understand a sense of volume, depth and penetration.

5 The lead of an architect's pencil disappears (drawn away) metamorphoses.

To take a site: present tracings, outlines, figments, apparitions, $X$-rays of thought. Mediations on the sense of erasures. To fabricate a construction of time.

To draw out by compacting in. To flood (liquid densification) the place-site with missing letters and disappeared signatures. To gelatinize forgetfulness."

-John Hejduk, Thoughts of an Architect, 1986. In Theories and Manifestos of Contemporary Architecture. 


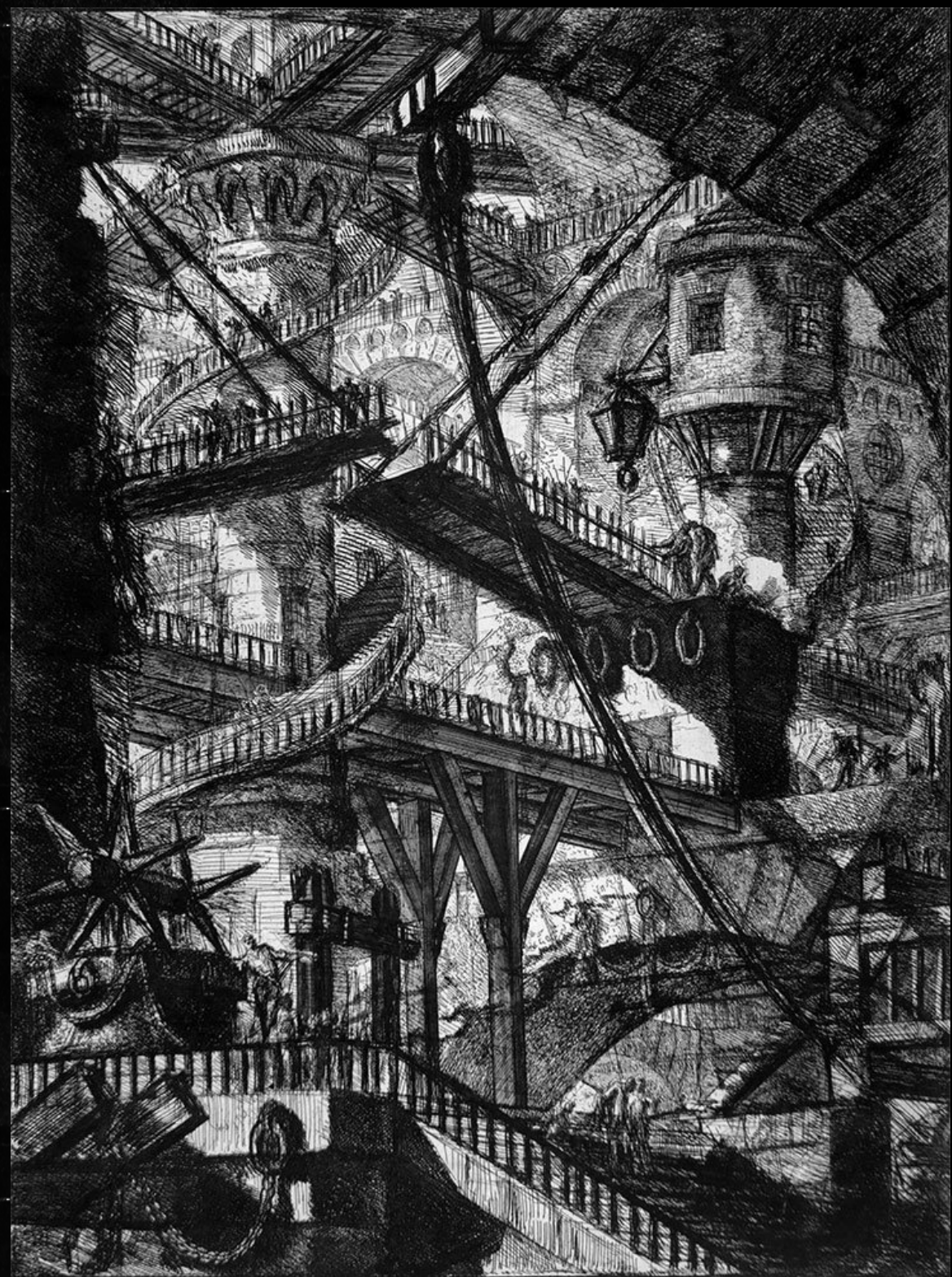

Figure 3.14. "Carceri VIII - The Drawbridge" (1745). Giovanni Battista Piranesi 
3.3 COSMOPOIESIS: DRAWING Cosmopoesis, or world making, 'always AS WORLD MAKING starts from a world already at hand; the making is remaking' (Frascari). In this regard representations can be more real than the reality to which they refer. Our fluctuating present is endowed with myths, stories and shadows that harbour the past and insight future potentials. As Neil Spiller notes: "it is the making of the drawing that builds our understanding of our world," (268) Robin Evans in his influential book Translations from Drawing to Building and Other Essays implied that the built world is constructed through the world of representation. This notion serves to become an explanatory link between architecture and drawing in the context of this thesis.

As seen in the seminal works of Giovanni Battista Piranesi, the unbuilt architecture of the drawing becomes a space for the production and exploration of ideas. In his Carceri, Piranesi liberated the space of representation from the confines of perspectival and orthographic projection to allow the drawing to become a repository of thought and emotion, as well as opening up a world of possibility. He utilises the tools of architectural representation to subvert the normative conventions; lines, cross-hatching, infill, shading, chiaroscuro are all used to define elements within the drawings, yet they are also used to obscure (Stoppani, 104). The speed and precision of the lines varies, blurring, distorting, and obscuring figures and objects. The spaces that are born out of a result of this process reveal themselves to be incomplete, distorted, and at times impossible. Yet in the spaces created, we are arrested by this distortion. The eye is allowed to linger, wander and roam across the page. We become immersed in the spaces Piranesi creates. The Prison series freed drawing from the conventional limitations of the time, allowing the drawing to become a "site of both understanding and emergence, a repository of information on the one hand, and a location of multiple potential imaginaries on the other. (French, 21). As seen in the Carceri, architectural drawings create worlds, these worlds help shape and define our physical realm. This thesis investigation employs the drawing as a means of world-making, as well as a repository of thought and emotion. 
DRAWING AS

COMMUNICATING

\section{VESSELS}

2014

Neil Spiller
Neil Spiller, Deputy Pro-Vice Chancellor at the University of Greenwhich, as well as theorist and architect, argues for a re-evaluation of the role of technologies in the discussion and imagination of architectural space. His lifelong project Communicating Vessels, has contributed hundreds of drawings and writings to the speculative architetcural discourse. "It is a rumination on the impact of 21st Century technology on architectural space and materiality. It is also a personal memory theatre, a surreal contemplation on the house/ garden dialectic in the contemporary world and a meditation on reflexive space and augmented reality."

Critical to Spiller's practice is the movement between physical and digital modes. The series displayed on the opposite page are named "Frustum Upper Chamber" is particular relevant to the progression of this thesis as it deals with threshold, convergence, transformation and multiplicity. In "Night time in the frustum 1" (figure 3.15) an ancient threshold separates the light from the dark, free space from the blur. Another threshold with a curtain is seen behind and beyond the first. Multiple thresholds coalesce in the same image, indicating multiple worlds. Through the progression of the series, the notion of time is introduced through the progressive darkening and obscuring of the image. Spiller attributes the coming darkness to a virtual or augmented storm, forcing day into night. The depth of the image is reversed, the darkness in the top right of Frustum Upper Chamber 3 (figure 3.17 ) obscures all traces of light, only tears in the layers reveal that it is still there. Spiller uses layering and transformation to indicate the passing of time and the coming of darkness. 


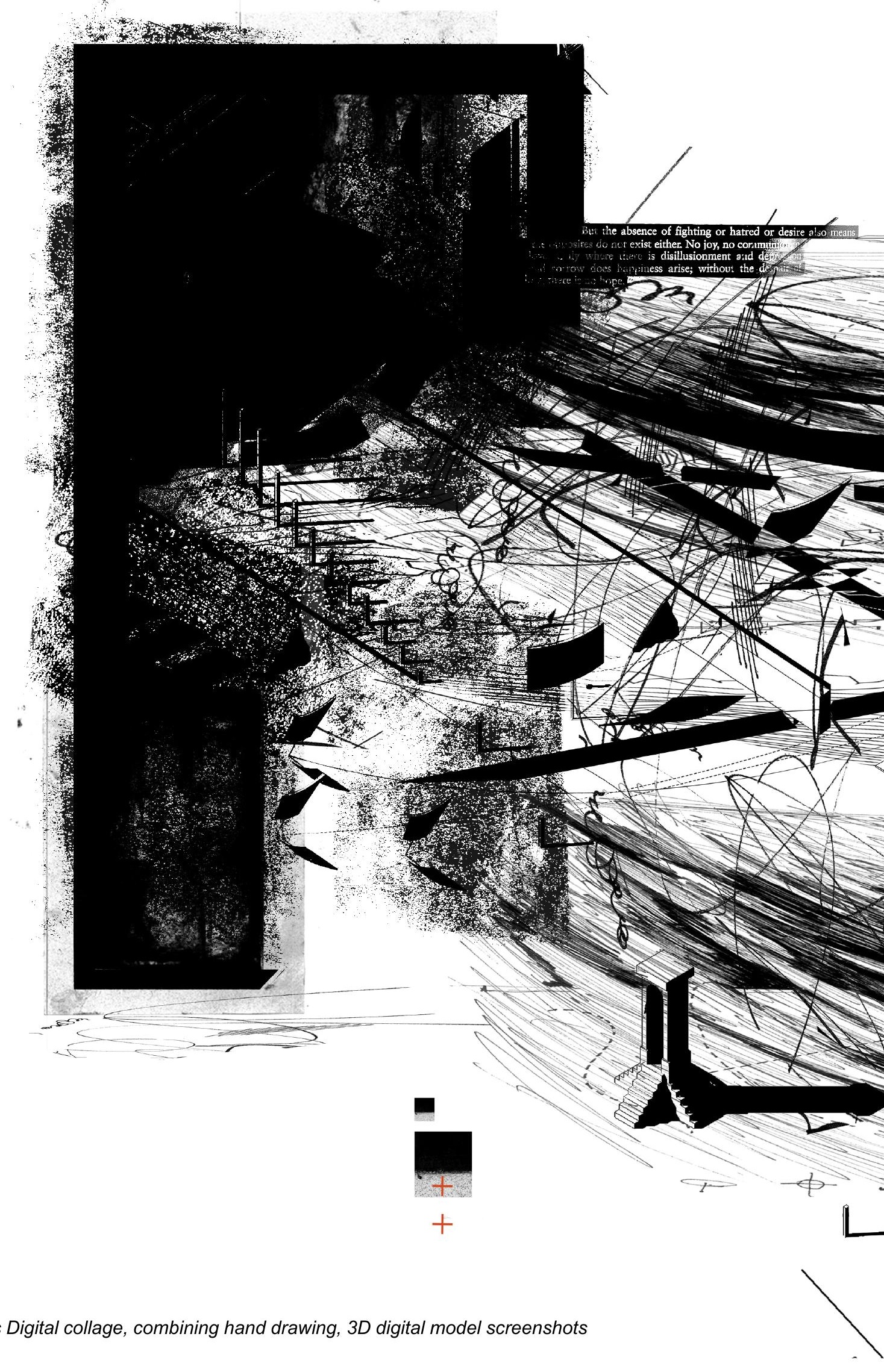

Figure 3.18. The Shadow Grounds Digital collage, combining hand drawing, 3D digital model screenshots and layering. 


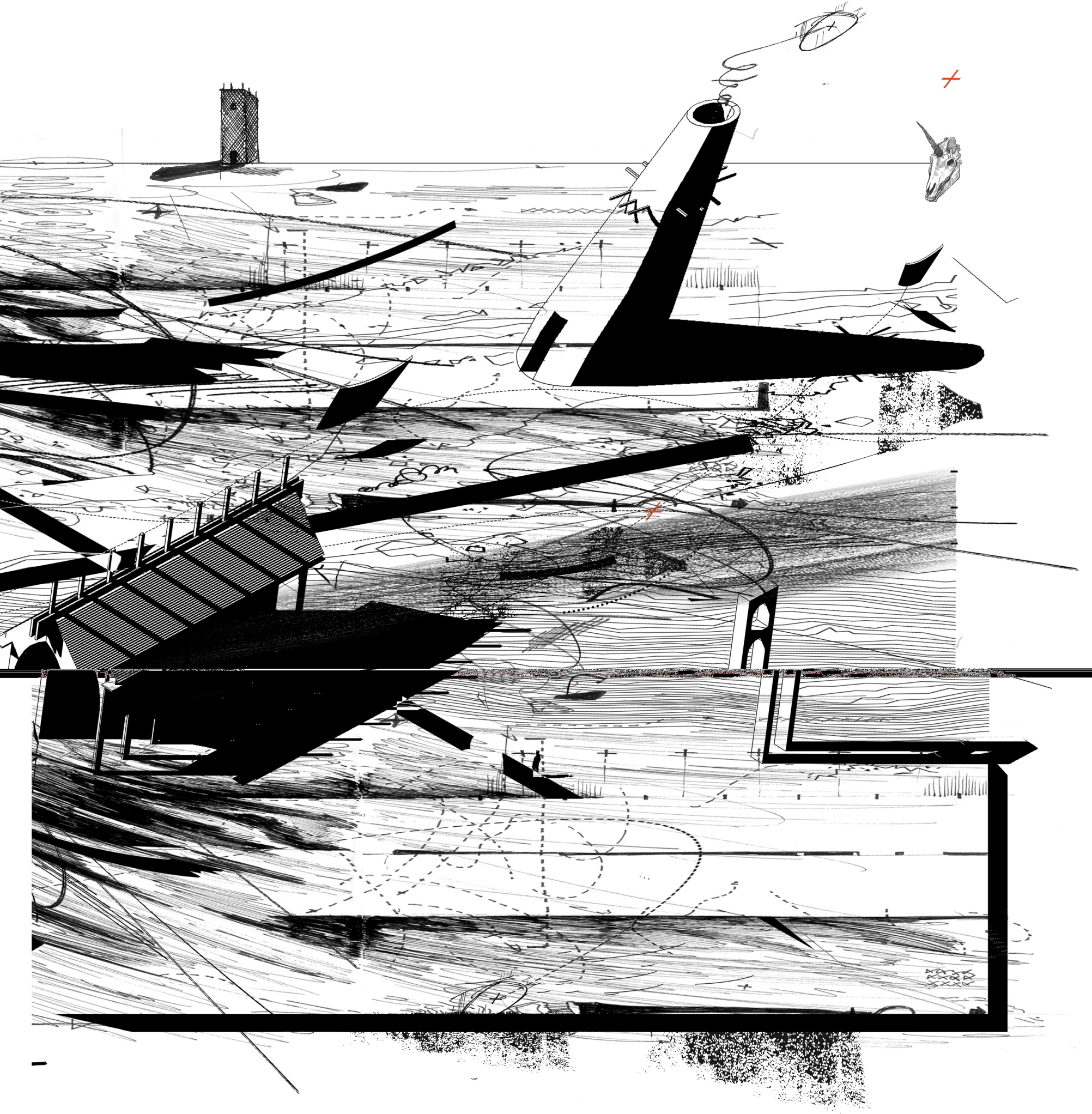




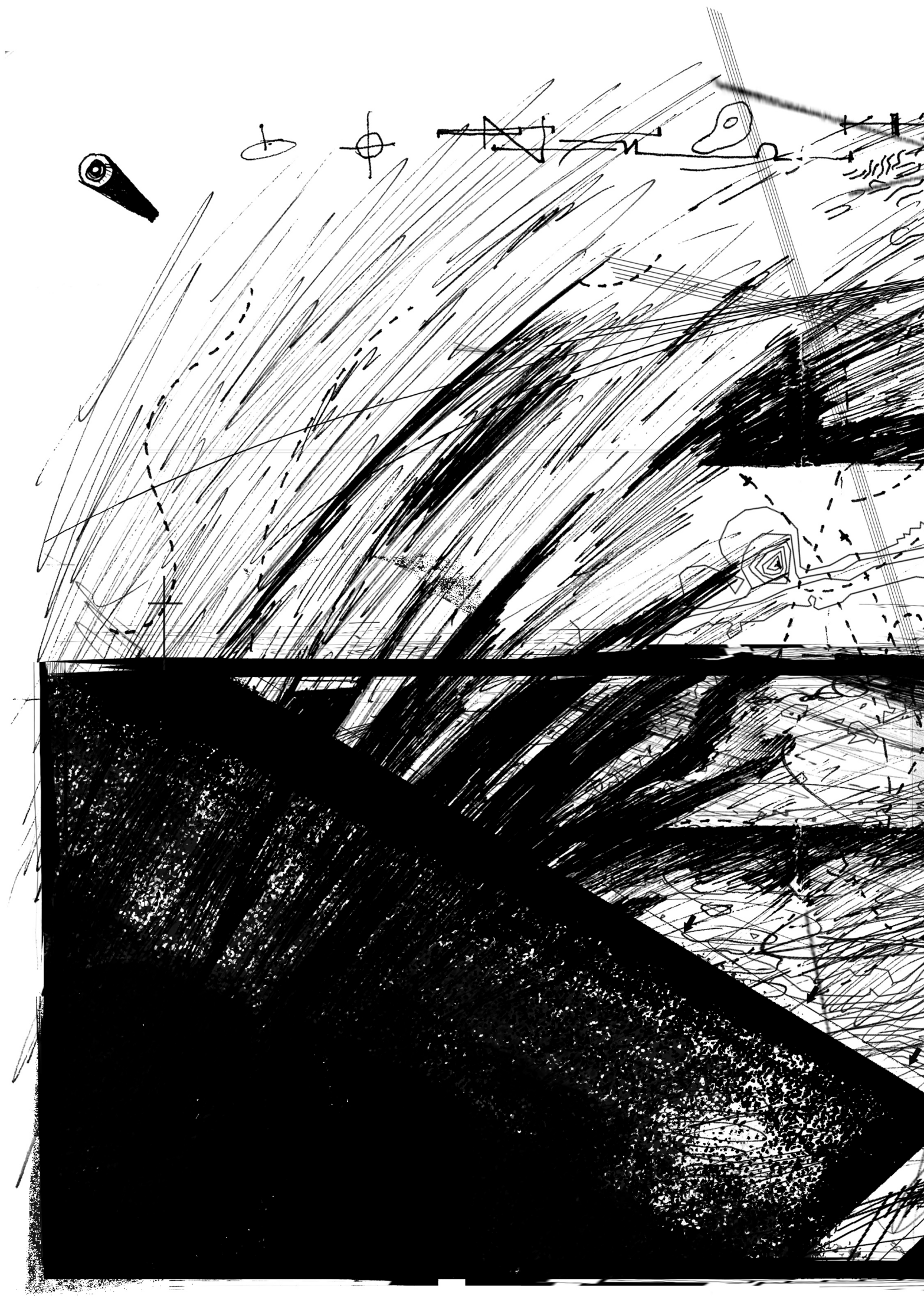

Figure 3.19. The Shadow Grounds Digital collage, combining hand drawing, 3D digital model screenshots and layering. 


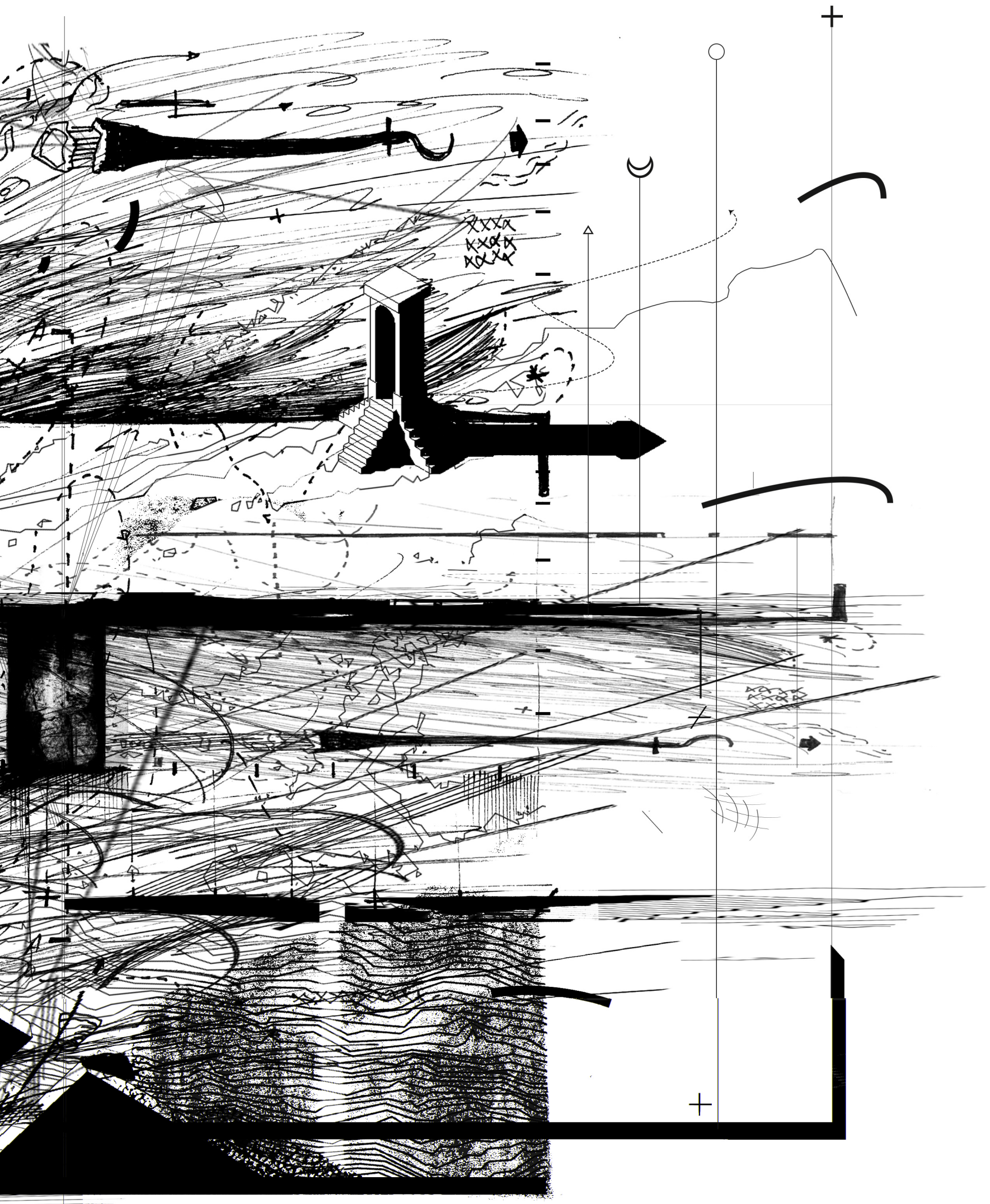




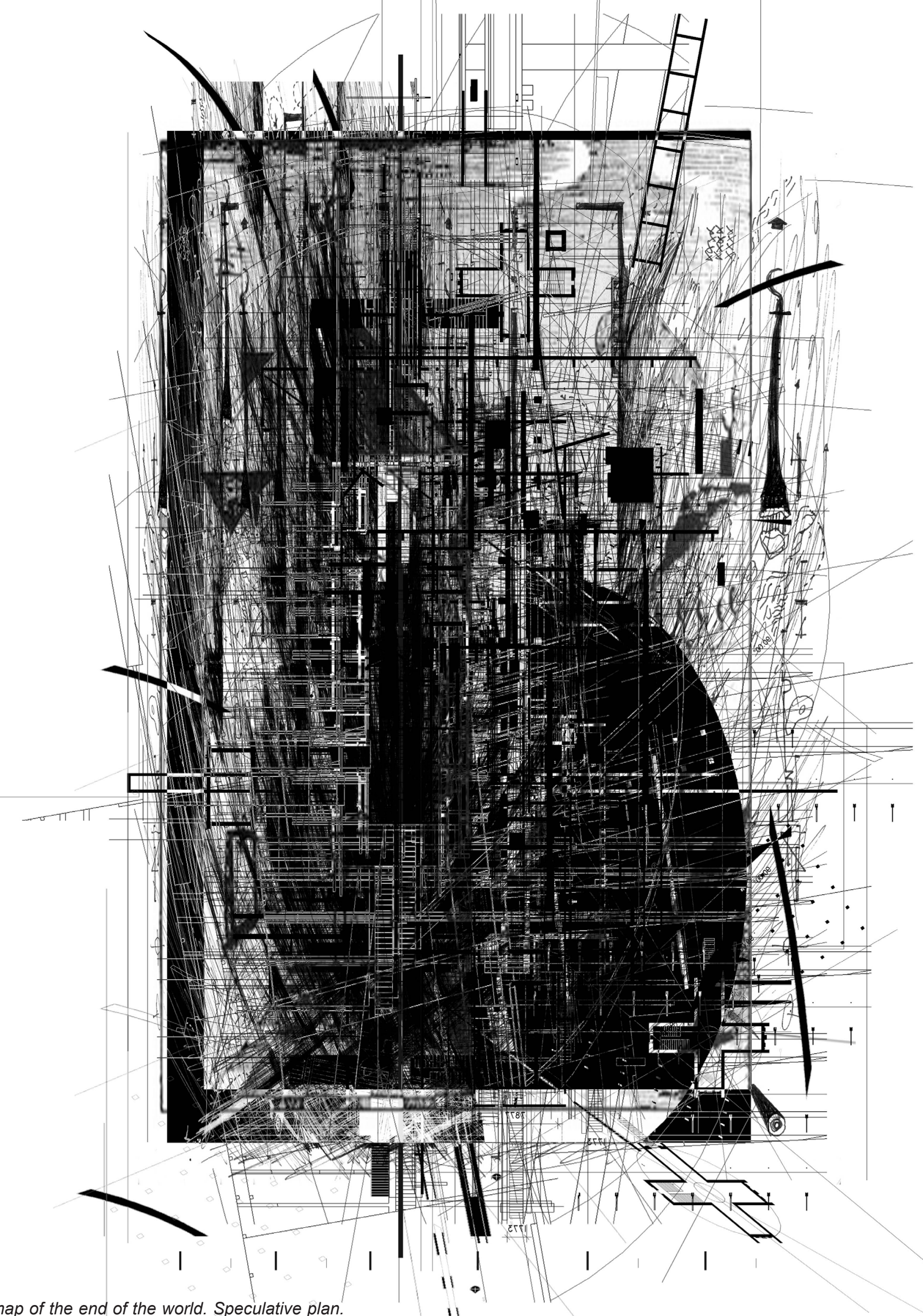

Figure 3.20. A map of the end of the world. Speculative plan. Digital Collage 
Using Spiller as a foundation, the mode of drawing was shifted. The requirement for convergence (mediation of oppositions), and a shift in visual language was recognised - Spiller's example gave insight into how layering might allude to multiple worlds, introduce the notion of time and subvert tradtional and normative drawing methods. Layering in architectural drawing allows for expanded meanings and combinations to arise. Drawing is no longer confined to the orthographic, line drawing but also expands into collage, painting, digital productions, animations etc. The collage of elements allows multiple dialogues and possible relationships to emerge.
Figure 3.18, uses layering and collage to depict The Shadow Grounds. It is composed as a series of architectural artefacts among a field of dynamic lines, shifting thresholds and among multiple layers. Figurative geometry is offset against the blur, the shift and layers of obscurity. A truncated cone, reminscent of Rossi is seen as a tower, A gabled rooffragment alludes to the house. This image visualises the Gateway and Shadow Grounds as a threshold between layers both above and below, inner and outer, and emerging field of architectural fragments. The convergence of black and white layers refers to oppositions that seek resolution. Elements of earlier sketch experiments make their way into the drawing. Text is introduced into the drawing field as a way of integrating visual + verbal.

Figure 3.19 applies similar principles to figure 64 but subverts some of the layers, most of the drawing elements are the same, indicating that the two somehow are connected across space and time. A blur is emerging out of the darkness, layers slide and shift under and through each other, light and shadow oscillate.

Figure 3.20 is an experimental collaged plan. Using Revit, black and white line drawings were taken from the array of 3-D models and tests in the model space. Screenshots were taken and re-composed in photoshop to create a speculative plan drawing. Elements of the plan are still visible in places, stairs, walls, doorways, yet the drawing remains obscured, layered and dynamic. Superposition, scaling, cutting and nesting were all used in the process of creating the drawing. The logical processes of the three-dimensional model realm were then reimagined through the analogical realm of the shadow. Whilst provocative, the overlayed plan eschews all legibility, maybe the blur is too much? When does the darkness become impenetrable? 


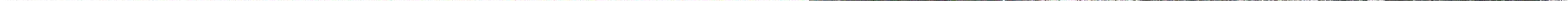


Figure 3.21 is a site plan for the Shadow Grounds. From the previous experiments further exploration in the digital model was explored. Seeking to translate the ideas and learnings from the iterative design sequence the site plan becomes the physical embodiment of the threshold. Compromising Gateway, Gatehouse, Watch Tower and Bridge it is seen from above, it is the shadows that give us clues as to their identity. The architetcure is conceived in layers, so too is the drawing. The panel of white on the left side of the page seems as though it is being slid away, revealing the shadows below. The introduction of colour adds another set of dualities that end up living together. There is indication of layers below the architetcural structures, what lies beneath? The Gatehouse sits upon two parallel tracks, drawn back and out of the Gateway, it is captured, entrapped in time. There is a notion of multiple thresholds both in the drawing and in the archietctural constructs. All thresholds coalesce to create architecture. The border of the drawing is white, alluding to a page above and beyond, as though the Shadow Grounds have been carved out and into the plane of the page. The fluid lines of the landscape become the striated lines of the architecture, blurring the boundary between the two. Shadows inhabit the page. The drawing seeks to embody the allegorical architectural project.

INNOVATION_use of a 'breach' to disrupt normative design process

TRANSFORMATION_blurring, layering and obscuring

MULTIPLICITY_motion versus rest, speed and slowness, diversity in methods, digital model+hand drawing+digital manipulation

CONVERGENCE_the progressive mediation of oppositions 


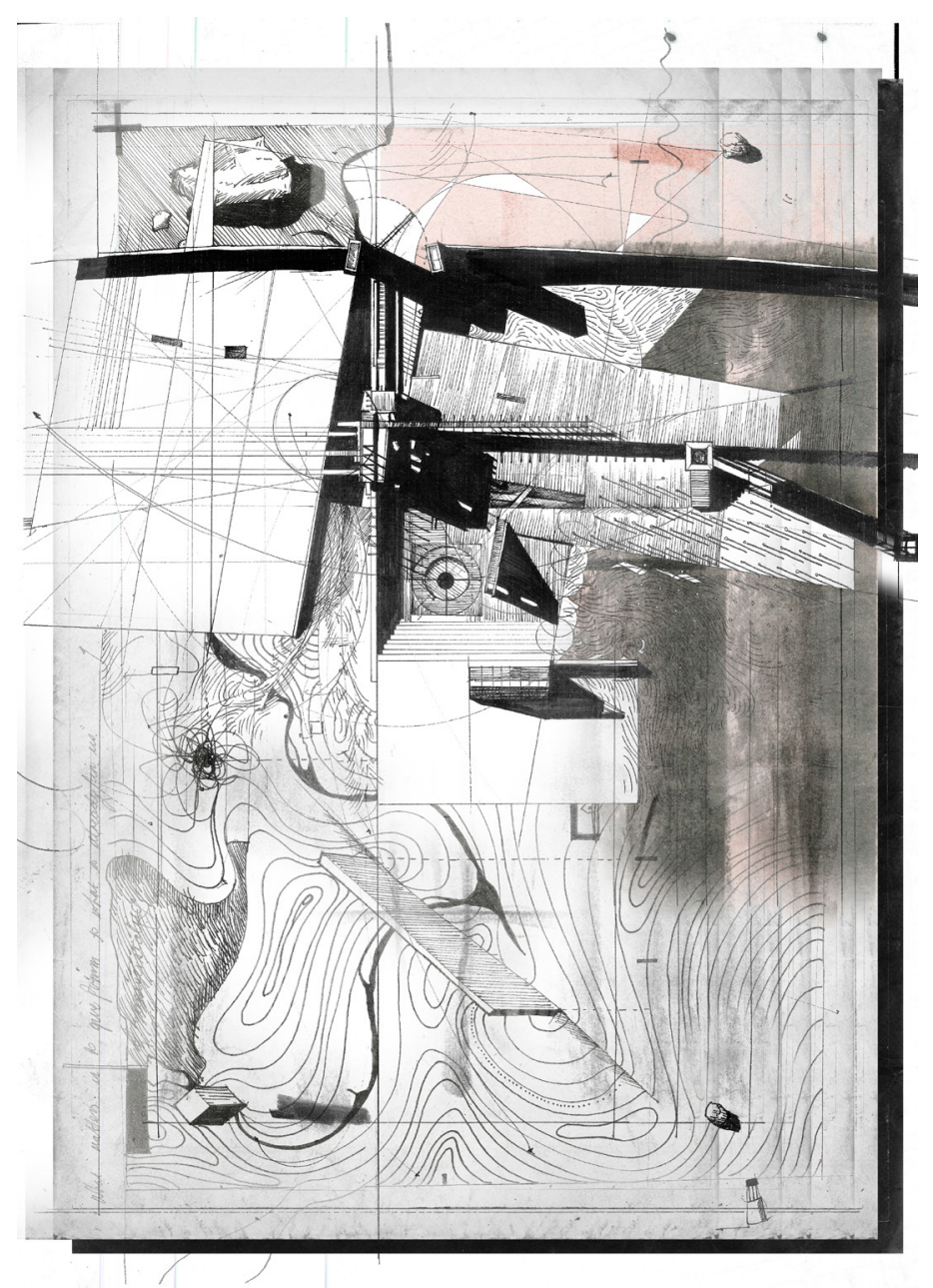

3.22

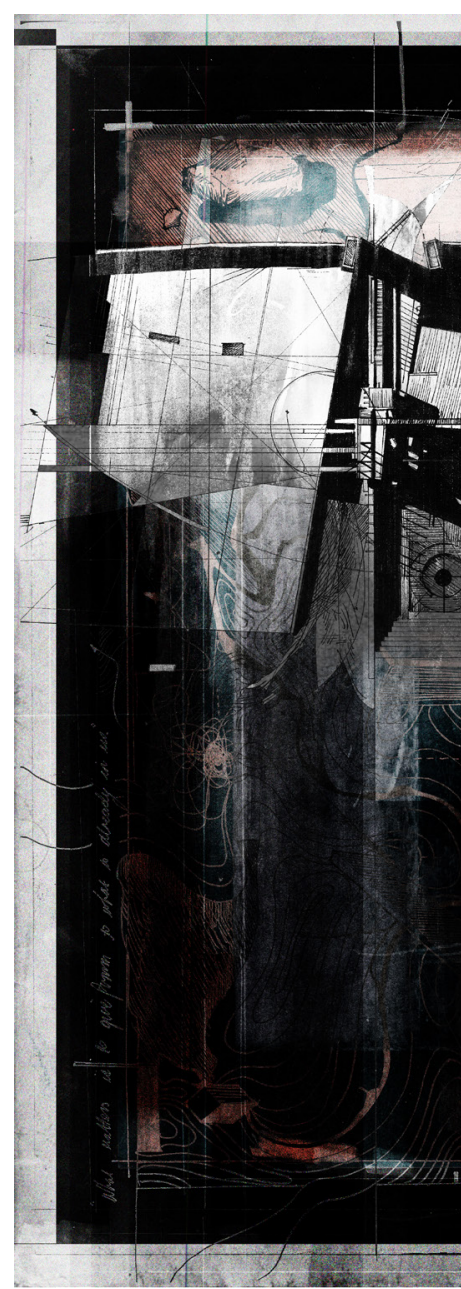

3.21

Figure 3.22. Site plan_Gateway + Shadow Grounds 1

Figure 3.21. Site plan_Gateway + Shadow Grounds 2

Figure 3.23. Site plan_Gateway + Shadow Grounds 3 

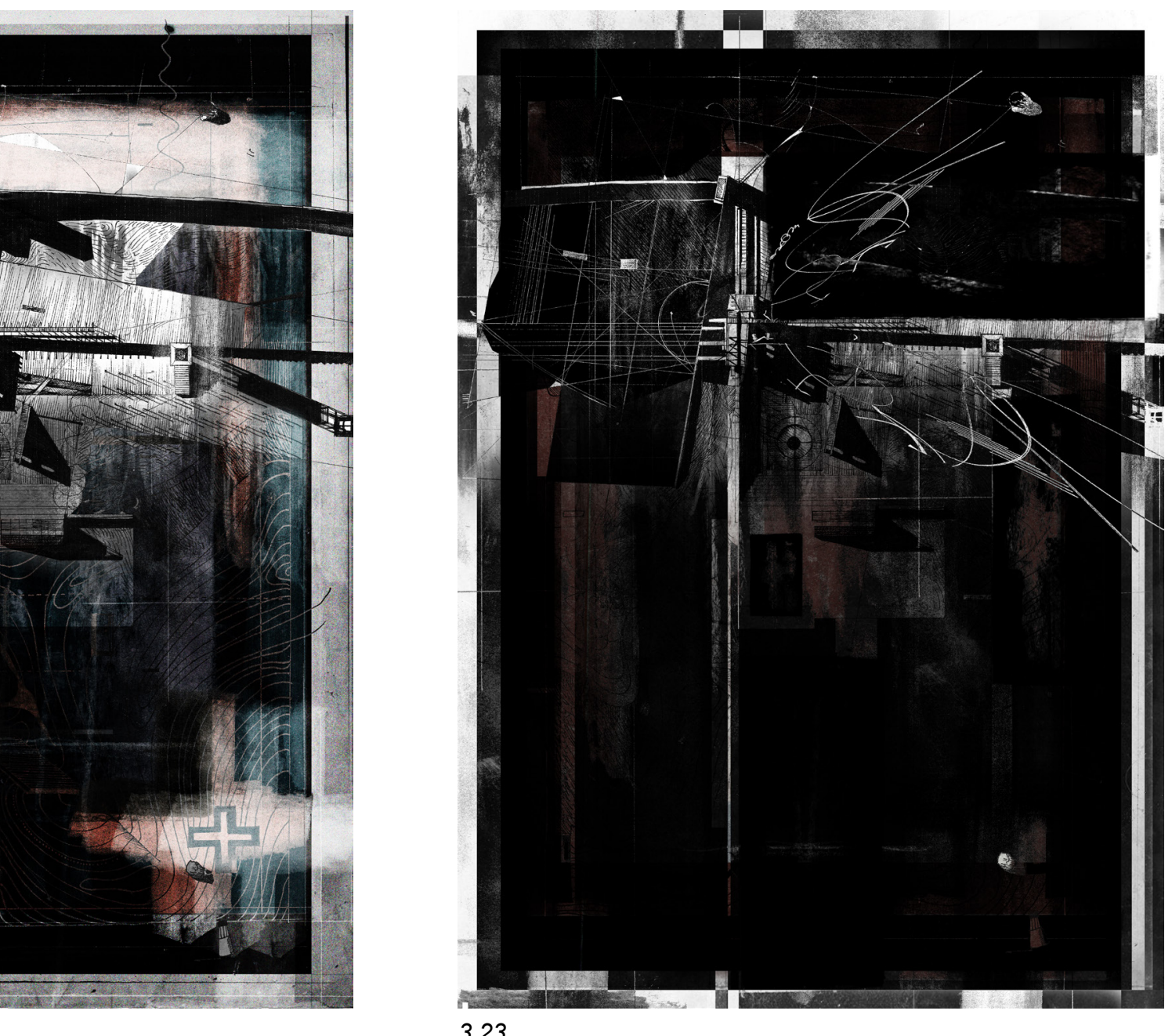

Cast in different light, the architecture takes on an altogether different identity. Moving from light framing shadow to the shadow framing the light. 


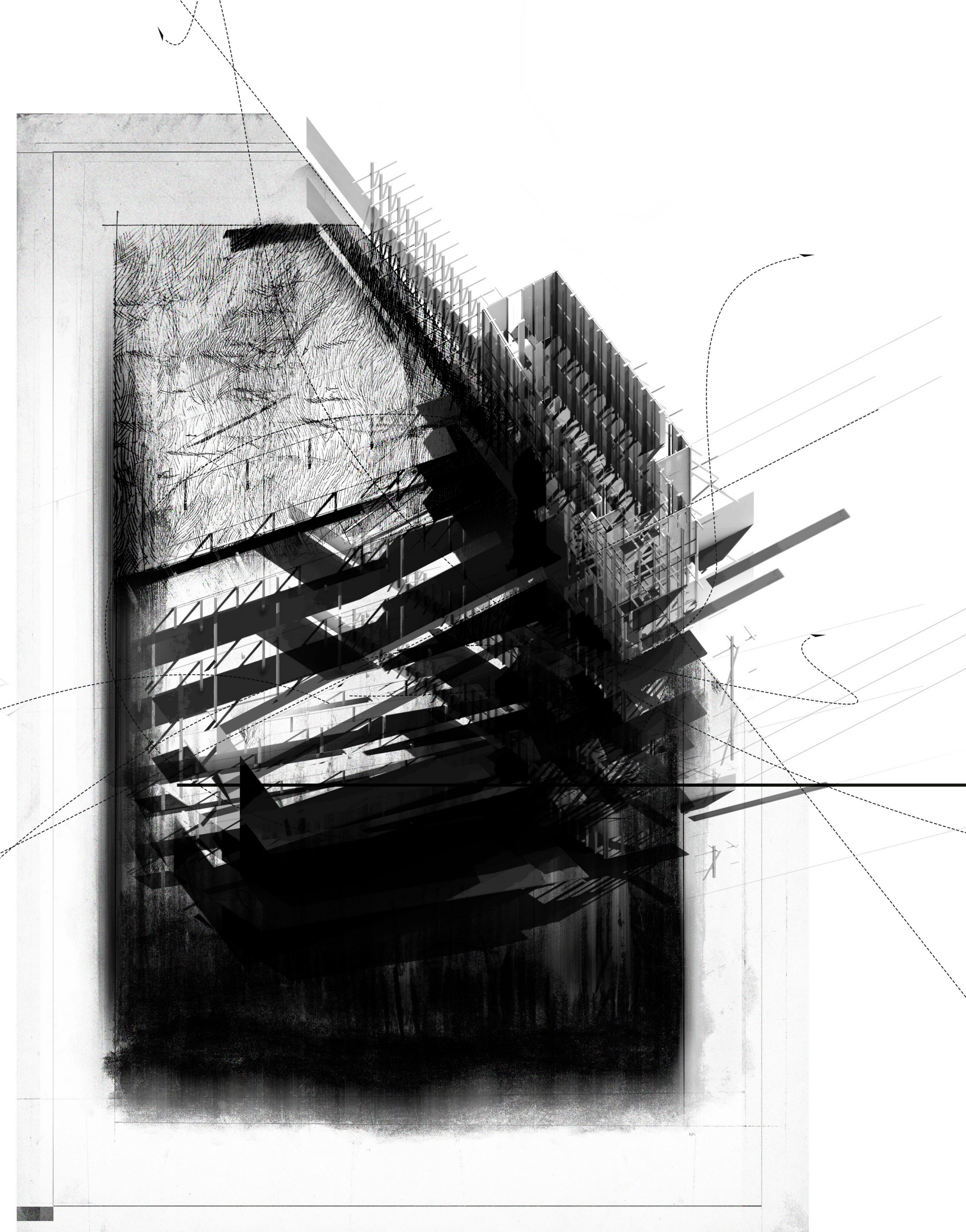

Figure 3.24. isometric cutaway. Mixed media drawing, digital model + sketch + digital collage. image by author 
Figure 3.24 is an isometric study of the Gatehouse. It is seen as a threshold between the light and the dark. Layers beneath the plane of the page, shift, transform and multiply. There are allusions to something below the Gatehouse. It is no longer just a threshold between inner and outer, it is a threshold between above and below, light and shadow. 
$+$

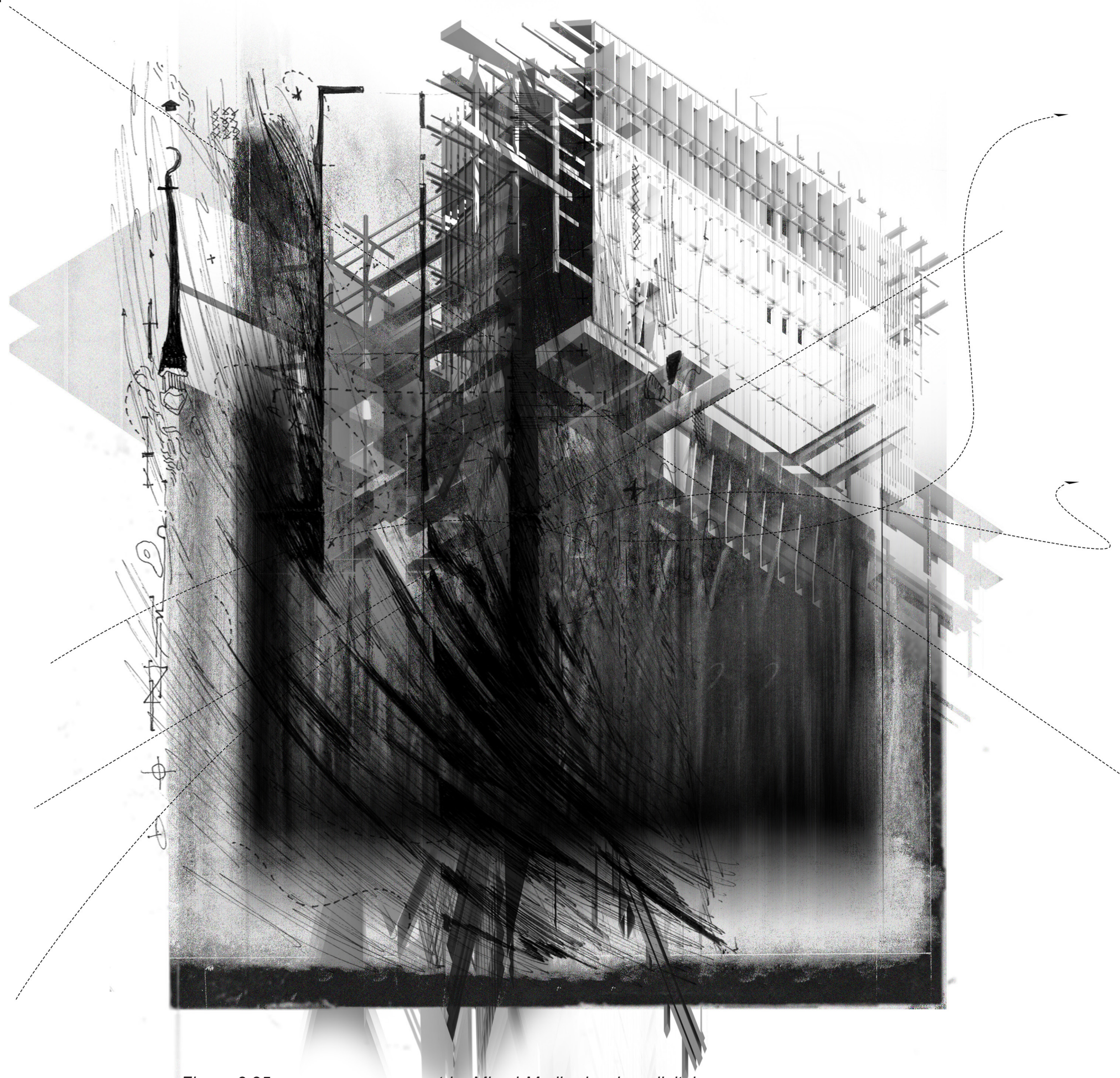

Figure 3.25. wormseye axonometric. Mixed Media drawing, digital model + sketch + digital collage. image by author 
Figure 3.25 is an experimental wormseye axonometric, looking at the Gatehouse from the below. Darkness seeps out from beneath the house, darkness that penetrates its depths, settles in its alcoves and corners. The house is figurative, the below is obscured. What lurks in the darkness?

Figure 3.26 looks at the Gatehouse in section. Using a rendered section from the digital model, it was then distorted, layered and obscured to form the architectural constructs that exist below. Through this process, it was evident that the below is the imaginary shadowy world of the above, and that the two are not opposite but intertwined, interrelated. 


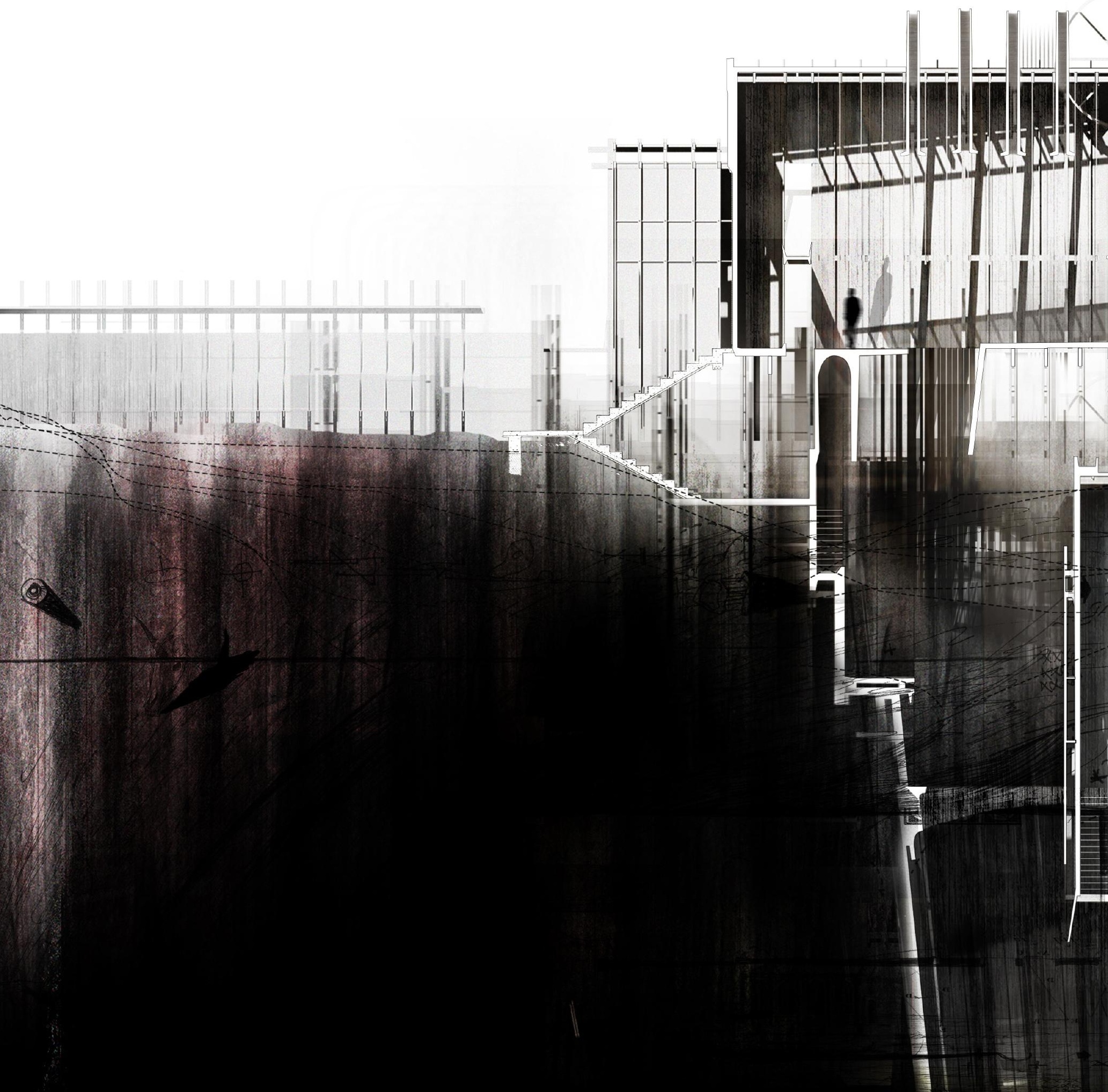




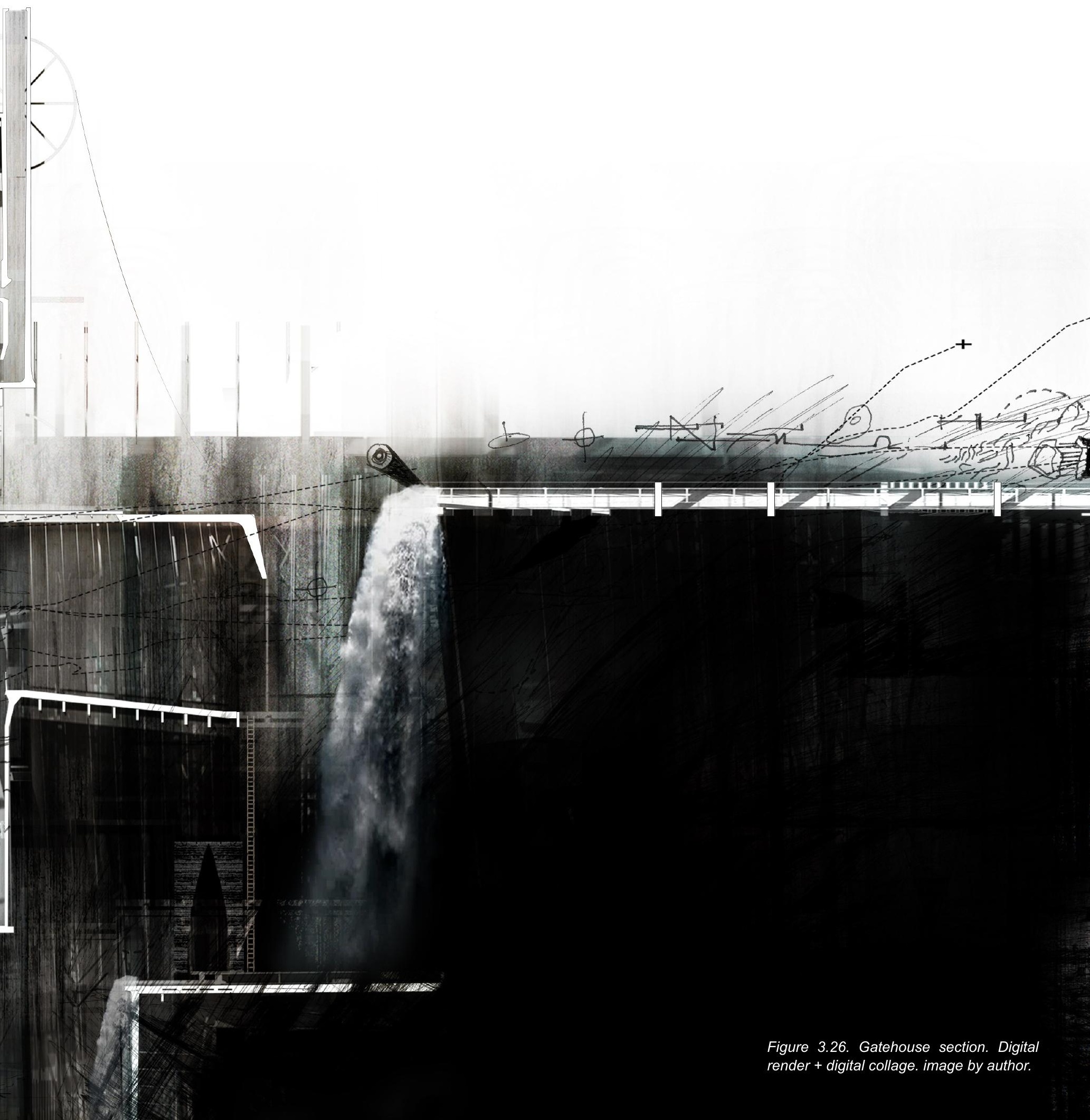


A film, artwork or text is not necessarily architecture but it can, at the very least, be architectural in specific ways, whether spatial, material or temporal, especially if it is considered as a series of strategies, elements and techniques rather than an indivisible whole. This suggests that anyone wanting to produce architecture should, first, discard the preconceived boundaries of the discipline and, second, be prepared to learn from architecture wherever it is found, whoever it is produced by.

— Jonathan Hill, 139 
This chapter highlighted the potential for architectural drawing to invite an allegorical architecture project. Through a series of iterative and speculative design experiments, semblance of an architetcural construct emerges. The learnings from Part 1 and Part 2 of the investigation were imbued within the drawing experiments, seeking to resolve a formal and experiential outcome for the Gateway and Shadow Grounds. As highlighted in the previous chapter, experiments included Jerome Bruner's key features of narrative construction, as a means of constructing an architectural narrative that activates allegory within the drawing. The idea of convergence wasn't evident in the studies on the shadow and therefore Part 3 sought to engage this as a fundamental component to the allegory of the shadow.

In the second volume CODA, that precedes this chapter, the investigatory studies will be combined to form an allegorical architectural narrative that parallels a journey through the Gateway and Shadow Grounds. This developed design outcome will be critically analysed against the five essential attributes of an "Allegorical Architectural Project", assessing whether the speculative design outcome considers all five. 


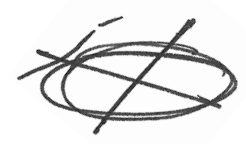


We shall not cease from exploration

and the end of all our exploring

will be to arrive where we started.

And know the place for the first time.

Through the unknown, unremembered gate.

When the last of earth left to discover

Is that which was the beginning. 
Architectural Design Research Venice 204 Pre Symposium Book.Pdf. https:// www.mtm.ac.nz/wp-content/uploads/2015/05/Architectural-DesignResearch-Venice-204-pre-symposium-book.pdf. Accessed 28 Jan. 2020.

Arkell,Andrew. "Drawingas Architecture:RepresentationalSpaceArchitecturally Transformed." Inquiry: The University of Arkansas Undergraduate Research Journal, vol. 14, no. 1, Jan. 2013, https://scholarworks.uark.edu/inquiry/ vol14/iss $1 / 4$.

Cridge, Nerma. Drawing the Unbuildable: Seriality and Reproduction in Architecture. Routledge, 2015.

"Dalibor Vesely." Wikipedia, 20 Dec. 2017. Wikipedia, https://en.wikipedia. org/w/index.php?title=Dalibor_Vesely\&oldid $=816321684$.

Foucault, Michel, and Jay Miskowiec. "Of Other Spaces." Diacritics, vol. 16, no. 1, 1986, p. 22. Crossref, doi:10.2307/464648.

Frascari, Marco, et al. From Models to Drawings: Imagination and Representation in Architecture. Routledge, 2013.

Goodbun, John, and David Cunningham. "On Surrealism and Architecture (With Some Stylistic Apologies to André Breton).” Architectural Design, vol. 75, no. 2, 2005, pp. 66-69. Wiley Online Library, doi:10.1002/ad.49.

Haralambidou, Penelope. The Allegorical Project: Architecture as Figurative Theory. www.academia.edu, https://www.academia.edu/1189899/The_allegorical_project_ architecture_as_figurative_theory. Accessed 5 Feb. 2020.

Harries, Karsten. The Ethical Function of Architecture. MIT Press, 1998.

Hendrix, John Shannon, and Lorens Eyan Holm. Architecture and the Unconscious. Routledge, 2016. ProQuest Ebook Central, http://ebookcentral.proquest.com/lib/ vuw/detail.action?docID $=4560487$.

Hill, Jonathan. "Drawing Forth Immaterial Architecture." Arq: Architectural Research Quarterly, vol. 10, no. 1, Mar. 2006, pp. 51-55. Cambridge Core, doi:10.1017/ S135913550600011X.

Hittinger, Russell. "Charles Taylor, 'Sources of the Self."' The Review of Metaphysics, vol. 44, no. 1, 1990, pp. 111-30. JSTOR.

Holm, Lorens. "Reading through the Mirror: Brunelleschi, Lacan, Le Corbusier: The Invention of Perspective and the Post-Freudian Eye/I." Assemblage, no. 18, 1992, pp. 21-39. JSTOR, JSTOR, doi:10.2307/3171204.

Hughes, Glenn. Transcendence and History: The Search for Ultimacy from Ancient Societies to Postmodernity. University of Missouri Press, 2003.

Jakobson_Roman. On Realism in Art. https://monoskop.org/images/b/be/Jakobson_ Roman_1922_1987_On_Realism_in_Art.pdf. Accessed 3 Mar. 2020.

Jamieson, Claire. NATØ: Narrative Architecture in Postmodern London. Routledge, 2017. www.taylorfrancis.com, doi:10.4324/9781315561028.

Johnson, Paul-Alan. The Theory of Architecture: Concepts Themes \& Practices. John Wiley \& Sons, 1994.

Juxtapoz Magazine - Drawings and Sketches by Italian Architect Aldo Rossi. https:// www.juxtapoz.com/news/drawings-and-sketches-by-italian-architect-aldo-rossi/. Accessed 26 Nov. 2019. 
Kashid, Mrinal. Integration of Arts and Architecture-A Need For Revival. www.academia.edu, https://www.academia.edu/39640122/Integration_of_Arts_and_Architecture-A_Need_ For_Revival. Accessed 12 Dec. 2019.

Kite, Stephen. Shadow-Makers: A Cultural History of Shadows in Architecture. Bloomsbury Publishing Plc, 2017. ProQuest Ebook Central, http://ebookcentral.proquest.com/lib/vuw/ detail.action?docID $=4901321$.

Kulper, Perry. "A World Below." Architectural Design, vol. 83, no. 5, 2013, pp. 56-63. Wiley Online Library, doi:10.1002/ad.1663.

Kwun, Aileen. In Praise of Shadows. p. 19.

Lê, Viết Thanh. The Return of Nature. www.academia.edu, https://www.academia. edu/40242602/The_Return_of_Nature. Accessed 30 Jan. 2020.

Livesey, Graham. "POLYPHILO OR THE DARK FOREST REVISITED, AN EROTIC EPIPHANY OF ARCHITECTURE', Alberto Pérez-Goméz (Book Review).” The Structurist; Saskatoon, vol. 0, no. 33, Jan. 1993, pp. 102-105.

Malpas, Jeff. Place and Experience a Philosophical Topography / J.E. Malpas. Cambridge University Press, 1999. tewaharoa.victoria.ac.nz, http://site.ebrary.com/lib/vuw/ Doc?id=10014863.

McLaughlin, Jeff. "Edmund Burke - On the Sublime." The Originals: Classic Readings in Western Philosophy, Thompson Rivers University/BCcampus, 2017. pressbooks.bccampus. ca, https://pressbooks.bccampus.ca/classicreadings/chapter/edmund-burke-on-thesublime/.

Meninato, Pablo. Unexpected Affinities: The History of Type in Architectural Project from Laugier to Duchamp. Routledge, 2018. ProQuest Ebook Central, http://ebookcentral. proquest.com/lib/vuw/detail.action?docID $=5400717$.

Baxandall, Michael. Shadows_and_Enlightenment. Scribd, https://www.scribd.com/ document/435802746/Michael-Baxandall-Shadows-and-Enlightenment-z-lib-org-pdf. Accessed 2 Mar. 2020.

Mindrup, Matthew. Interrogating the Gap Between the Material and Formal Imaginations: An Introduction. www.academia.edu, https://www.academia.edu/9773887/Interrogating the_Gap_Between_the_Material_and_Formal_Imaginations_An_Introduction. Accessed 12 Dec. 2019.

---. The Material Imagination: Reveries on Architecture and Matter. Routledge, 2016.

Osborne, Peter. Walter Benjamin: Modernity. Taylor \& Francis, 2005.

Pallasmaa, Juhani. "Embodied and Existential Wisdom in Architecture: The Thinking Hand." Body \& Society, vol. 23, no. 1, Mar. 2017, pp. 96-111. SAGE Journals, doi:10.1177/1357034X16681443.

---. The Eyes of the Skin: Architecture and the Senses. John Wiley \& Sons, 2012.

Pérez-Gómez, Alberto. "Hermeneutics as Discourse in Design." Design Issues, vol. 15, no. 2, 1999, pp. 71-79. JSTOR, JSTOR, doi:10.2307/1511843.

Printed Space: Critically Exploring the (Re)Production of Meaning in Architecture Details. $\quad$ https://viewer.waireto.victoria.ac.nz/client/viewer/IE163632/details?dps_ dvs $=1556072338588 \sim 328$. Accessed 24 Apr. 2019.

Rich, Susan. "The [In]Visible Architecture of Existence." Northwest Review, vol. 47, no. 2, May 2009, pp. 94-. Academic OneFile.

Riessman, Catherine Kohler. Narrative Analysis. SAGE, 1993.

Saint-Cyr, Viviana M. "Creating a Void or Sublimation in Lacan." Recherches en psychanalyse, vol. $\mathrm{n}^{\circ}$ 13, no. 1, Sept. 2012, pp. 15-21. 
Scranton, Laird. The Cosmological Origins of Myth and Symbol: From the Dogon and Ancient Egypt to India, Tibet, and China. Simon and Schuster, 2010.

Seamon, David. Life Takes Place: Phenomenology, Lifeworlds, and Place Making. Routledge, 2018. www. taylorfrancis.com, doi:10.4324/9781351212519.

Shields, Jennifer A. E. Collage and Architecture. Routledge, 2014.

Smith, Daniel W. Essays on Deleuze. Edinburgh University Press, 2012.

Snodgrass, Adrian, and Richard Coyne. Interpretation in Architecture: Design as Way of Thinking. Routledge, 2013. www.taylorfrancis.com, doi:10.4324/9780203873366.

“SPILLER'S WORLD.” LEBBEUS WOODS, 19 Mar. 2011, https://lebbeuswoods.wordpress.com/2011/03/19/ spillers-world/.

Surrealism and Architecture by Stavros Martinos - Issuu. https://issuu.com/smartinos/docs/surrealism_and_ architecture. Accessed 23 Apr. 2019.

"Surrealism: New Worlds." Issuu, https://issuu.com/weinstein_gallery/docs/surrealism-new_worlds. Accessed 23 Apr. 2019.

The Architecture of Pilgrimage: Sacred Site and Sacred Self in the Quest for Meaning - Details. https://viewer. waireto.victoria.ac.nz/client/viewer/IE162962/details?dps_dvs=1556072334401 832. Accessed 24 Apr. 2019.

"The Reality of Experimental Architecture: An Interview with Lebbeus Woods By Lorrie Flom - PDF Free Download." Zdoc.Pub, https://zdoc.pub/the-reality-of-experimental-architecture-an-interview-with-l.html. Accessed 9 May 2019.

Thomas, Helen. "Invention in the Shadow of History: Joseph Rykwert at the University of Essex." Journal of Architectural Education, vol. 58, no. 2, Nov. 2004, pp. 39-45. DOI.org (Crossref), doi:10.1162/1046488042485349. Vesely, Dalibor. Architecture in the Age of Divided Representation: The Question of Creativity in the Shadow of Production. MIT Press, 2004.

Vidler, Anthony. The Architectural Uncanny: Essays in the Modern Unhomely. MIT Press, 1992.

What Is Myth? https://faculty.gcsu.edu/custom-website/mary-magoulick/defmyth.htm. Accessed 4 Feb. 2020.

Williamson, James. Cosmological Architectures: Notes on Drawing. www.academia.edu, https://www.academia. edu/364670/Cosmological_Architectures_Notes_on_Drawing. Accessed 16 Dec. 2019.

Wood, Peter. DRAWING THE LINE: A WORKING EPISTEMOLOGY FOR THE STUDY OF ARCHITECTURAL DRAWING. p. 376. 
1.3. Stone House with Soul Hole. Hannsjorg Voth

1.4. Jan Reich. Scmichov-Concord Street, 1979.

1.5. Kinesis: Kotahi-ki-Kotahi. Shane Cotton

1.6. Black Window-Towards Aramoana. Ralph Hotere

1.8. Sketch drawing for San Cataldo Cemetery. Aldo Rossi

1.14. Coloured drawing for San Cataldo Cemetery. Aldo Rossi

1.15. Provisonal Sketch for the project at Modena. Aldo Rossi

1.16. Provisonal Sketch for the project at Modena. Aldo Rossi

1.18. Einstein's Tomb. Visual + Verbal. Lebbeus Woods

1.19. Einstein's Tomb. Lebbeus Woods

1.21. Dark Box Bird Cage. Exterior Elevation. Hiroshi Nakao

1.22. Dark Box Bird Cage. Internal Void. Hiroshi Nakao

1.23. Dark Box Bird Cage. External Courtyard. Hiroshi Nakao

1.24. Dark Box Bird Cage.Internal Living Room. Hiroshi Nakao

1.25. Dark Box Bird Cage. Ladder to mezzanine. Hiroshi Nakao

1.26. Hannsjorg Voth. City of Orion

1.27 City of Orion. Hannsjorg Voth

1.28 City of Orion. Hannsjorg Voth.

2.12. Paul Caponigro, Avebury Stone Cricel, Wiltshire, 1967

3.8. Vessels of Memory. Wellington Reiter.

3.9. Vessels and Fields. Wellington Reiter.

3.14. Carceri VIII- The Drawbridge. Giovanni Battista Piranesi. 1745

3.16. Nightime in the Frustum 1

3.17. Nightime in the Frustum 1

3.18. Nightime in the Frustum 1

All unattributed figures belong to author. 